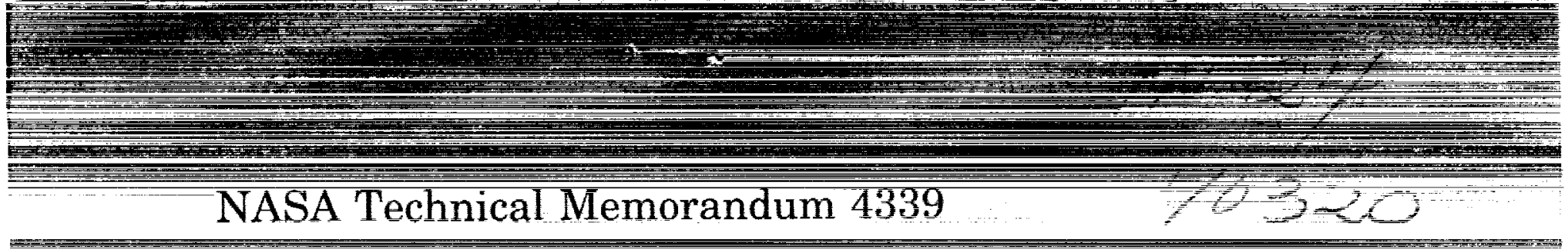

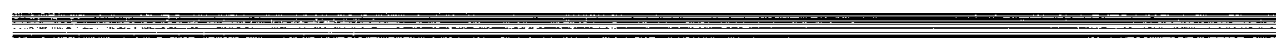

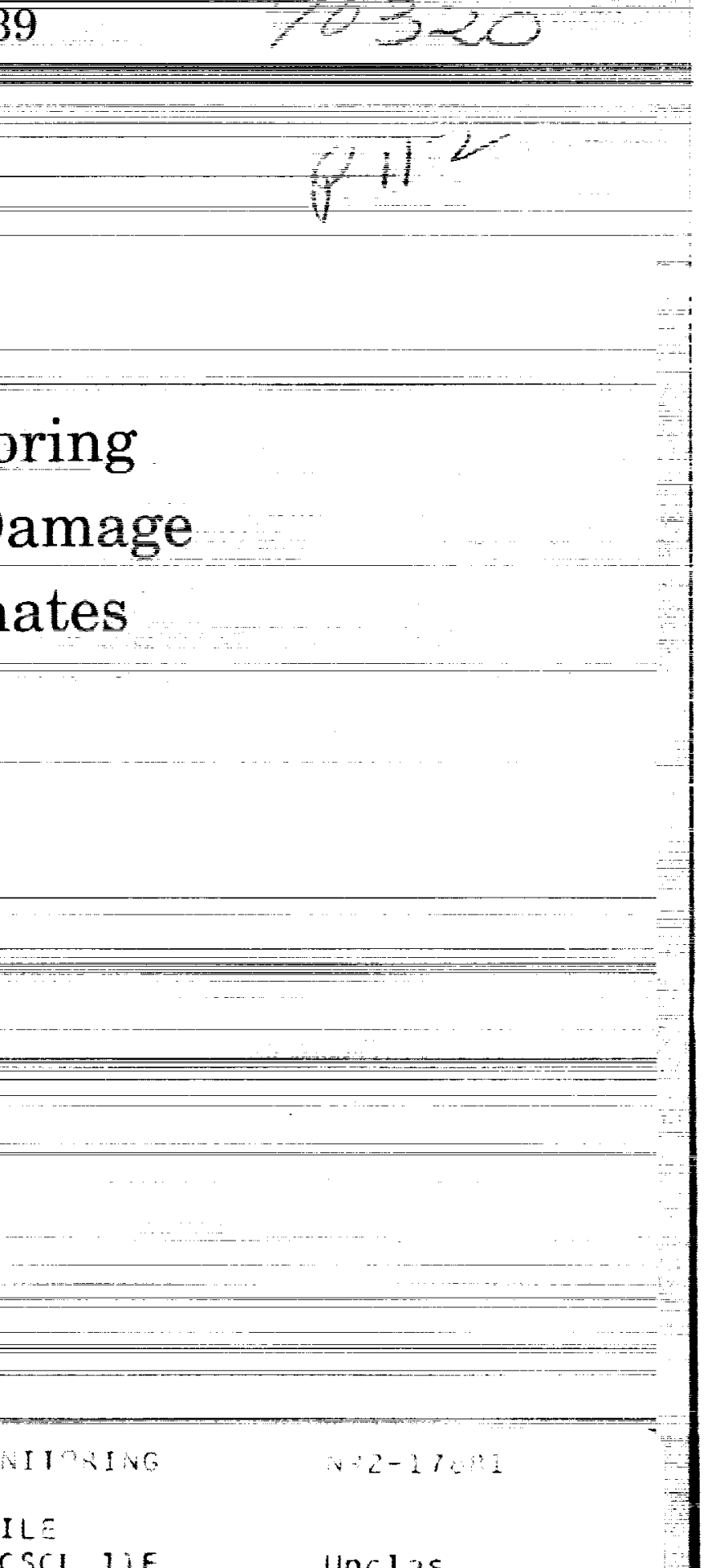

\title{
Acoustic Emission Monitoring of Low Velocity Impact Damage in Graphite/Epoxy Laminates During Tensile Loading
}

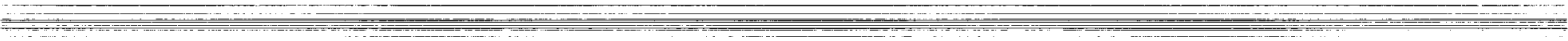
Bradford $\mathrm{H}$. Parker

\author{
FEBRUARY 1992
}




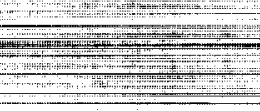

$=$

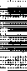

a

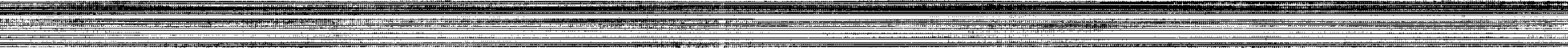

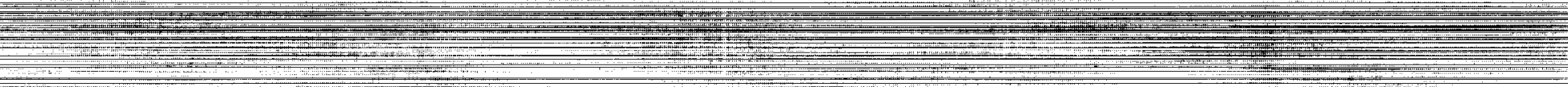

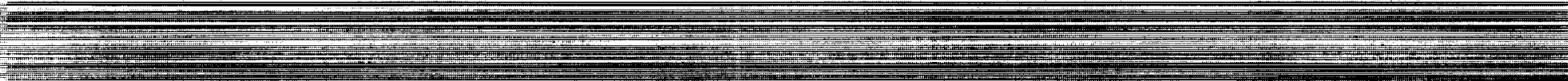

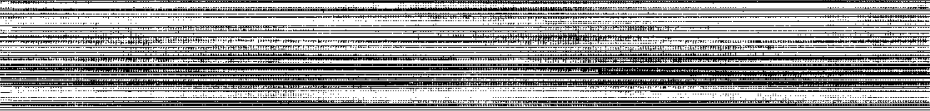

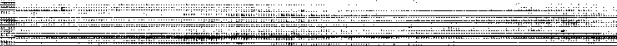

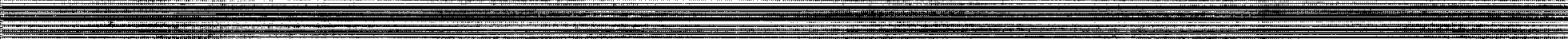

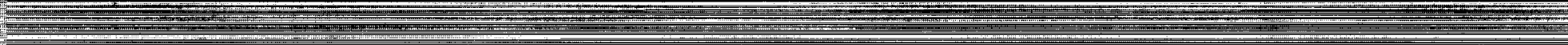
$+2$

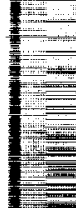

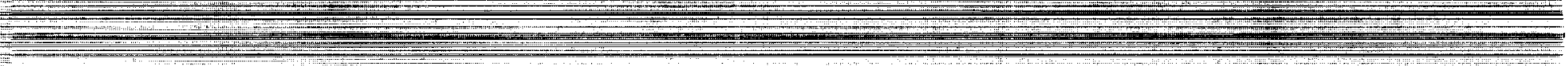

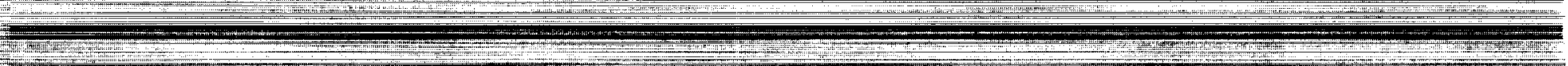

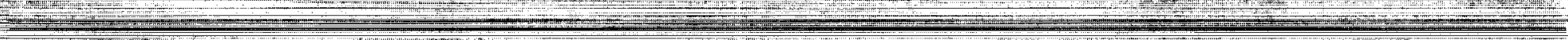

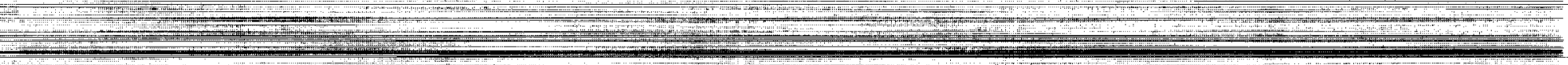

$=-2=0$

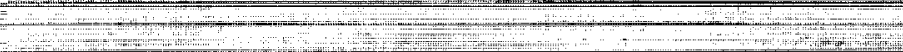


NASA Technical Memorandum 4339

\title{
Acoustic Emission Monitoring of Low Velocity Impact Damage in Graphite/Epoxy Laminates During Tensile Loading
}

\author{
Bradford H. Parker \\ Goddard Space Flight Center \\ Greenbelt, Maryland
}

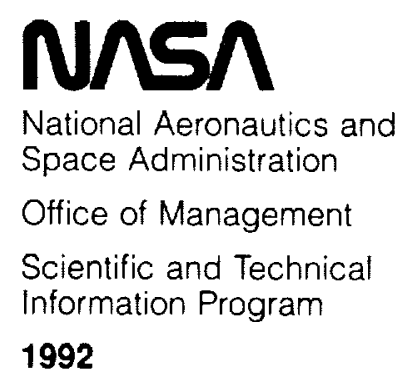




\section{TABLE OF CONTENTS}

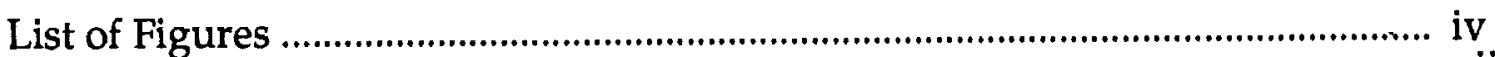

List of Tables ............................................................................................... vii

1.0 INTRODUCTION ................................................................................ 1

2.0 MATERIALS ............................................................................................... 3

2.1 Johns Hopkins University Applied Physics Laboratory ....................... 3

2.2 GSFC Fabrication Branch ....................................................................... 6

3.0 LOW VELOCITY IMPACT DAMAGE ........................................................... 10

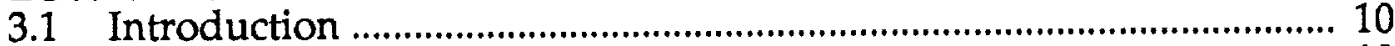

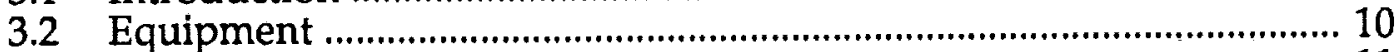

3.3 Support Configuration ...................................................................... 11

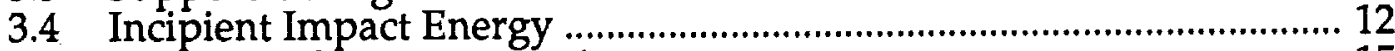

3.5 Selection of Impact Energies .................................................................. 15

4.0 DAMAGE ASSESSMENT ….................................................................... 17

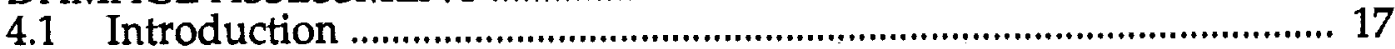

4.2 Cross-sectional Examination ............................................................. 17

4.3 Penetrant Enhanced Radiography ....................................................... 18

4.4 Ultrasonic Inspection ........................................................................... 18

4.4.1 Equipment ................................................................................. 18

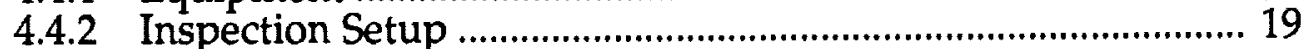

4.4.3 Inspection Results ...................................................................... 21

4.4.4 System Characterization ............................................................. 27

4.4.4.1 Flaw Magnification .................................................... 27

4.4.4.2 Scan Dimension Accuracy ……………………............ 30

4.4.4.3 Specimen and Reflector Positioning ………............... 33

4.4.4.4 Focussed Transducers and the Pulse-Echo

Technique ......................................................................... 36

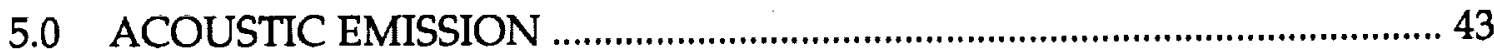

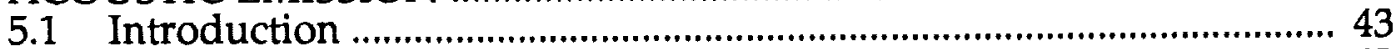

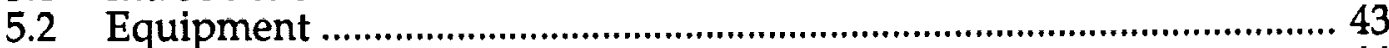

5.3 System Characterization ..................................................................... 44

5.4 Failure Mechanism Signature Analysis ..................................................4 46

5.4.1 Amplitude Distributions .............................................................. 46

5.4.2 Frequency Spectra Analysis ..................................................... 54

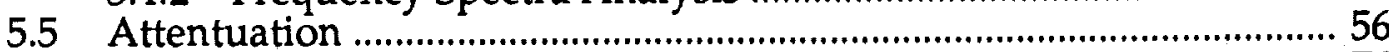

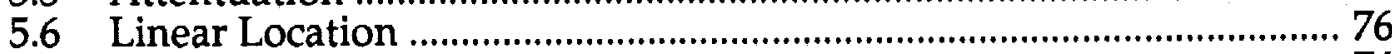

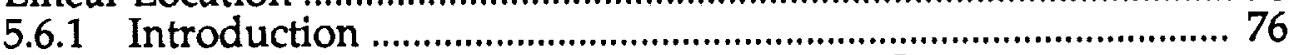

5.6.2 Specimens Impacted With an Aluminum Support

Configuration ......................................................................... 77

5.6.3 Specimens Impacted With a Membrane Support Configuration

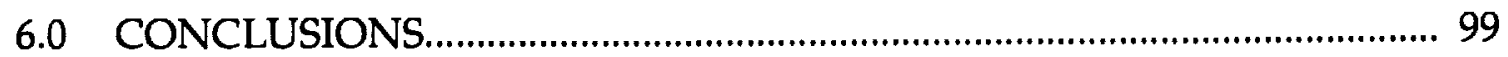

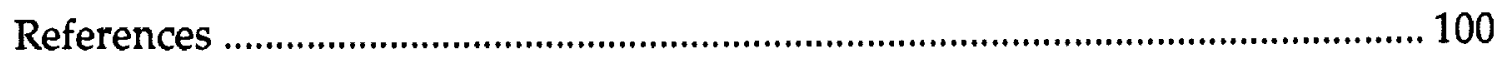




\section{LIST OF FIGURES}

Figure 1. Cure cycle for Hexcel T-300/F-155.................................................... 4

Figure 2. Specimen configurations................................................................... 5

Figure 3. Cure cycle for Fiberite T-300/934 ....................................................... 7

Figure 4. Photomicrograph at 50X magnification of the crack tip created by Teflon insert in mode I delamination specimens......... 9

Figure 5. Impact records from an aluminum plate......................................... 13

Figure 6. Impact records from a graphite/epoxy laminate.............................. 14

Figure 7. Ultrasonic data acquisition methods: (a) pulse-echo, (b) through-transmission, (c) reflector-plate throughtransmission, (d) angle-beam [28]...

Figure 8. Variation of acoustic pressure with distance ratio for a circular search unit [29]. 20

Figure 9. Immersion ultrasonic C-scan acquisition parameters.................... 22

Figure 10. Immersion ultrasonic $C$-scan images from $[0, \pm 45,90]_{S}$ specimens impacted using membrane support. Top row: 0.8 , middle row: 0.6 , and bottom row: $0.3 \mathrm{ft}-\mathrm{lbs}$.

Figure 11. Immersion ultrasonic C-scan images from $[90, \pm 45,0]_{S}$ specimens impacted using membrane support. Top row: 0.8 , middle row: 0.6 , and bottom row: $0.3 \mathrm{ft}-\mathrm{lbs}$.

Figure 12. Immersion ultrasonic $C$-scan images from $[0, \pm 45,90]_{S}$ specimens impacted using aluminum plate support configuration. Top row: 1.7, middle row: 3.4 , and bottom row: $6.8 \mathrm{ft}$-lbs.

Figure 13. Attenuation C-scans corresponding to three flaw sizes and two depths. Left column: mid-ply, right column: 14-15th ply

Figure 14. Immersion ultrasonic $C$-scan image of $1 / 2$ " diameter Grafoil insert at laminate midplane

Figure 15. Examples of traced C-scans............................................................... 31

Figure 16. Plot of actual Y-scan dimension versus step size for one by one inch C-scans......................................................................... 31

Figure 17. Scaled version of C-scan in Figure 14............................................... 32

Figure 18. Specimen, transducer and reflector positioning................................ 34 
Figure 19. Immersion ultrasonic C-scan images for various specimen, transducer and reflector positions. Top to bottom $\mathrm{C}$-scans correspond to (a) through (d) in Figure 18........................ 35

Figure 20. Comparison of pulse-echo and reflector-plate throughtransmission C-scans.

Figure 21. A-scans from focussed and nonfocussed $10 \mathrm{MHz}$ transducers.

Figure 22. Pulse-echo depth resolution from a 16 ply quasi-isotropic laminate.

Figure 23. Pixel value color differences. Top row: difference of 1 , second row: difference of 2 , third row: difference of 3 .

Figure 24. Acoustic emission system characterization setup 45

Figure 25. Relationship between actual and recorded hit and event rates. 45

Figure 26. Amplitude distribution from matrix microcracking specimen.... 49

Figure 27. Point plot of amplitude versus time for matrix microcracking specimen. 50

Figure 28. Amplitude distribution from delamination specimen................... 51

Figure 29. Amplitude distribution from delamination specimen.................... 52

Figure 30. Point plot of amplitude versus load for a delamination specimen..

Figure 31. Response of PAC-WD transducer to broadband noise.

Power density frequency spectra from 0 to $500 \mathrm{KHz}$

Figure 32. Power density frequency spectra for matrix microcracking.......... 57

Figure 33. Power density frequency spectra for delamination......................... 58

Figure 34. Power density frequency spectra for lead break events on $[90, \pm 45,90]_{2 s}$ laminate.

Figure 35. Power density frequency spectra for lead break events on $[0]_{16}$ laminate.

Figure 36. Power density frequency spectra for pulser events on $[90, \pm 45,90]_{2 s}$ laminate.

Figure 37. Power density frequency spectra for pulser events on $[0]_{16}$ laminate..

Figure 38. Typical lead break voltage versus time signals. 
Figure 39. Typical pulser voltage versus time signals.

Figure 40. Attenuation of lead break events for an eight ply quasiisotropic laminate.

Figure 41. Amplitude distribution from matrix cracking specimen. Transducer \#1, closest to source.

Figure 42. Amplitude distribution from matrix cracking specimen. Transducer $\$ 2,2.3$ inches from the source.

Figure 43. Amplitude distribution from matrix cracking specimen. Transducer \#3, 4.6 inches from the source. 69

Figure 44. Attenuation of matrix microcracking events. 70

Figure 45. Amplitude distribution from delamination specimen. Transducer \#1, closest to source.

Figure 46. Amplitude distribution from delamination specimen. Transducer \#2, 3.2 inches from the source.

Figure 47. Amplitude distribution from delamination specimen. Transducer \#3, 6.4 inches from the source. 74

Figure 48. Attenuation of delamination events. 75

Figure 49. Linear location test setup. 78

Figure 50. Three-dimensional location histogram from specimen with no damage.

Figure 51. Three-dimensional location histogram from specimen with $6.8 \mathrm{ft}-\mathrm{lb}$ impact event.

Figure 52. Three-dimensional location histogram from specimen with $3.4 \mathrm{ft}-\mathrm{lb}$ impact event. 82

Figure 53. Three-dimensional location histogram from specimen with $1.7 \mathrm{ft}$-lb impact event 83

Figure 54. Examples of failure sites in impacted specimens. 84

Figure 55. Location histogram from $[90,+45,0]_{S}$ specimen which experienced catastrophic tab bond failure prior to location of impact site. Specimen impacted at $0.8 \mathrm{ft}-\mathrm{lbs}$.

Figure 56. Point plot of amplitude versus location for events shown in Figure 55

Figure 57. Series of location histograms for specimen impacted at $0.6 \mathrm{ft}-\mathrm{lbs}$. 
Figure 58. Location histogram from $[90,+45,0]_{S}$ specimen which experienced catastrophic tab bond failure prior to location of impact site. Specimen impacted at $0.6 \mathrm{ft}-\mathrm{lbs}$.

Figure 59. Point plot of amplitude versus location for events shown in Figure 58 .

Figure 60. Micrograph at 100X magnification showing specimen porosity

Figure 61. Location histogram from $[0, \pm 45,90]_{S}$ specimen impacted at $0.8 \mathrm{ft}$-lbs and loaded using Instron Model 10FA wedge grips.......

Figure 62. Point plot of amplitude versus location for events shown in Figure 61 95

Figure 63. Series of location histograms for specimen impacted at $0.6 \mathrm{ft}$-lbs and loaded using MTS Model 647.10 hydraulic wedge grips. Impact site centrally located 96

Figure 64. Series of location histograms for specimen impacted at $0.6 \mathrm{ft}-1 \mathrm{bs}$ and loaded using MTS Model 647.10 hydraulic wedge grips. Impact site located at approximately 2 inches

\section{LIST OF TABLES}

Table 1. Impact Parameters for $[0, \pm 45,90]_{S}$ Specimens ....................................... 16

Table 2. Impact Parameters for $[90, \pm 45,0]_{S}$ Specimens ......................................... 16

Table 3. Characterization of Ultrasonic Flaw Magnification ................................ 30

Table 4. Ultrasonic Bridge Assembly Scan Dimension Accuracy ........................ 33

Table 5. Ultrasonic Depth Resolution for 16 Ply Quasi-Isotropic Laminate ...... 39 


\subsection{INTRODUCTION}

The low coefficient of thermal expansion (CTE) and high specific stiffness of fiber reinforced composites make these materials attractive for aerospace applications requiring dimensional stability $[1,2,3]$. An example of a recent application of composites at the National Aeronautics and Space Administration (NASA), Goddard Space Flight Center (GSFC) is the Upper Atmospheric Research Satellite (UARS). The UARS truss is constructed of FERRO HMS/CE339 graphite/epoxy tubes. Another example is the Far Ultraviolet Spectrographic Explorer (FUSE). GSFC is investigating the use of Fiberite T50/934 graphite/epoxy to fabricate a tubular truss structure and Amoco P$75 / 1965$ to construct an optical bench for FUSE. Both of these projects are using graphite/epoxy laminates in order to meet pointing accuracy requirements.

All GSFC payloads intended for flight on the National Space Transportation System (Space Shuttle) must meet the requirements of GSFC 7310005, "General Fracture Control Plan for Payloads using the Space Transportation System (STS)" [4]. GSFC 731-0005 indicates that linear fracture mechanics technology is not currently available for fiber reinforced composites. Therefore, fracture control of critical composite components relies on either proof testing to 1.25 times the limit load or performing a damage tolerance assessment.

Damage tolerance programs involve testing of flight-like components with artificial or induced flaws. The flaws have a size and shape corresponding to the detection capability of the nondestructive (NDE) technique to be used on the flight components. Conducting such a program involves fabricating and testing numerous specimens, qualifying a NDE technique and performing flight hardware inspections. Proof testing is typically easier to perform and requires no NDE. Therefore, proof testing is the fracture control method most commonly used on composite structures.

One disadvantage of proof testing is that a component may pass the test on a global scale, but experience microscopic and/or sublaminate failures. Transverse matrix microcracking typically occurs before fiber failure, and hence, complex networks of cracks often develop long before global laminate failure [5]. Matrix microcracking can result in large reductions in the torsional stiffness of composite tubes and can create relatively large changes in CTE [6]. In addition, defects such as porosity or low velocity impact damage create intralaminar and interlaminar stress concentrations during loading. These stresses can produce intralaminar cracks and delaminations .

These composite failure mechanisms produce large amounts of acoustic emission $(\mathrm{AE})[7,8]$. Hence, monitoring $\mathrm{AE}$ can provide information about damage initiation and progression during proof testing. $\mathrm{AE}$ has been used during the proof testing of composite rocket motor cases [9] and has been successful in determining the structural adequacy of fiber reinforced plastic storage tanks and equipment [10].

A research program was initiated within the GSFC Materials Branch to investigate the capability of $\mathrm{AE}$ to detect and locate low velocity impact damage in graphite/epoxy composite materials during tensile proof testing. Low velocity impact damage was selected for investigation because aerospace structures are subjected to a variety of low velocity impact threats, such as dropped tools and moving equipment during assembly and handling [11]. 
Epoxy matrix composite materials are relatively brittle, and hence have a poor impact damage tolerance [12]. The damage induced by low velocity impacts can propagate during proof loading and result in significant reductions in compressive and tensile strength $[13,14]$.

The research program consisted of inducing low velocity/low energy impact damage in eight-ply quasi-isotropic graphite/epoxy specimens using an instumented drop weight tower. During impact, the specimens were supported using either an aluminum plate or a membrane configuration. The types and amounts of impact damage were documented using microscopic cross sectional examination and immersion ultrasonics.

An AE system was then used to monitor the damaged specimens during quasi-static tension loading. Two transducers were used in an linear array in order to detect and locate damage initiation and progression. The goal of the program was to determine if $\mathrm{AE}$ could increase the reliability of structural proof tests. 


\subsection{MATERIALS}

\subsection{John Hopkins University Applied Physics Laboratory}

The primary source of the composite materials investigated in this program was the TE2 Materials Laboratory at the Johns Hopkins University Applied Physics Laboratory (APL) in Laurel, MD. The GSFC Materials Branch contracted with APL for composite fabrication. The material supplied by APL, which was based solely on availability, was a Hexcel F-155 epoxy resin with T300 graphite fibers prepreg tape.

The composite laminates were fabricated by Mr. Paul Biermann who manages the TE2 composites facility. The autoclave cure followed the vendors suggested cycle for $\mathrm{F}-155\left(250^{\circ} \mathrm{F}\right.$ cure) systems. The temperature and pressure profiles for the cure cycle are shown in Figure 1. The vacuum on the bag was released when the autoclave pressure reached 30 pounds per square inch (psi).

In the first phase of the program, an eight ply quasi-isotropic $\left([0, \pm 45,90]_{S}\right)$ laminate fabricated from the Hexcel prepreg was investigated. The panel dimensions were 18 by 12 by 0.048 inches thick. Aluminum tabs were bonded to the panels at APL using Hysol EA 9309.3 NA glass microsphere filled epoxy. After the adhesive had cured for five days at room temperature, the tabbed panels were cut into one inch wide specimens. Holes were drilled into the tab section at each end of the specimen in order to accommodate Instron 1125 pin loading fixtures. The specimen configuration is shown in Figure 2. The Instron 1125 was used to load the specimens during AE testing.

Tabs are usually made of cross-ply fiberglass and designed for wedge grip loading. However, the crushing of the fiberglass tabs by the wedge grip faces during tensile loading creates extremely high rates of $\mathrm{AE}$ activity. This background noise may mask the $\mathrm{AE}$ activity generated at the damage site. The aluminum tabs and pin loading configuration were recommended by Jim Mitchell of Physical Acoustics Corporation to minimize the amount of AE activity emanating from the grips. The tabs were designed as recommended by Cunningham et al. [15] who addressed the effect of tab design on stress concentrations in tensile specimens.

During the first phase of the program, the tab bonds failed at shear stress levels significantly lower than the value reported by Hysol, the manufacturer. Several factors may have contributed to the low bond strengths.

First, APL did not abrade the surface of the graphite/epoxy laminates in fear of damaging the laminate and causing a decrease in tensile strength. Abrasion is a common bonding preparation technique which increases bond area and promotes mechanical adhesion. The lack of abrasion was significant because of the smooth surface of the laminates. The smooth surface which was due to the caul plates in the lay-up stack was requested to improve the coupling of the $\mathrm{AE}$ transducers.

The lap shear strength value reported by Hysol was for aluminum bonded to aluminum. After discovering the bonding problem, lap shear tests were performed in accordance with ASTM D 1002, "Standard Test Method for 


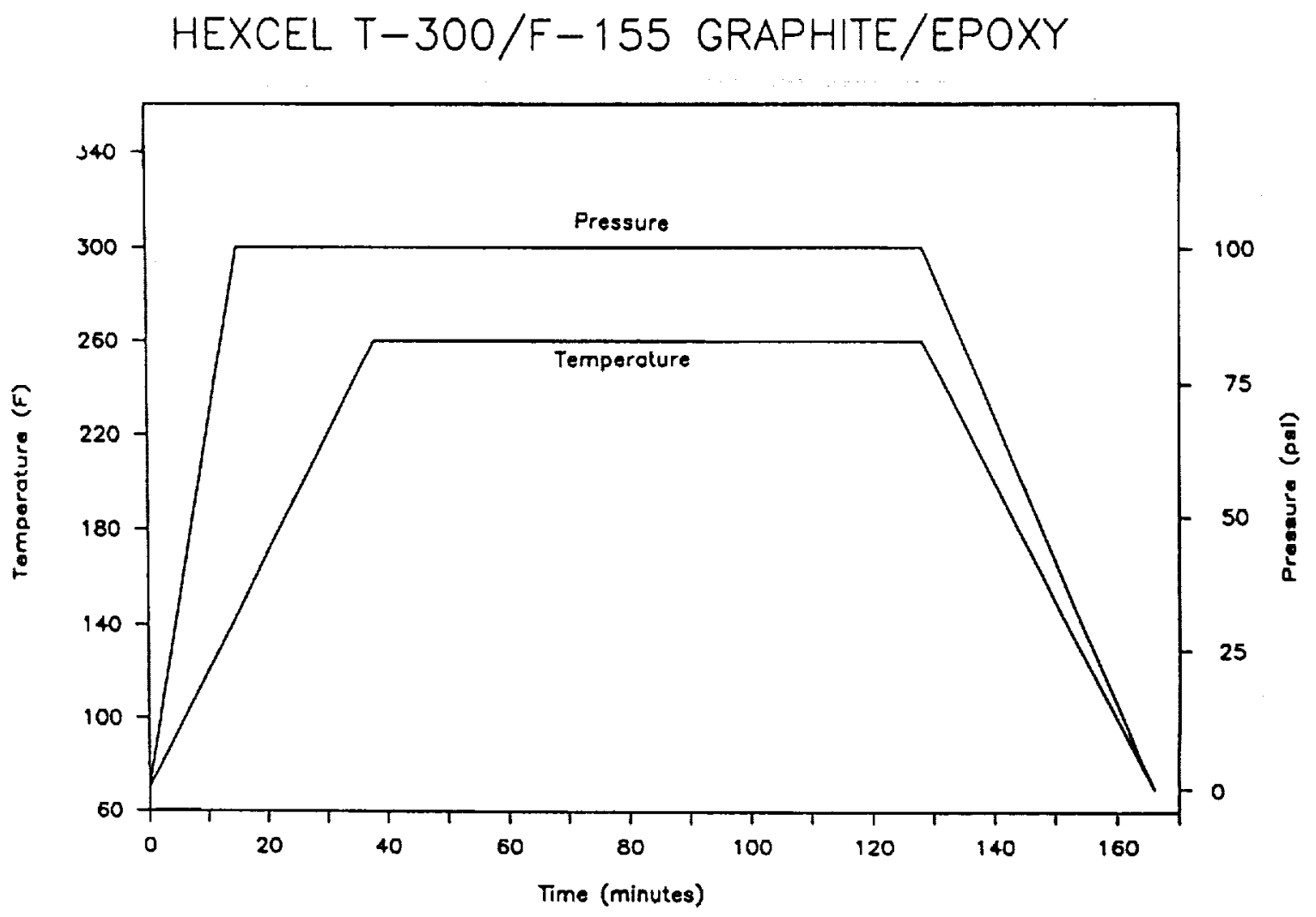

Figure 1. Cure cycle for Hexcel T-300/F-155. 

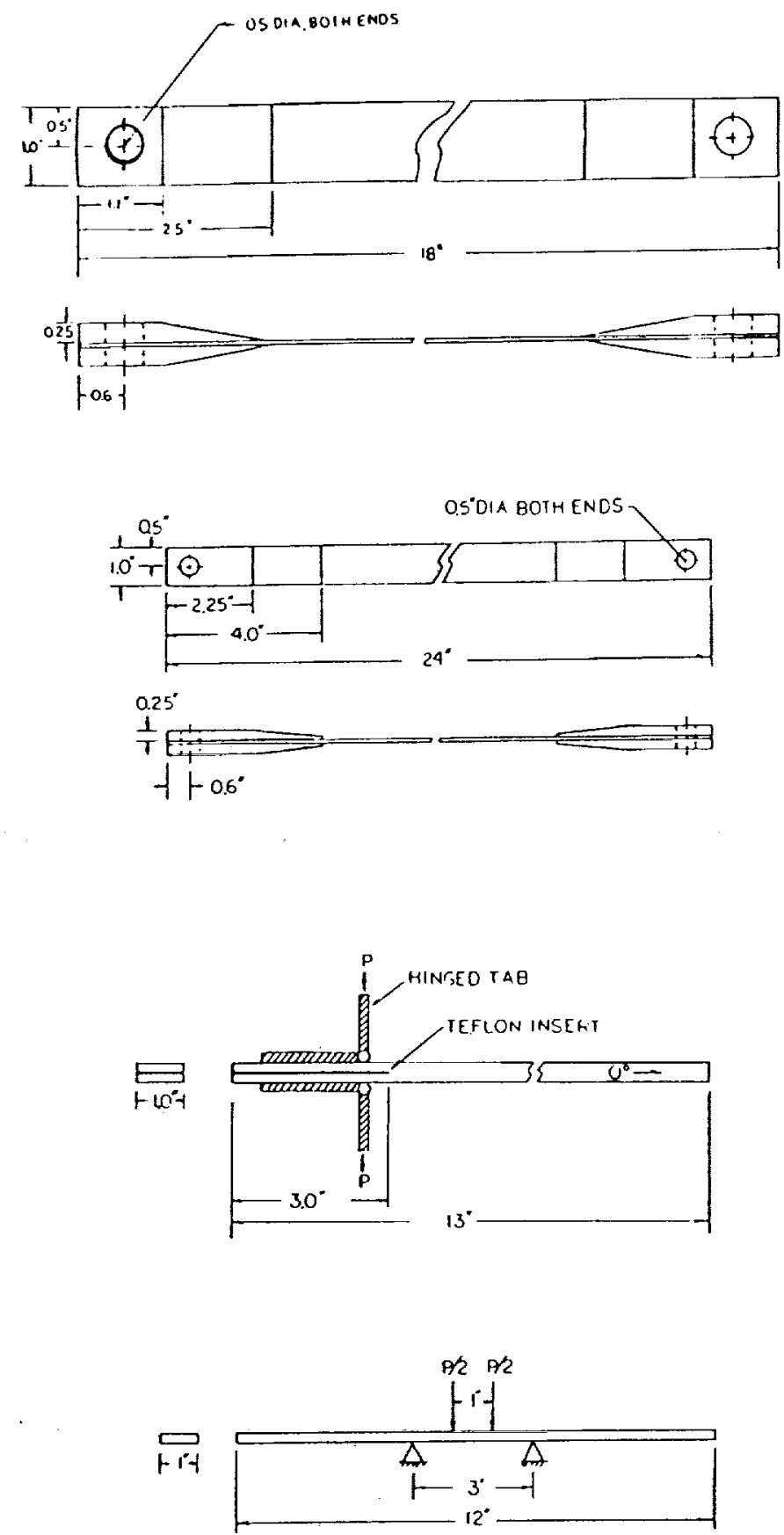

Figure 2. Specimen configurations.
Tension, Phase 1

Tension, Phase 2

\section{Mode I Delamination}

Matrix Cracking 
Strength Properties of Adhesives in Shear by Tension Loading," [16] for aluminum bonded to graphite/epoxy. The average shear strength value was 2,700 psi, which is significantly less than the value of 4,800 psi reported by Hysol. The reported shear strength value and a safety factor of two were used to calculate the required bond area. The reduced shear strength decreased the safety factor to 1.1 .

The tab design called for a 10 degree taper ending in a "feather" edge. Because of aluminum's relatively high ductility, the machining of the taper resulted in a slight warpage of the tabs at the feather edge (taper end). The warping could have resulted in an uneven bond line thickness. In addition, there was no compensation for the stress concentrations at the pin loaded holes. The combination of these factors may have contributed to the low shear strength of the tab bonds. The bonds typically failed at loads corresponding to a shear strength of less than 1,000 psi.

During the second phase of the program, two eight ply quasi-isotropic laminates with different stacking sequences - $[0, \pm 45,90]_{S}$ and $[90, \pm 45,0]_{S}$ - were investigated. The panel lengths were increased to 24 inches. In addition, several changes were made in the tab design and bonding procedure in order to improve the bond strength.

APL noted that the aluminum tabs made it difficult to cut the specimens from the laminate. Therefore, the one inch wide specimens were cut from the panels before tab bonding. Tab design changes included lengthening the tabs to increase the shear area and eliminating the feather edge to prevent warping. The 10 degree taper in the tabs was stopped when the thickness was 0.010 inches. Finally, the tab bonding was performed by the Polymers Section of the GSFC Materials Branch using procedures which included abrading the graphite/epoxy and etching the aluminum tabs prior to bonding. The design aspect which did not change was the $1 / 2$ inch diameter loading holes. The specimen configuration is shown in Figure 2. It appears that the stress concentrations produced at the holes may have been the most critical design flaw as the bonds continued to prematurely fail and compromise the AE testing results.

\subsection{GSFC Fabrication Branch}

Recently, the GSFC Fabrication Branch established a composite material fabrication facility. The facility has lay-up tables, bagging facilities and storage freezers. In addition, the facility has ovens used for expanding manderal tube fabrication. The Fabrication Branch has a contract with the University of Maryland, College Park, Aerospace Engineering Department which provides access to an autoclave for laminate curing.

The Fabrication Branch fabricated specimens designed for acquiring AE signatures of delamination, matrix microcracking and transverse matrix splitting. These specimens were fabricated from a Fiberite T-300/934 unidirectional prepreg tape. Fiberite's suggested cure cycle, which is shown in Figure 3, was used during the autoclave curing of the panels.

The specimen designs, which are shown in Figure 2, were similar to those used by Garg and Ishai [17]. The delamination specimens were cut from a section of a 16 ply unidirectional laminate ([0]16) containing a 3 by 6 by 0.005 


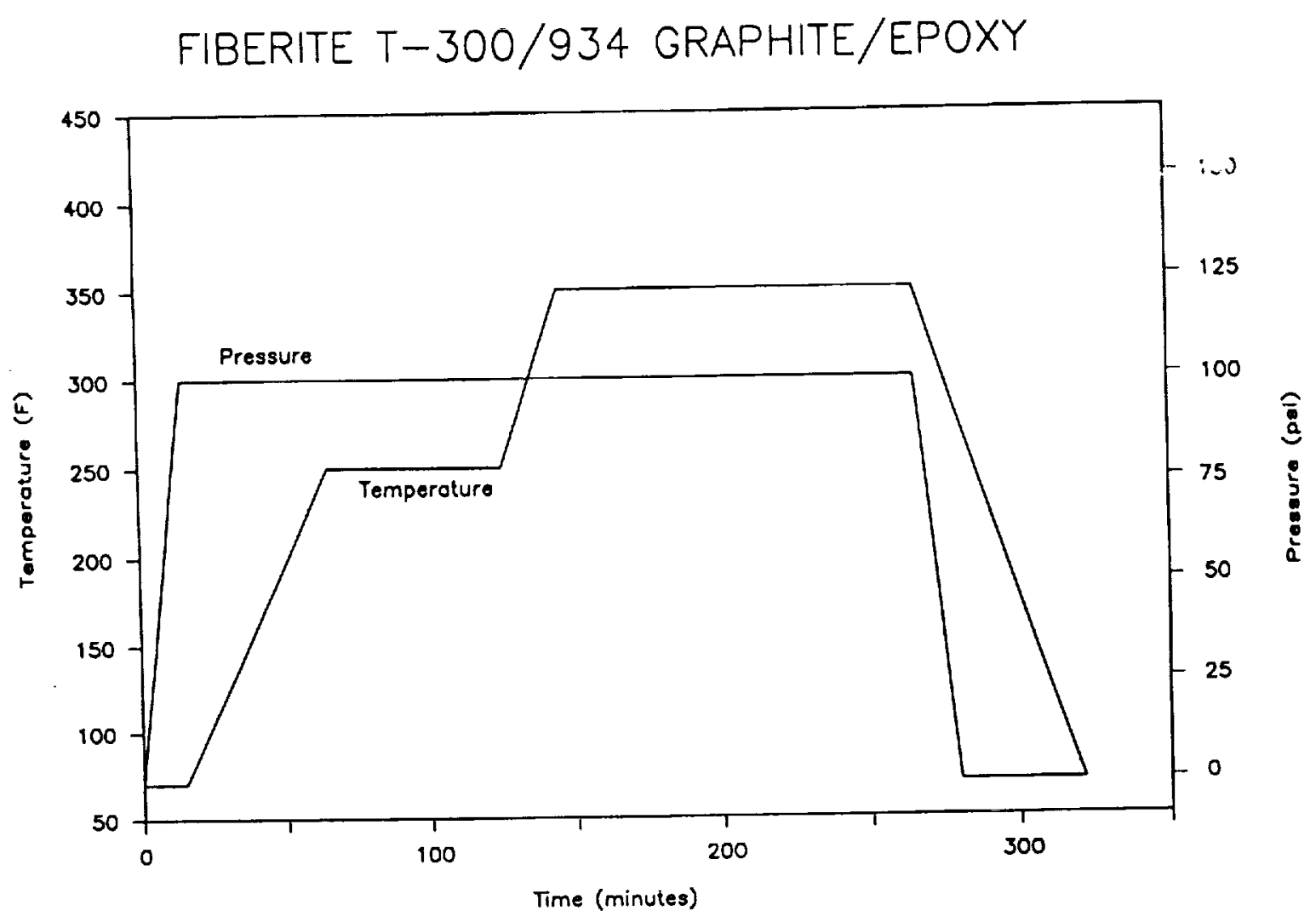

Figure 3. Cure cycle for Fiberite T-300/934. 
inch thick teflon insert. Figure 4 shows a crack tip produced by a teflon insert. Hinged tabs were attached to the specimens using a fast setting epoxy resin with amine hardener from Cole Parmer. The specimens were loaded to produce mode I delamination.

The matrix microcracking and transverse matrix splitting specimens were cut from a 16 ply laminate with a $[90, \pm 45,90]_{2 s}$ lay-up. The specimens were designed for four point flexure loading. 


\section{Teflon Insert}

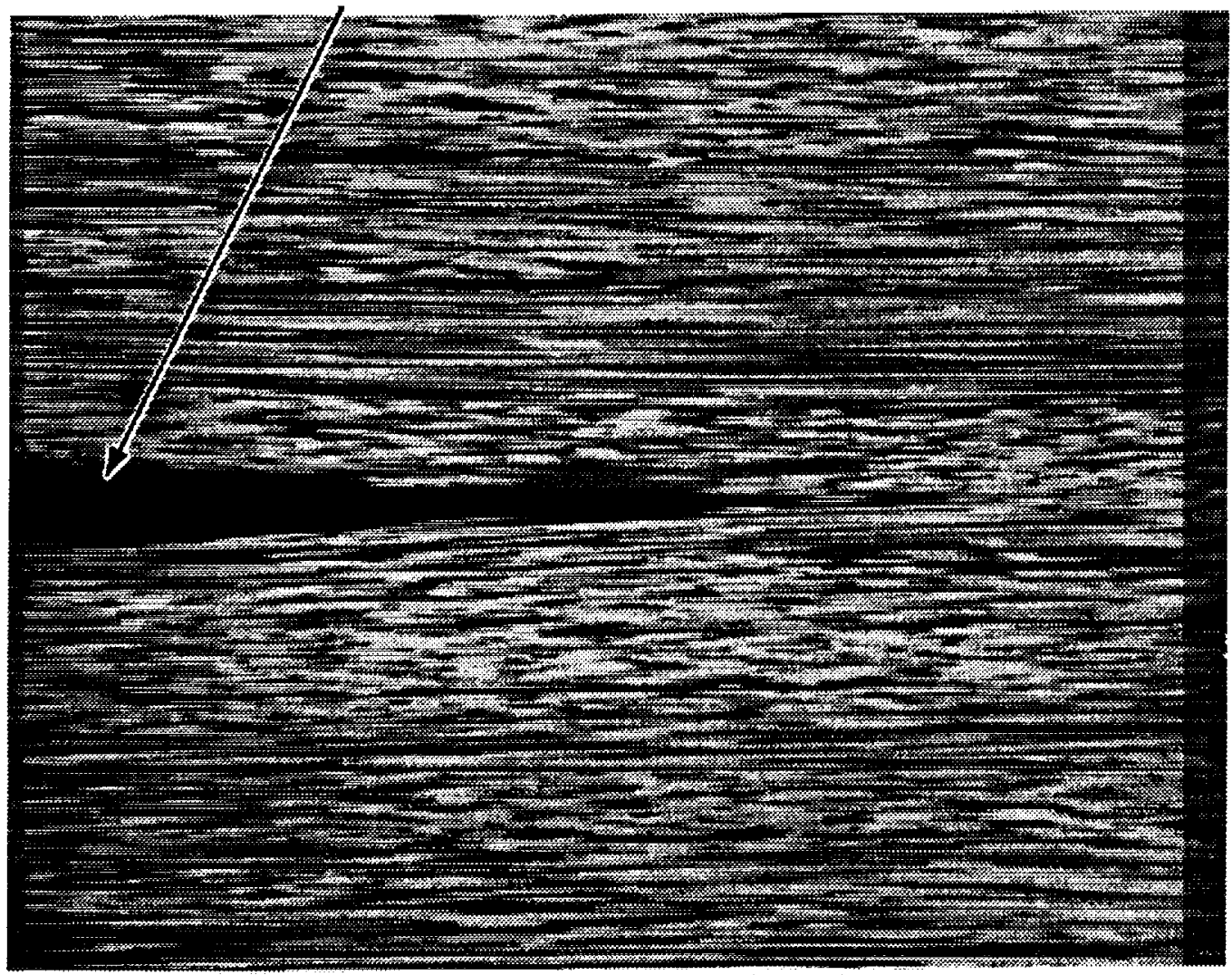

Figure 4. Photomicrograph at 50X magnification of the crack tip created by Teflon insert in mode I delamination specimens. 


\subsection{LOW VELOCITY IMPACT DAMAGE}

\subsection{Introduction}

Low velocity/low energy impact damage was investigated because it can occur during assembly, handling and the often extensive verification testing of aerospace structures. This type of damage is particularily relevent to graphite/epoxy materials because of their brittle nature [18]. The brittleness results in a low tolerance for stress concentrations and a poor ability to resist impact damage.

The detrimental effects of impact damage on both compressive and tensile strength in brittle matrix composites have been reported by several investigators $[13,14,19,20]$. Low energy impact damage is usually confined to the matrix with little fiber breakage. In this case, the matrix's ability to stabilize the fibers in compression can be significantly degraded while there is little or no loss of inplane tensile strength. However, certain impact conditions can lead to fiber failure and a significant loss of tensile strength.

\subsection{Equipment}

A General Research Corporation (GRC) Dynatup Model 8200 Impact Test Machine equipped with a GRC Model 730-I Data Acquisition System was used to induce the low velocity impact damage in the composite specimens. The model 8200 machine was a drop weight tower with a maximium drop height of 36 inches. The corresponding maximum velocity was 9,400 inches per minute. The crosshead weight could be varied from approximately 2.5 to 30 pounds (lbs). This combination of available drop heights and crosshead weights provided an impact energy range of less than 1 to $90 \mathrm{ft}$-lbs.

The Materials Branch has a GRC 8496-2, 10,000 lb instrumented tup (load cell) with four interchangeable charpy and dart type heads. The GRC 8496-2 was configured for the standard Model 8200 crosshead which had a weight range of 6 to 30 lbs. In addition, there is a light weight crosshead which was configured for a GRC 8730, 3,500 lb instrumented tup which had a 1/2 inch diameter hemispherical head.

The GRC 730-I data acquisition system utilized an IBM-PC AT computer equipped with a high speed data acquisition board in order to acquire, analyze, plot, and store complete impact event records. The board acquired data from the instrumented tup when triggered either externally by a flag passing through a velocity detector or internally when a threshold load was exceeded. The data acquisition time ranged from 2.5 to 10,000 milliseconds with 1,024 samples recorded during the time interval. A 12 bit A/D converter gave a load cell signal resolution of 3,640 increments in the positive direction over the selected load range and 456 increments over $1 / 8$ of the selected load range in the negative direction. 


\subsection{Support Configuration}

During the first phase of the program, specimens were completely supported by a $1 / 4$ inch thick aluminum plate. This support configuration limited specimen deflection, and as a result, the majority of the damage was in the form of matrix cracking and fiber breakage with little or no delamination.

A review of the literature on the impact testing of fiber reinforced composites revealed that the most common support configuration used is a membrane [14]. This type of support is more representative of the in-service usage of composites and was employed during the second phase of the program. A membrane configuration allows for more bending deflection of the laminate. The increased deflection results in higher bending shear and consequently, more delamination damage. The membrane support can also result in back surface fiber breakage and matrix cracking.

Investigators $[14,21,22]$ did not use a consistent membrane support diameter to projectile diameter ratio. Nettles [14] used a $4.2 \mathrm{~mm}$ diameter dart type tup in conjunction with a $10.3 \mathrm{~mm}$ diameter membrane. This setup resulted in a membrane to tup diameter ratio of 2.5. Moore and Prediger [21] used a 40 $\mathrm{mm}$ circular membrane and a $10 \mathrm{~mm}$ diameter hemispherical tup which yielded a ratio of 4 . Gardiner et al. [22] used a 5/8 inch diameter tup with a four inch square membrane (6.4 ratio). One recommendation is to select the membrane support and tup diameters which best simulate the in-service support configuration and impact events.

The support design in this study was limited by the one inch composite specimen width. A 3/4 inch diameter membrane was selected to insure uniform support. The light weight crosshead and the GRC 3,500 lb tup were used because the load level required to induce damage in the laminate was typically less than $200 \mathrm{lbs}$. The $3,500 \mathrm{lb}$ tup had a $1 / 2$ inch diameter hemispherical head, and the resulting membrane to tup diameter ratio was 1.5 .

Another variable was the specimen width to tup diameter ratio. Husman et al. [13] investigated the effect of this ratio on a glass fiber/epoxy matrix (Scotch-ply/1002) cross ply laminate supported as a cantilever beam. The impact velocities ranged from 150 to over 600 feet per second $(\mathrm{ft} / \mathrm{sec}$ ). The authors indicated that the specimen width to projectile or tup diameter ratio should be six in order to eliminate edge effects. It is unclear if this criterion applies to other materials, lay-ups, support configurations and impact velocities.

In this program, one inch wide quasi-isotropic graphite/epoxy specimens were supported with a membrane and impacted with a $1 / 2$ inch diameter tup at velocities below five $\mathrm{ft} / \mathrm{sec}$. The specimen width to tup diameter ratio was two, which is considerably less than the ratio recommended by Husman et al; however, the material, support configuration and impact velocities used in this program were dramatically different from those investigated by Husman et al.

In summary, the composite specimens in both phases of this study were impacted using the light weight crosshead $(2.67 \mathrm{lbs})$ and the $3,500 \mathrm{lb}$ instrumented tup with a $1 / 2$ inch diameter hemispherical head. In the first phase of the program, the specimens were completely supported by a $1 / 4$ inch 
thick aluminum plate. In the second phase, the specimens were supported by a $3 / 4$ inch diameter membrane. In both cases the impact was normal to the specimen surface and located at the center of the $1 \mathrm{inch}$ specimen width. The GRS 730-I load and time ranges used for the aluminum plate support were 2,500 $\mathrm{lbs}$ and 25 milliseconds. The values for the membrane support were $500 \mathrm{lbs}$ and 10 milliseconds. In both cases the velocity flag data acquisition trigger mode was used with no time delay.

\subsection{Incipient Impact Energy}

One objective of this program was to determine the incipient damage energy for the selected composite laminate, support configuration, and tup diameter. The incipient damage point, which according to Lloyd and Knight [20] corresponds to the onset of laminate failure, was characterized by a sharp load drop in the load versus time plot generated by the GRC 730-I data acquisition system. The incipient damage energy is the amount of energy absorbed by the laminate at the point of the load drop.

A survey of the literature on impact testing revealed conflicting interpretations of the incipient damage point $[14,21,23]$. Zang et al. [23] indicated that front surface indentation should represent the first step of laminate plastic deformation. The authors suggested that for brittle matrix composites, the small load drop that occurred early in the load versus time plot corresponded to the point where the tup created matrix cracks on the front surface. Microscopic examination of several specimens impacted at $0.8 \mathrm{ft}$-lbs revealed extremely tight matrix splits parallel to the fiber direction in the area of the impact indentation. However, the splits were not found in all of the specimens which exhibited the characteristic load drop. These findings suggest that the load drops do not correspond to the formation of surface matrix splits.

Nettles [14] did not agree that the load drop corresponded to the onset of laminate failure. Nettles found no damage in several specimens which exhibited the characteristic drop during impact. In addition, Nettles indicated that the same type of load drops were observed during the impact of aluminum specimens. Nettles concluded that the load drop may be a decrease in force due to a shock wave rebound effect.

The results of this study did not confirm Nettles' findings. Immersion ultrasonic examinations were performed on all the impacted specimens. Damage was detected in all specimens which exhibited a load drop during impact. An aluminum plate was also impacted. The load versus time plot shows a discontinuity at the early stage of the impact event (Figure 5). A similar discontinuity was observed in the impact records from graphite/epoxy specimens. However, the discontinuity was not a sharp load drop and was quite different from the incipient damage points identified in the impact records (Figure 6).

Moore and Prediger [21] noted that load versus deflection plots for low energy impacts of graphite/epoxy laminates consisted of two parts. There was an approximately linear elastic region followed by oscillations or a series of load drops. Based on photography during impact, the authors concluded that the start of the oscillations corresponded to the onset of back surface tension cracking (matrix splitting). The amount of energy absorbed at the onset of 

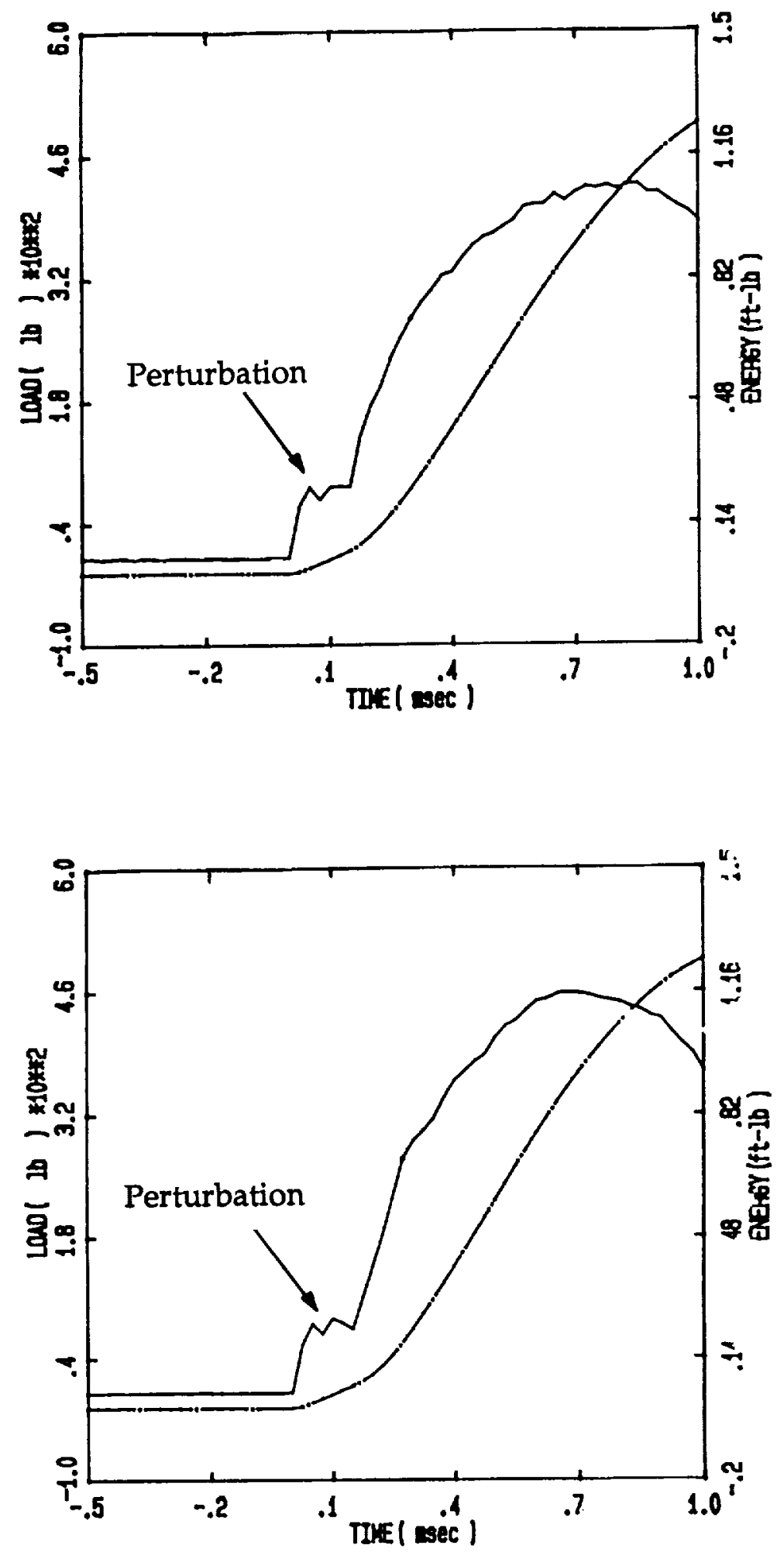

Figure 5. Impact records from an aluminum plate. 

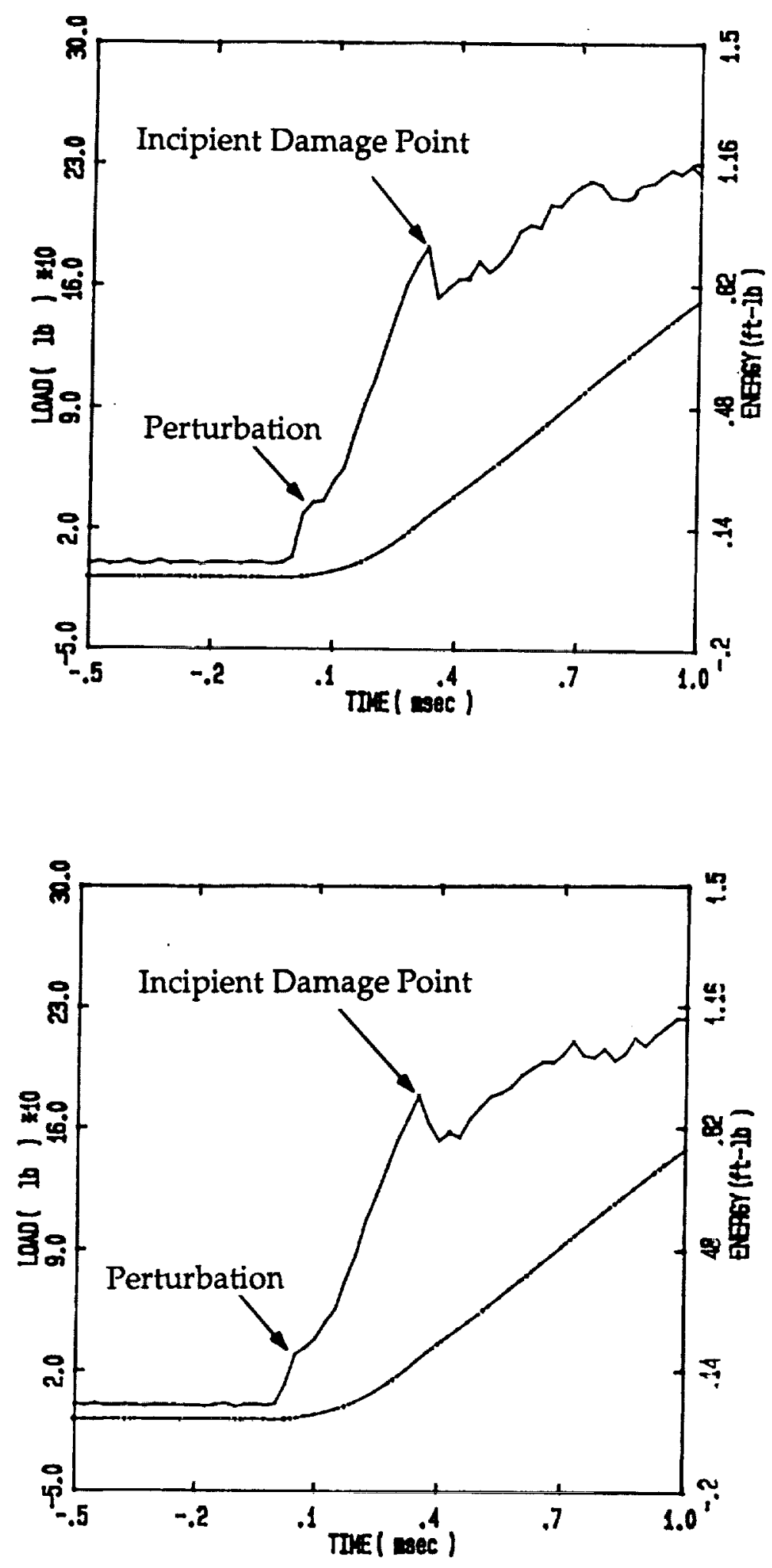

Figure 6. Impact records from a graphite/epoxy laminate. 
cracking was relatively consistent for each material and lay-up tested. For example, an average value of 0.23 Joules $(\mathrm{J})$ with a standard deviation of $0.014 \mathrm{~J}$ was reported for a $\mathrm{T}-300 / 934[+45]_{2 \mathrm{~s}}$ laminate. Based on immersion ultrasonic C-scans, the energy required to produce delaminations was also approximated and found to be higher than the energy required to produce tension cracks (e.g., $0.35 \mathrm{~J}$ for the T-300/934 laminate).

The results of this program suggest that the absorded impact energy at the point of the load drop corresponds to a critical impact energy. Impacting specimePns at this critical energy typically results in no load drop in the test record and no detectable damage using immersion ultrasonics. However, all of the specimens impacted at this energy level did exhibit back surface matrix splits. One of the six specimens impacted at this critical impact energy showed a load drop, and damage was detectable using immersion ultrasonics. In addition, one of the specimens which exhibited no load drop when impacted at the critical energy had detectable damage. These findings suggest that the absorbed energy corresponding to the small load drop is a threshold or critical energy for the onset of laminate failure. However, the exact failure mechanism associated with the load drop has not been identified.

\subsection{Selection of Impact Energies}

In order to determine the critical or incipient impact energy, specimens from both laminate lay-ups were impacted at energies of approximately 0.9 and $1.4 \mathrm{ft}$-lbs. These impact events resulted in back surface damage without complete tup penetration. The average impact energy at the point of the first detectable load drop for both laminate lay-ups was approximately $0.3 \mathrm{ft}$-lbs.

In the first phase of the program (aluminum plate support configuration), specimens were impacted at the incipient energy ( $1.7 \mathrm{ft}-\mathrm{lbs})$ and at two and four times the incipient energy ( 3.4 and $6.8 \mathrm{ft}-\mathrm{lbs})$. In the second phase of the program (membrane support configuration), specimens were impacted at the incipient energy $(0.3 \mathrm{ft}-1 \mathrm{bs})$ and at two and 2.7 times the incipient energy $(0.6$ and $0.8 \mathrm{ft}$ lbs). Tables 1 and 2 provide a complete summary of the impact events.

The impact energies in the second phase of the program were selected to keep the amount of visible damage at a minimum. In retrospect, the energies should have been based on residual tensile strength after impact. Nettles [14] investigated the residual tensile strength of several graphite/epoxy materials with eight ply unidirectional, bidirectional, and quasi-isotropic lay-ups. Nettles found that all of the materials showed a sharp decrease in tensile strength at what he called a critical energy level. For impact energies below the critical level, small amounts of damage were visibly detected.

Nettles [14] also indicated that the impact energy at which fiber damage first occurred corresponded to the energy level at which the tensile strength began to rapidly decrease. The microscopic examination of cross sections of impacted specimens from the three energy levels used in the second phase of the program revealed no fiber breakage. This finding suggests that these impact energies were below the laminate's residual tensile strength critical energy level. 
Table 1. Impact Parameters for $[0, \pm 45,90]_{S}$ Specimens

\begin{tabular}{|c|c|c|c|}
\hline Specimen ID & $\begin{array}{c}\text { Impact Energy } \\
\text { (ft-lbs) }\end{array}$ & $\begin{array}{c}\text { Energy Absorbed } \\
\text { (ft-lbs) }\end{array}$ & $\begin{array}{c}\text { Max. Load } \\
\text { (lbs) }\end{array}$ \\
\hline Q1 & 0.83 & 0.415 & 262.0 \\
Q2 & 0.83 & 0.425 & 261.0 \\
Q3 & 0.84 & 0.513 & 249.7 \\
\hline Q4 & 0.64 & 0.308 & 227.2 \\
Q5 & 0.65 & 0.295 & 230.5 \\
Q6 & 0.63 & 0.359 & 217.2 \\
\hline Q7 & 0.31 & 0.121 & 163.5 \\
Q8 & 0.31 & 0.117 & 163.7 \\
Q9 & 0.31 & 0.126 & 161.5 \\
\hline
\end{tabular}

Table 2. Impact Parameters for $[90, \pm 45,0]_{S}$ Specimens

\begin{tabular}{|c|c|c|c|}
\hline Specimen ID & $\begin{array}{c}\text { Impact Energy } \\
\text { (ft-lbs) }\end{array}$ & $\begin{array}{c}\text { Energy Absorbed } \\
(\mathrm{ft}-\mathrm{lbs})\end{array}$ & $\begin{array}{c}\text { Max. Load } \\
\text { (lbs) }\end{array}$ \\
\hline S1 & 0.63 & 0.280 & 230.5 \\
S2 & 0.62 & 0.287 & 229.4 \\
S3 & 0.63 & 0.325 & 223.1 \\
\hline S4 & 0.82 & 0.404 & 258.3 \\
S5 & 0.85 & 0.594 & 240.6 \\
S6 & 0.82 & 0.405 & 260.1 \\
\hline S7 & 0.32 & 0.127 & 163.9 \\
S8 & 0.31 & 0.132 & 164.4 \\
S9 & 0.32 & 0.127 & 163.1 \\
\hline
\end{tabular}




\subsection{DAMAGE ASSESSMENT}

\subsection{Introduction}

Microscopic cross-sectional examination and conventional NDE techniques were employed to assess the type and amount of damage produced by the impact events. Cross-sectional examination was used to characterize the types of damage (e.g., matrix cracking, delamination and fiber breakage) produced by the two support configurations. Penetrant enhanced radiography and immersion ultrasonics were used to nondestructively quantify the levels of damage in the AE specimens.

\subsection{Cross-sectional Examination}

The preferred method for destructively characterizing impact damage in relatively thin laminates is the deply technique which is described by Smith et al. [24]. The technique relies on the penetration of $\mathrm{AuCl}$ solution into the damaged areas. The limited damage on the back surface of the specimens in this program did not insure penetration of the solution. Therefore, cross-sectional examinations were performed to document the damage.

In the first phase of the program, specimens impacted at the incipient damage energy (1.7 ft-lbs) revealed bottom ply matrix cracking and back surface fiber breakage, but no delamination damage. The back surface fiber breakage was located directly below the impact site. The specimens impacted at twice the incipient damage energy ( $3.4 \mathrm{ft}-\mathrm{lbs})$ showed some small areas of delamination between the bottom two plies. The delaminations showed a preference for propagation at the resin rich ply interface. Again, damage was primarily in the form of matrix cracking and back surface fiber breakage. Isolated cases of fiber breakage were also found in internal plies located below the laminate midplane, i.e., in the bottom four plies of the eight ply laminate. The specimens impacted at four times the incipient damage energy $(6.8 \mathrm{ft}-\mathrm{lbs})$ showed extensive matrix cracking, delamination, back surface fiber breakage and internal ply fiber breakage.

It is important to note that all three levels of impact produced back surface fiber breakage. However, significant delamination damage was only found in specimens impacted at four times the incipient impact energy.

None of the cross-sectioned specimens from the second phase of the program exhibited back surface or internal ply fiber breakage. The damage was primarily delamination and matrix cracking at all impact energies. Again, the delaminations showed a preference for propagation in the resin rich ply interfaces below the specimen midplane. Microscopic examination revealed that all specimens had several back surface matrix splits parallel to the fiber direction.

In general, the specimens with zero degree outer plies $\left([0, \pm 45,90]_{S}\right.$ lay-up), which have a higher bending stiffness, exhibited more delamination damage. This finding was confirmed by immersion ultrasonics which is discussed later in this report. 


\subsection{Penetrant Enhanced Radiography}

During the first phase of the program, penetrant enhanced radiography was used to assess the amount of impact damage. The penetrant solution recipe, which was obtained from the Materials Response Group at Virginia Polytechnic Institute and State University , consisted of 60 grams (g) of zinc iodide, 10 milliliters (ml) of water, $10 \mathrm{ml}$ of isopropyl alcohol and $10 \mathrm{ml}$ of Kodak Photo Flo. The solution was applied to the back surface of each specimen. The matrix cracking and fiber failure on the back surface provided an access path to internal damage. The solution dwell time was 30 minutes.

The specimens were radiographed using a 15 kilovolt beam, 1.5 milliampere current, 4.7 minute exposure time, and a source to film distance of approximately 10 inches. The radiographic indications from the solution were limited to the small area of visible back surface damage. No indications of internal delaminations were found in any of the specimens, which suggested the solution was not penetrating into the areas of internal damage. The lack of solution penetration could be attributed to insufficient dwell time and/or the tortuous and sometimes intermittent fracture path.

Penetrant enhanced radiography is time consuming and involves the use of hazardous materials (zinc iodide). In addition, the penetrant solution may have adverse effects on material properties. Therefore, immersion ultrasonics was utilized in place of radiography during the second phase of this program to assess the amount of impact damage.

\subsection{Ultrasonic Inspection}

Ultrasonics is probably the most common NDE technique used to inspect composite materials $[25,26,27]$. There are a variety of ultrasonic techniques such as through-transmission, pulse-echo, polar backscatter, ultrasonic resonance, and ultrasonic correlation. Of these techniques, through-transmission and pulse-echo are the easiest to automate. The major difference between the two techniques is through-transmission involves the measurement of signal attenuation only, while pulse-echo can measure both attenuation and time-of-flight. Signal attenuation is used to detect flaws, and time-of-flight is used to measure the depth of flaws.

\subsubsection{Equipment}

The ultrasonic inspections were performed using a Physical Acoustics Corporation ULTRAPAC I PC based immersion system. The system consisted of an immersion tank, scanning bridge assembly, pulser/receiver, and an IBM PC XT compatible computer with a PC motion controller and data acquisition software. The system is capable of displaying $\mathrm{A}$ and $\mathrm{C}$-scans. The A-scans, which are basic displays of amplitude versus time for a single point, are typically used to set up data acquisition gates. C-scans, which are maps of signal attenuation or time-of-flight, are used to display results of $X-Y$ area scans.

The dimensions of the immersion tank, which was constructed of plexiglass for easy viewing, were 18.5 by 18.5 by 12 inches deep. The bridge 
assembly was capable of 12 inch $X$ and $Y$ axis scan dimensions. Motion in the $X$ and $Y$ directions were effected by stainless steel leadscrews driven by stepper motors. The step size resolution was $0.001 \mathrm{inch}$, and scan speeds were variable up to 1.5 inches per second. A manually movable $Z$ axis search tube was attached to the bridge and supported a manual dual angle manipulator. The manipulator had a standard 0.75 inch diameter UHF mount for transducers.

The pulser/receiver was a model 1010-PR from ACCU-TRON Inc. This was a general purpose broadband pulser/receiver which could be used in either the through-transmission or pulse-echo mode. The pulse shape was a negative spike with a less than 10 nanosecond risetime and four selectable energy levels $(18,49,79$ and 110 microjoules). Repetition rate and damping were also user selectable. The receiver had a 0.1 to 10 megahertz $(\mathrm{MHz})$ bandwidth. Selectable gain levels were 20,40 and 60 decibels $(\mathrm{dB})$, and attenuation ranged from 0 to 68 dB.

The system software was version 1.51 of TestPro by Infometrics, Inc. Infometrics markets numerous ultrasonic software modules ranging from C-Scan Capability (CSC) and Transducer Evaluation Test (TET) to Flaw Classification Enhancement (FCE) and an Artificial Intelligence/Expert System (AIS). These individual modules or programs were accessed by a software shell called the Program Director (PDR). Only the basic system software - PDR, CSC and TET was available.

This version of the software did not provide for image scaling, selection of areas of interest, feature analysis or image enhancement. In addition, the hard copy output on the system's color dot matrix printer was slow (over 20 minutes per image) and limited to either a 16 color or eight gray scale palette. Infometrics was contacted to determine how to access the raw ultrasonic data so that imaging programs such as NIH-Image could be used to improve both the usefulness and hard copy representation of the data.

The C-scan images stored by the TestPro software were stored EGA screens. Tim Van Sant of the Materials Branch acquired a $C$ language program from Infometrics which converted the stored EGA screen files into $\AA S C I I$ text integer files. The ultrasonic data had 6 bit resolution ( $\wedge$ integer values: 0 to 63 ) which suggested that the ULTRAPAC's peak detector used a six bit A/D converter. The EGA screen to ASCII text file conversion program scaled the data to 128 integer values. However, the true resolution remained at 6 bits. Mr. Van Sant then wrote a Pascal program which converted the text files into single-byte integer files. These integer files could be imported into NIH-Image, a public domain image analysis software package. NIH-Image provided "tools" for image area selection, scaling, feature extraction, image enhancement, etc. Images could be produced using a variety of palettes on a QMS Color Script 100 printer in one to two minutes.

\subsubsection{Inspection Setup}

The graphite/epoxy specimens, which were 24 inches long were placed at an approximately 45 degree angle in the tank. A modification of the throughtransmission technique called "reflector-plate through-transmission" was used [28]. In this technique, which is shown schematically in Figure 7, a reflector was placed below the specimen, and the data acquisition gate was setup on the echo 


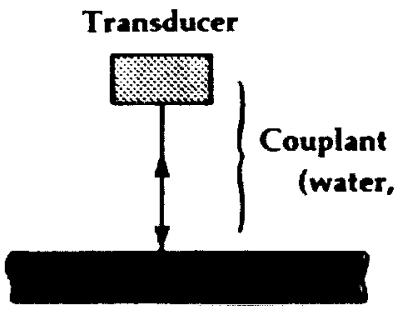

(a)

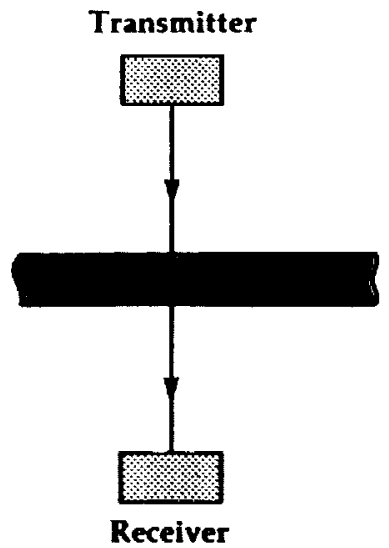

(b)
Transducer

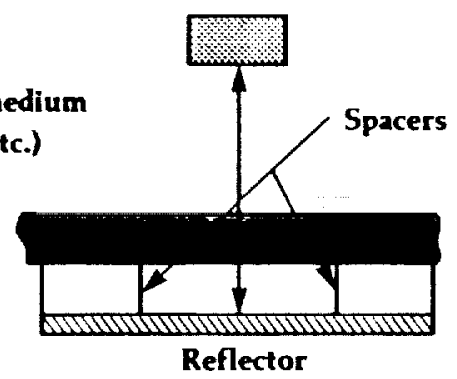

(c)

Transmitter

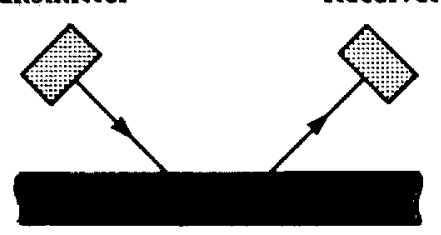

(d)

Figure 7. Ultrasonic data acquisition methods:

(a) pulse-echo, (b) through-transmission, (c) reflector-plate through-transmission, (d) angle-beam [28].

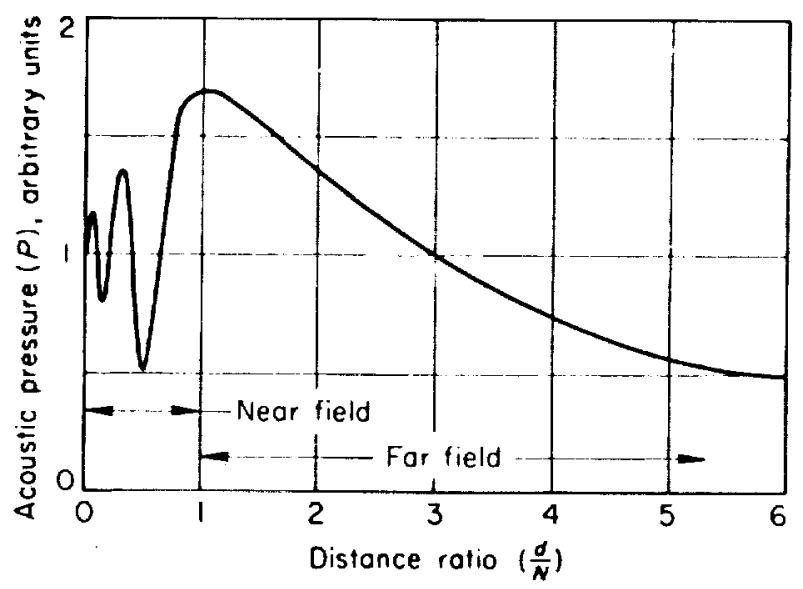

Figure 8. Variation of acoustic pressure with distance ratio for a circular search unit [29]. 
from the reflector. The technique is similar to through-transmission in that only attenuation data is meaningful. One advantage of this technique compared to standard through-transmission is that the ultrasound passes through the specimen twice, which increases sensitivity to small flaws. Pulse-echo was not used for the relatively thin eight ply laminate (approximately 0.048 inches) because it was difficult to setup up a reliable data acquisition gate between the specimen front and back surface reflections.

A $10 \mathrm{MHz}$ nonfocussed transducer with a 0.25 inch diameter element was used for the inspections. The natural focus (transition from near to far field) of the transducer was 2.66 inches. The transducer was approximately 0.7 inches above and normal to the specimen surface. The impacted side of the specimen faced the transducer. The tank bottom served as the reflector and was 0.5 inches below the specimen. For this setup, both the specimen and the reflector were within the transducer's near field.

Eric Madaras of NASA, Langley Research Center indicated that positioning the specimen in the transducer's near or far field does not dramatically influence sensitivity. According to Mr. Madaras, any sensitivity differences should only be due to beam profile or beam spread effects. Regardless, most reflector-plate inspections are performed with the specimen at or beyond the transducer's near field. There is a pattern of acoustic pressure maximums and minimums (Figure 8 ) which are caused by interference effects in the transducer's near field [29]. Placing the specimen in the transducer's far field eliminates the possiblity of large changes in the beam profile with small changes in the distance between the transducer and the specimen. The effect of positioning the specimen and reflector at various points in the transducers near and far field is discussed further in the System Characterization section of this report.

A one by one inch area of the specimen containing the impact damage site was scanned using a step size of 0.005 inches and a scan speed of 0.05 inches per second. For high resolution C-scans, the CSC software provided a maximum of 200 by 250 image elements (pixels). Selecting a step size of 0.005 inches for a 1 inch scan dimension resulted in a full utilization of the 200 available image elements. The scan speed was the maximum that could be used without losing data during the scan. The key pulser/receiver, digitizer, data acquisition gate, and scanning parameters are summarized on the inspection form shown in Figure 9 . The receiver gain and attenuation were selected to produce an approximately full scale gated signal amplitude when the transducer was positioned over defect free material.

\subsubsection{Inspection Results}

Figures 10 and 11 show the attenuation $C$-scans from the 18 impacted specimens. NIH-Image was used to "cut" the damaged areas from each individual C-scan and "paste" the images to create a montage. These C-scans simply mapped the bounds of the damaged areas. The damaged areas had an eliptical shape with the major axis of the elipse oriented in the direction of the fibers in the outer most ply. For the specimens with zero degree outer plies (Figure 10), the major elipse axis was in the longitudinal direction. For the specimens with 90 degree outer plies (Figure 11), the major elipse axis was in the 


\section{ULTRASONIC C-SCAN ACQOISITION PARAMETERS}

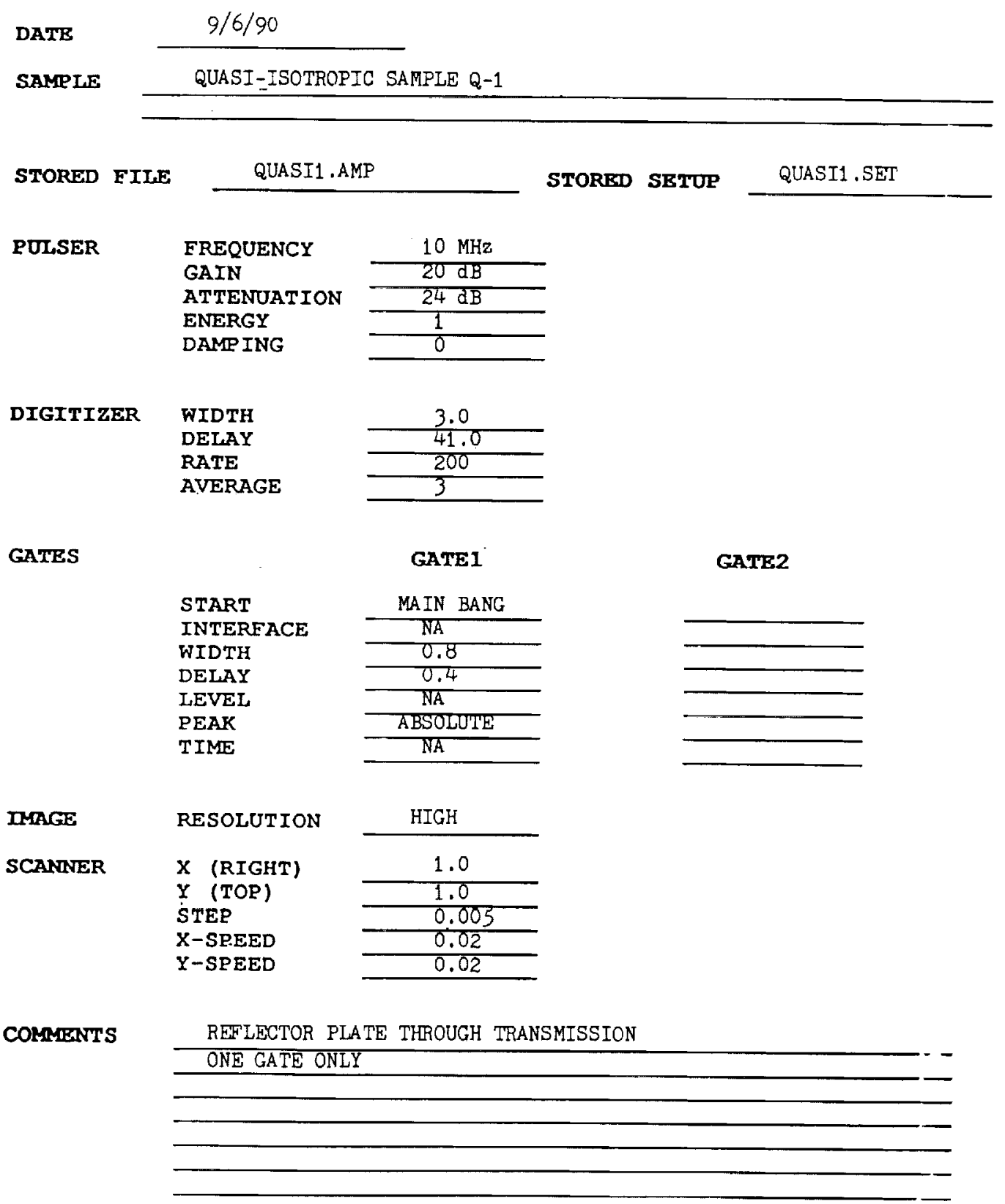

Figure 9. Immersion ultrasonic C-scan acquisition parameters. 


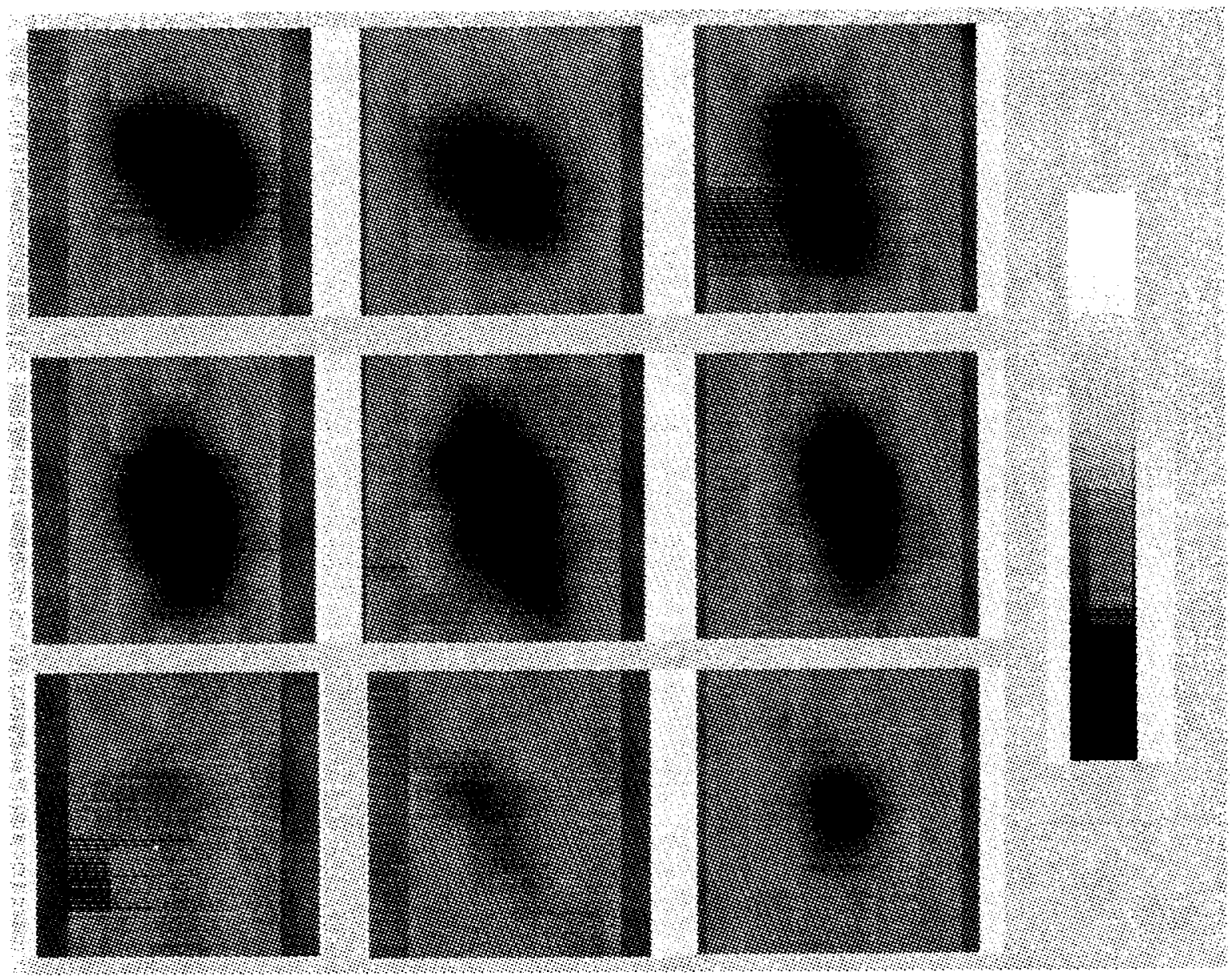

Figure 10. Immersion ultrasonic C-scan images from $[0, \pm 45,90]_{S}$ specimens impacted using membrane support. Top row: 0.8 , middle row: 0.6 , and bottom row: $0.3 \mathrm{ft}$-lbs. 


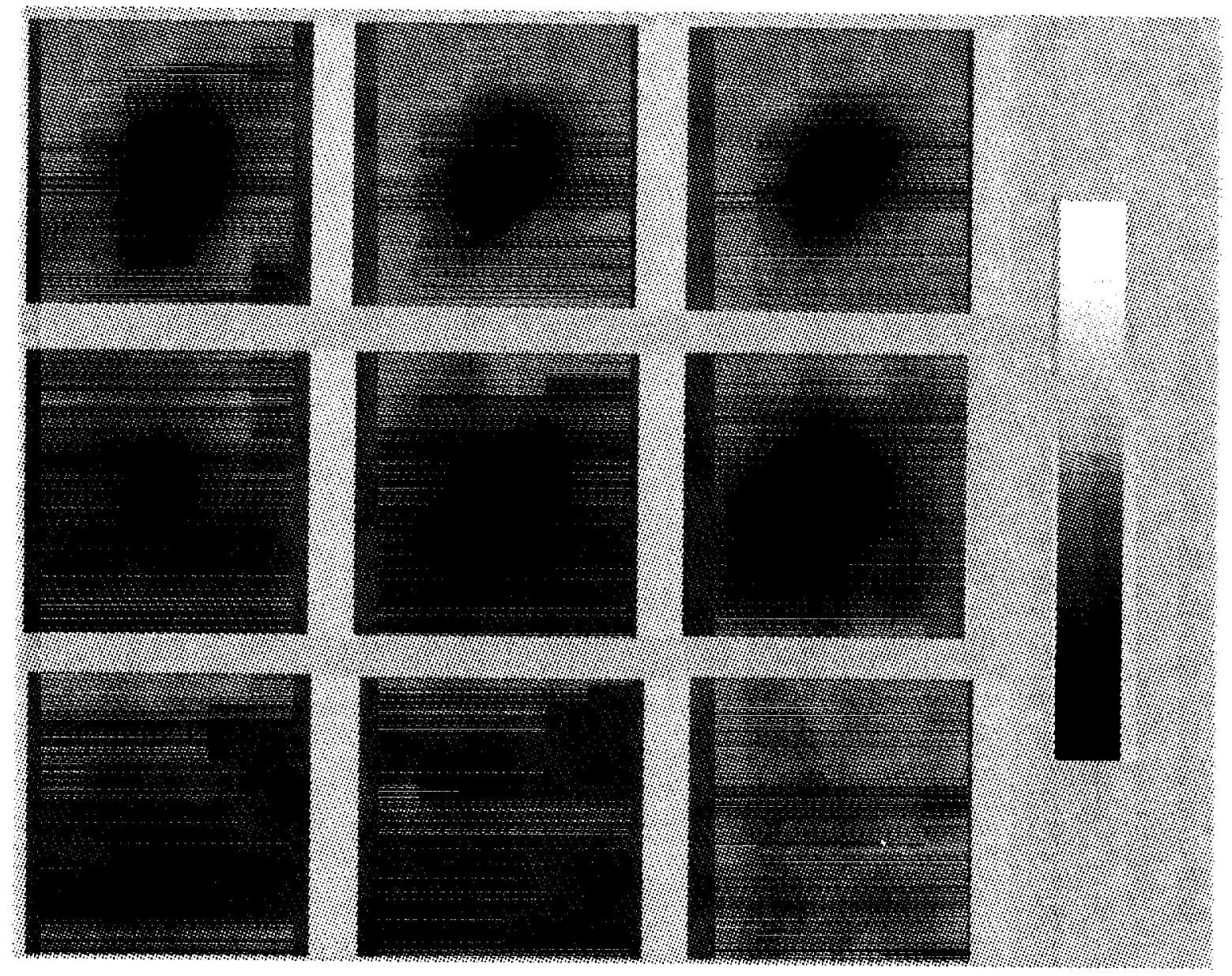

Figure 11. Immersion ultrasonic C-scan images from $[90, \pm 45,0]_{S}$ specimens impacted using membrane support. Top row: 0.8 , middle row: 0.6 , and bottom row: $0.3 \mathrm{ft}$-lbs. 
transverse direction. The highest levels of attenuation was at the center of the impact site.

Smith et al. [24] found that for thin laminates, the extent of damage increased as the distance from the impacted surface increased. This was consistent with the results of the cross-sectional examinations performed in this program which showed the largest area of delamination was between the two plies farthest from the impacted surface. Smith et al. also found that damage due to impact typically assumed a dumbbell shape with the axis of the dumbbell oriented in the direction of the fibers in the underlying lamina.

These findings suggest that the primary damage in the specimens in this program was a series of interply dumbbell shaped delaminations beginning at or below the laminate midplane. The size of the dumbbells should increase as the depth increases, and each dumbbell's axis should be oriented in the direction of the fibers in the underlying lamina. The attenuation C-scans should map the combined bounds of all the dumbbells (delaminations). Given that the largest dumbbell is typically between the two plies farthest from the impacted surface, it is not surprising that the axis of the eliptical shaped damage is in the direction of the fibers in the outer most ply. The attenuation data did not have a dumbbell shape because there was a series of overlapping dumbbells oriented in different directions.

The dumbbells originated from the impact site. This suggests that there may be delaminations at several ply interfaces in the region directly below the impact site. This finding was confirmed in the cross-sectional examinations. Therefore, it was not surprising that the degree of attenuation was highest at the center of the impact site as the ultrasonic beam was attenuated by more than one delamination.

In conclusion, the attenuation C-scans showed the boundary of the damage area. Both the shape and orientation of the boundary were consistent with findings reported in the literature [24] and the cross-sectional examinations performed in this study. The size of the indications were probably larger than the actual delamination area. The degree of magnification increased as the flaw size decreased. The magnification effects are discussed in the System Characterization section.

Attenuation C-scans were also performed on specimens which were impacted using the aluminum support plate configuration. The specimens inspected were not the same specimens which were used for AE data acquisition. The impacts were produced at a later date in order to determine if immersion ultrasonics could also detect damage that was primarily in the form of matrix cracking and fiber breakage. Figure 12 shows attenuation C-scans corresponding to the three impact energies used in the first phase of the program.

Recall that the cross-sectional examinations revealed no delamination for the $1.7 \mathrm{ft}-\mathrm{lb}$ impact energy and one small area of delamination for the $3.4 \mathrm{ft}-\mathrm{lb}$ impact. The attenuation C-scans, which were acquired using the reflector-plate through-transmission technique, provided no indication of damage in specimens impacted at these energies. This was not surprising as ultrasonics is most sensitive to planar defects perpindicular to the ultrasonic beam (delaminations) and has difficulties detecting defects parallel to the beam (matrix cracking and fiber breakage). Ultrasonics detected significant damage in the specimen 
ORIGINAL PAGE

BLACK AND WHITE PHOTOGRAPH

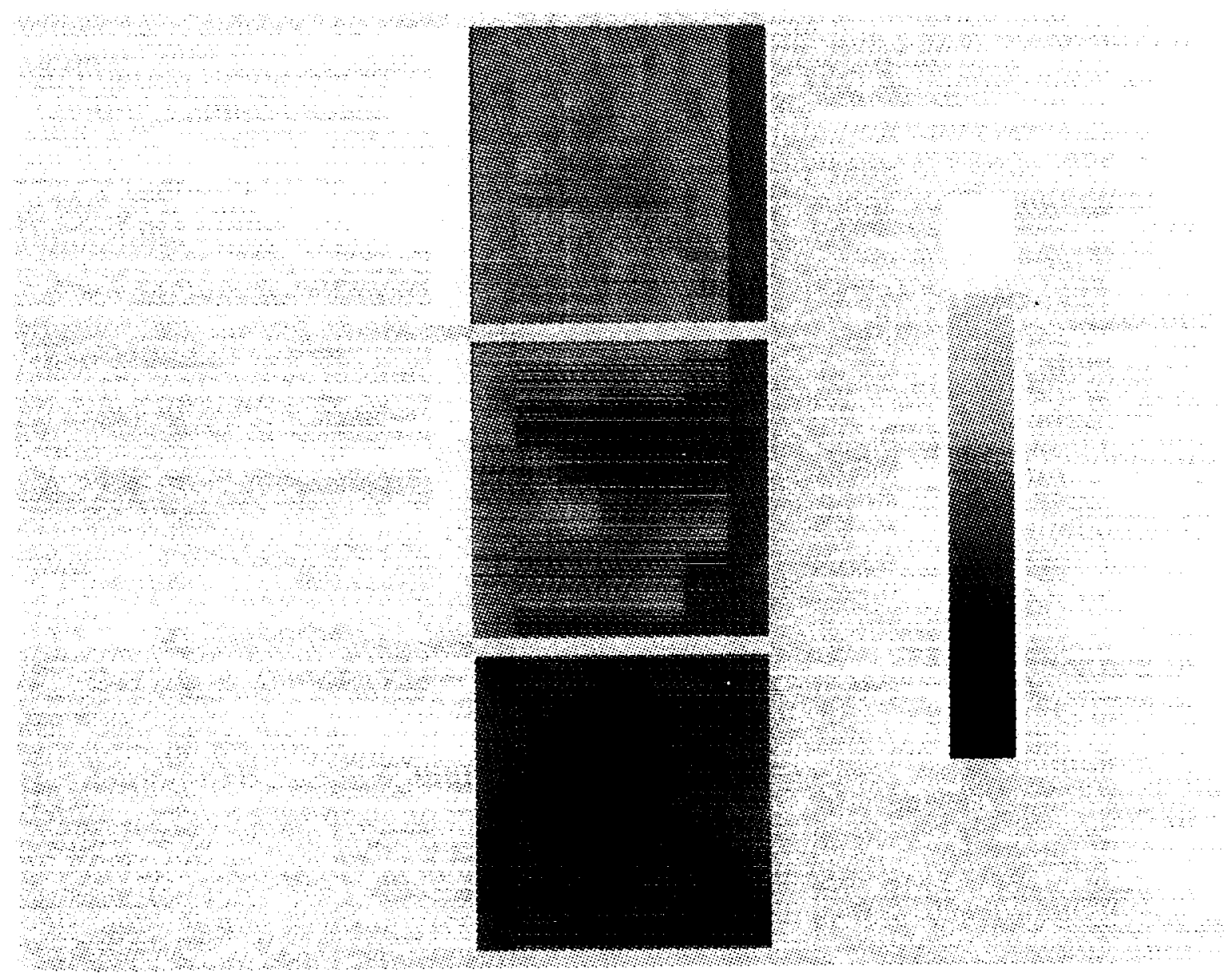

Figure 12. Immersion ultrasonic C-scan images from $[0, \pm 45,90]_{S}$ specimens impacted using aluminum plate support configuration. Top row: 1.7 , middle row: 3.4 , and bottom row: $6.8 \mathrm{ft}$-lbs. 
impacted at $6.8 \mathrm{ft}-\mathrm{lbs}$. The damage area characteristics were consistent with the delamination damage described by Smith et al. [24] and discussed above.

\subsubsection{System Characterization}

The majority of the system characterization was performed after the specimens were originally inspected. Aspects of the system investigated were flaw size magnification, scan dimension accuracy and the effect of specimen and reflector placement on flaw indications. In addition, the capabilities of $10 \mathrm{MHz}$ focussed and nonfocussed transducers were compared.

\subsubsection{Flaw Magnification}

The investigation of flaw size magnification was performed on a T$300 / 934$ graphite/epoxy 16 ply quasi-isotropic laminate containing circular grafoil inserts with diameters ranging from $1 / 8$ to $1 / 2$ inch in $1 / 16$ inch increments. The grafoil inserts, which were designed to simulate delaminations, were placed at all interply interfaces. The $10 \mathrm{MHz}$ nonfocussed transducer was used with the same reflector-plate through-transmission setup used to inspect the impacted specimens. In addition, the same pulser/receiver, digitizer, gate and scanning parameters were used. The only difference was the receiver attenuation, which was reduced by four $\mathrm{dB}$ in order to compensate for the difference in thickness between the 16 and eight ply laminates.

Attenuation data was acquired from the $1 / 2,1 / 4$ and $1 / 8$ inch diameter inserts positioned at the midply and between the 14th and 15th ply. The first ply was considered the ply closest to the transducer. These depths were chosen because all of the delaminations revealed in the cross sections of the eight ply specimens were at or below the laminate's midplane.

The most striking result of the C-scans was the eliptical shape of the flaw indications. Figure 13 shows the attenuation C-scans corresponding to the three flaw sizes and two depths. Figure 14, which is the C-scan of the $1 / 2$ inch diameter flaw located at the laminate midplane, clearly shows the eliptical nature of the flaw indications. In all of the C-scans, the longer elipse dimension was in the $Y$ scan direction. When the panel was rotated 90 degrees and the scans were repeated, the longer elipse dimension remained in the Y scan direction. This finding prompted an investigation of the scan dimension accuracy, which is discussed in the next section.

The $X$ scan dimension was determined to be correct. Hence, all magnification measurements were made only in the X direction. NIH-Image displayed numerical pixel values which corresponded to the position of a mouse-controlled cross-hair on the imported C-scan images. The pixel values corresponded to the absolute peak amplitude within the data acquisition gate. The range of pixel values for 6 bit resolution data was 0 to 63 , with low values corresponding to high signal attenuation. The pixel values for flawless areas ranged from 52 to 63 . If the pixel value was less than or equal to 50 , it was assumed to be a portion of the flaw indication.

Based on this criterion, the flaw magnification was found to be independent of flaw depth for the two depths investigated. The magnification 


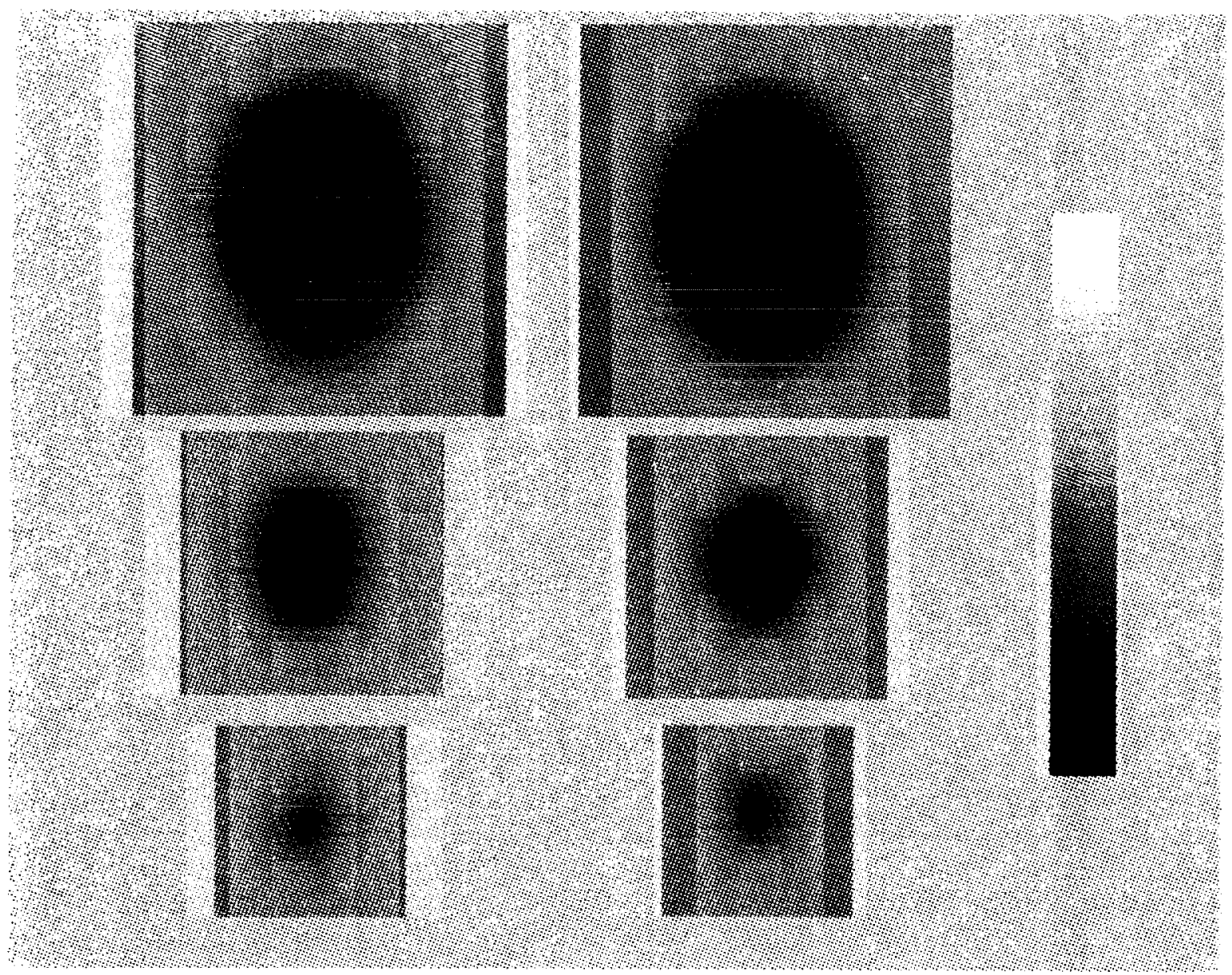

Figure 13. Attenuation C-scans corresponding to three flaw sizes and two depths. Left column: mid-ply, right column: 14-15th ply. 


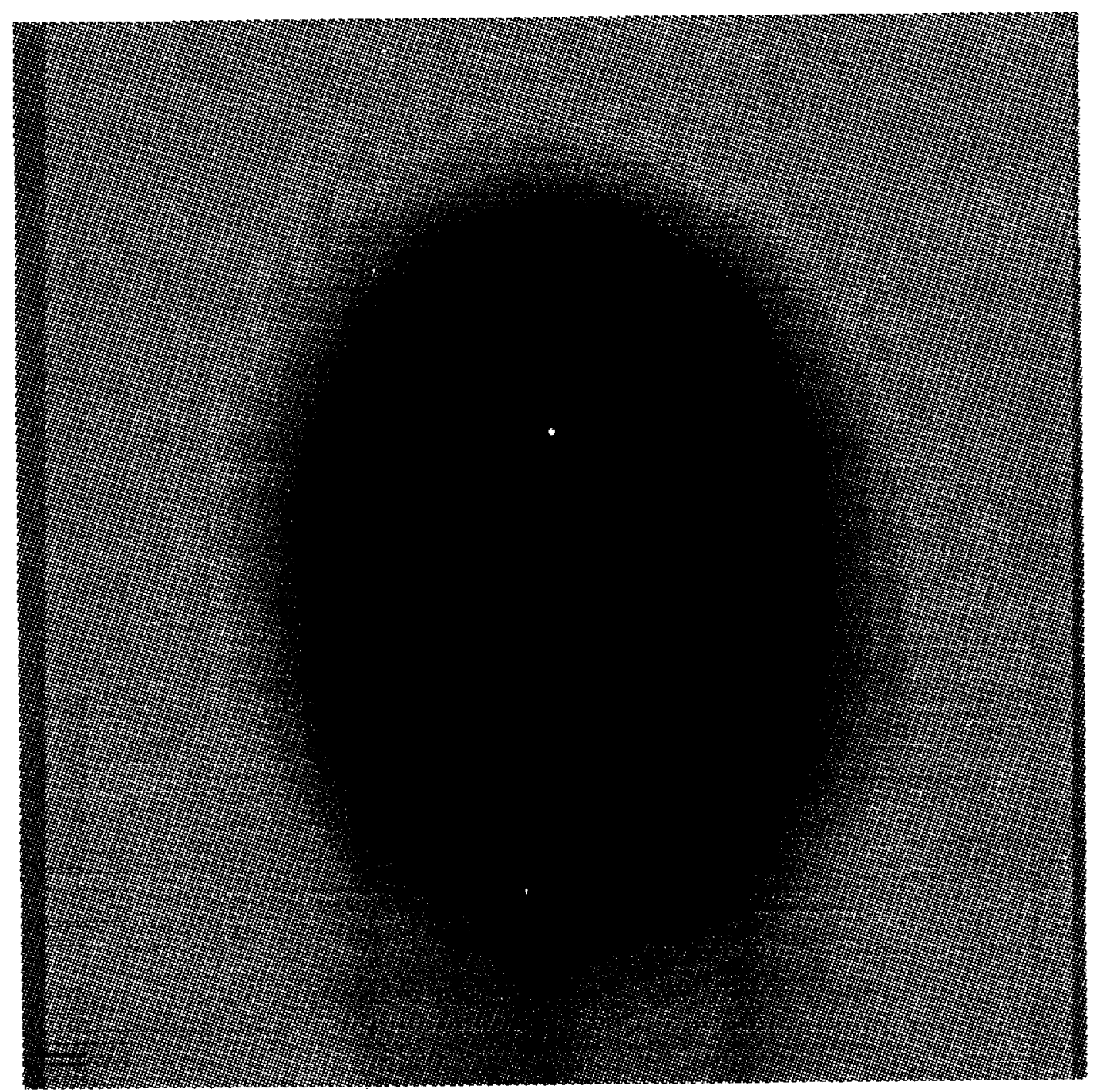

Figure 14. Immersion ultrasonic C-scan image of 1/2" diameter Grafoil insert at laminate midplane. 
measurements are summarized in Table 3 . The degree of magnification decreased as the size of the actual flaw increased.

Table 3. Characterization of Ultrasonic Flaw Magnification

\begin{tabular}{|c|c|c|c|c|}
\hline Flaw Diameter & \multicolumn{2}{|c|}{ Measured Diameter } & \multicolumn{2}{c|}{ Magnification } \\
\hline (in) & $\begin{array}{c}14-15 \text { th } \\
\text { (in) }\end{array}$ & $\begin{array}{c}\text { Midply } \\
\text { (in) }\end{array}$ & $14-15$ th & Midply \\
\hline 0.500 & 0.61 & 0.61 & 1.22 & 1.22 \\
0.250 & 0.42 & 0.38 & 1.68 & 1.52 \\
0.125 & 0.26 & 0.26 & 2.08 & 2.08 \\
\hline
\end{tabular}

\subsubsection{Scan Dimension Accuracy}

The eliptical shape of the flaw images obtained from circular artificial flaws prompted an investigation of the bridge scan accuracy. Scan accuracy was determined by attaching a felt-tip pen to the scanning bridge search tube and tracing scans with various dimensions, scan speeds and step sizes. Table 4 summarizes the software selected scan parameters and the corresponding actual scan dimensions. Figure 15 provides examples of the traced scans.

In all cases the $X$ scan dimension was approximately equal to the software selected value; however, the actual $Y$ scan dimension decreased as the step size decreased. This trend is shown in Figure 16, which is a plot of the actual Y scan dimension versus step size for one by one inch scans. When the $Y$ scan dimension was increased from one to six inches in one inch increments using a consistent step size and scan speed, the actual Y scan dimension was a consistent percentage of the input dimension. For one by one inch scans with a 0.025 inch step size, the actual Y scan dimension was independent of scan speed.

This measurement technique did not provide a completely accurate assessment of the scanning error. One problem was the widening of the traced lines due to bleeding of the ink. Additional errors may have been induced during the measurement of the trace dimensions which were performed manually using a ruler.

By selecting the appropriate scaling factors, NIH-Image could compensate for the inaccuracy in the $Y$ scan dimension. For example, Figure 17 is a scaled measured $Y$ scan dimension (0.74). The $X$ axis scale factor was one. The flaw indication became approximately circular when appropriate scaling factors were used. 


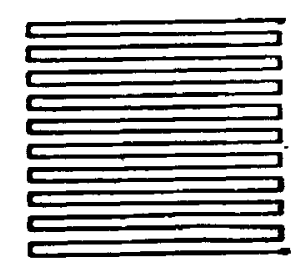

$0.100 "$ Step Size

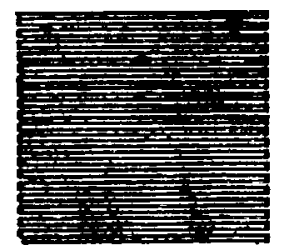

0.050" Step Size

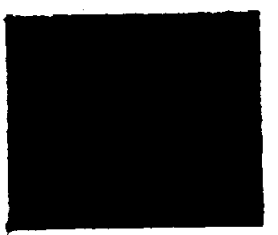

0.010" Step Size

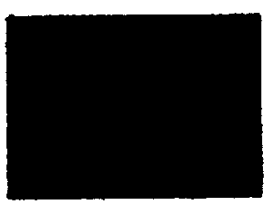

0.005" Step Size

Figure 15. Examples of traced C-scans.

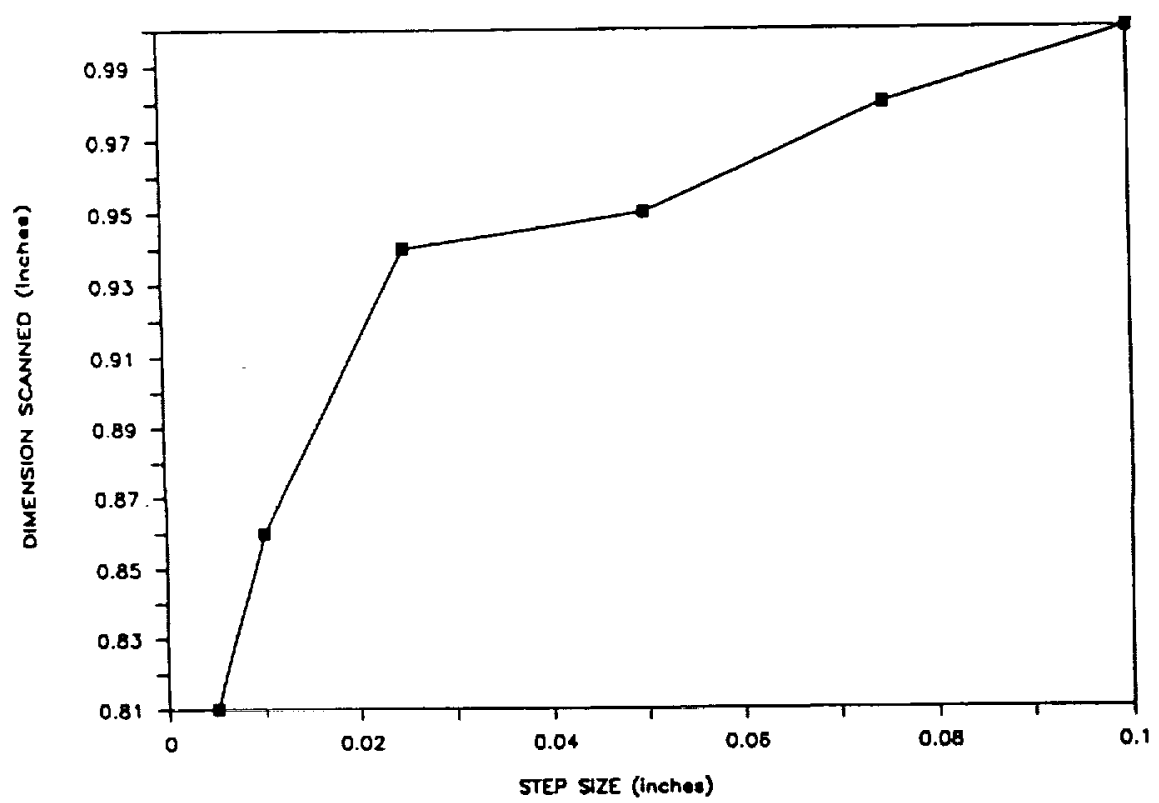

Figure 16. Plot of actual Y-scan dimension versus step size for one by one inch C-scans. 


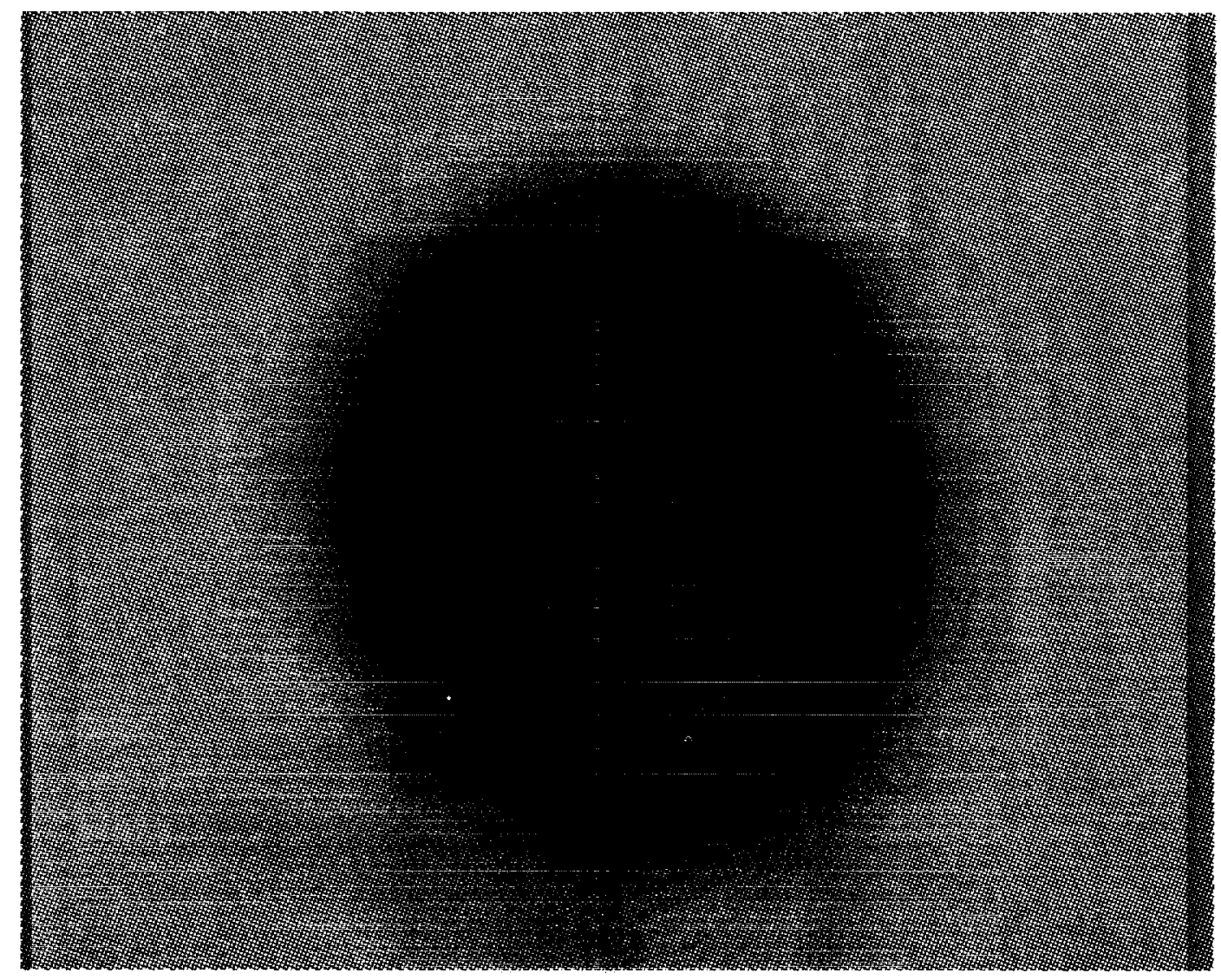

Figure 17. Scaled version of C-scan in Figure 14.

ORIGINAL PAGE BLACK AND WHITE PHOTOGRAPH 
Table 4. Ultrasonic Bridge Assembly Scan Dimension Accuracy

\begin{tabular}{|c|c|c|c|c|c|}
\hline \multicolumn{5}{|c|}{ Software Parameters } & \multicolumn{2}{c|}{ Actual Dimensions } \\
\hline $\begin{array}{c}\text { Step Size } \\
\text { (in) }\end{array}$ & $\begin{array}{c}\text { Speed } \\
\text { (in/sec) }\end{array}$ & $\begin{array}{c}\mathrm{X} \\
\text { (in) }\end{array}$ & $\begin{array}{c}\mathrm{Y} \\
\text { (in) }\end{array}$ & $\begin{array}{c}\mathrm{X} \\
\text { (in) }\end{array}$ & $\begin{array}{c}\mathrm{Y} \\
\text { (in) }\end{array}$ \\
\hline 0.005 & 0.25 & 1 & 1 & 1.03 & 0.81 \\
0.010 & 0.25 & 1 & 1 & 1.02 & 0.86 \\
0.025 & 0.25 & 1 & 1 & 1.01 & 0.94 \\
0.050 & 0.25 & 1 & 1 & 1.01 & 0.95 \\
0.075 & 0.25 & 1 & 1 & 1.01 & 0.98 \\
0.100 & 0.25 & 1 & 1 & 1.00 & 1.00 \\
\hline 0.05 & 0.25 & 1 & 1 & 1.01 & 0.95 \\
0.05 & 0.25 & 1 & 2 & 1.01 & 1.88 \\
0.05 & 0.25 & 1 & 3 & 1.01 & 2.91 \\
0.05 & 0.25 & 1 & 4 & 1.01 & 3.96 \\
0.05 & 0.25 & 1 & 5 & 1.01 & 4.91 \\
0.05 & 0.25 & 1 & 6 & 1.01 & 5.89 \\
\hline 0.025 & 0.25 & 1 & 1 & 1.01 & 0.94 \\
0.025 & 0.10 & 1 & 1 & 1.01 & 0.94 \\
0.025 & 0.05 & 1 & 1 & 1.01 & 0.94 \\
0.025 & 0.50 & 1 & 1 & 1.01 & 0.94 \\
\hline
\end{tabular}

\subsubsection{Specimen and Reflector Positioning}

As was noted in the discussion of the test setup, both the specimen and the reflector were placed in the near field of the $10 \mathrm{MHz}$ nonfocussed transducer. In order to confirm that this setup did not dramatically compromise the inspection sensitivity, a series of C-scans on the 1/4 inch diameter grafoil insert at the midplane of the 16 ply laminate were performed. The position of the specimen and reflector (tank bottom) in relation to the transducer for each C-scan is summarized in Figure 18.

Flaw indication diameters were measured based on pixel values equal to or below 50, which was the same criterion used to measure flaw magnifications. The diameters of the flaw indications for the four different transducer positions ranged from 0.33 to 0.36 inches. Based on the accuracy of the measurement technique, the indications were considered to be essentially equal. Figure 19 shows the four $\mathrm{C}$-scan images.

There was a larger degree of signal attenuation when both the specimen and reflector were within the transducer's near field. The pixel values at the center of this flaw indication were four or five. When the specimen, but not the reflector was in the near field, the majority of the pixel values were seven. When the focus was set at the specimen midplane, the majority of pixel values were eight. Finally, for the case where the specimen was in the far field, the values were nine or 10 . 


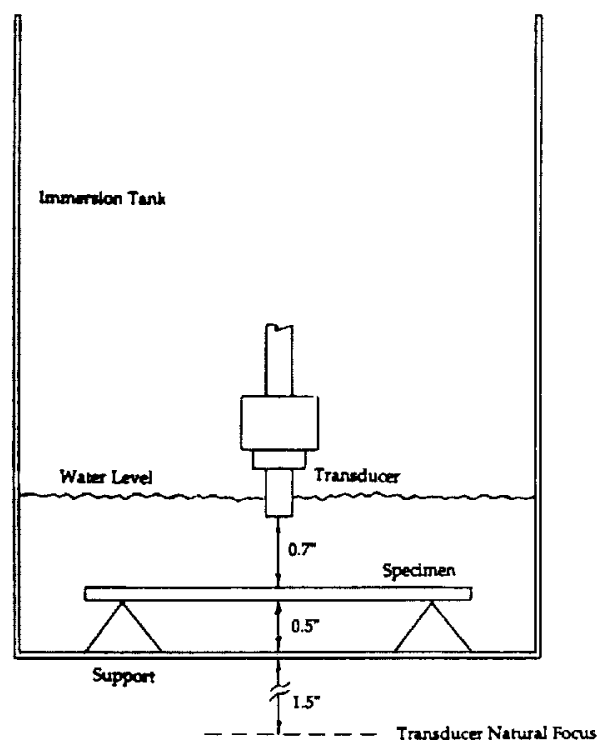

(a)

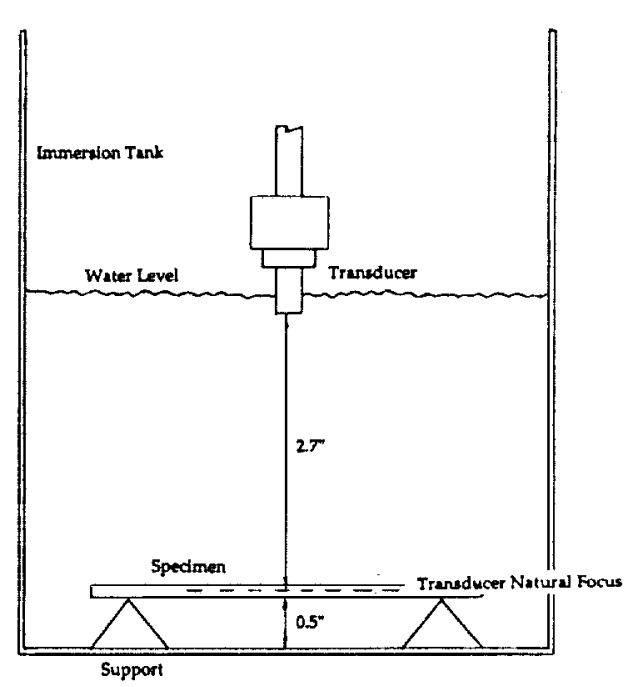

(c)

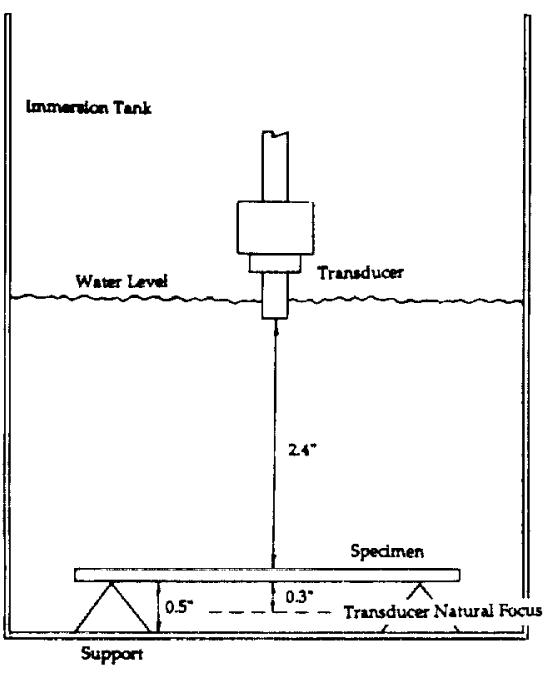

(b)

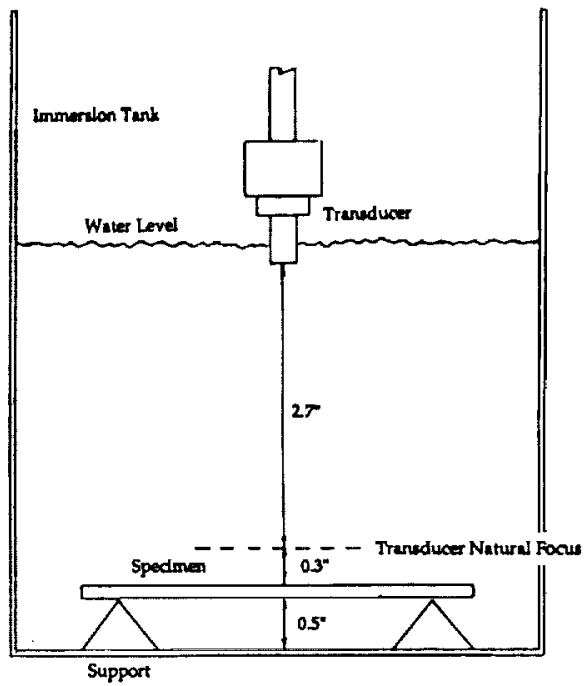

(d)

Figure 18. Specimen, transducer and reflector positioning. 


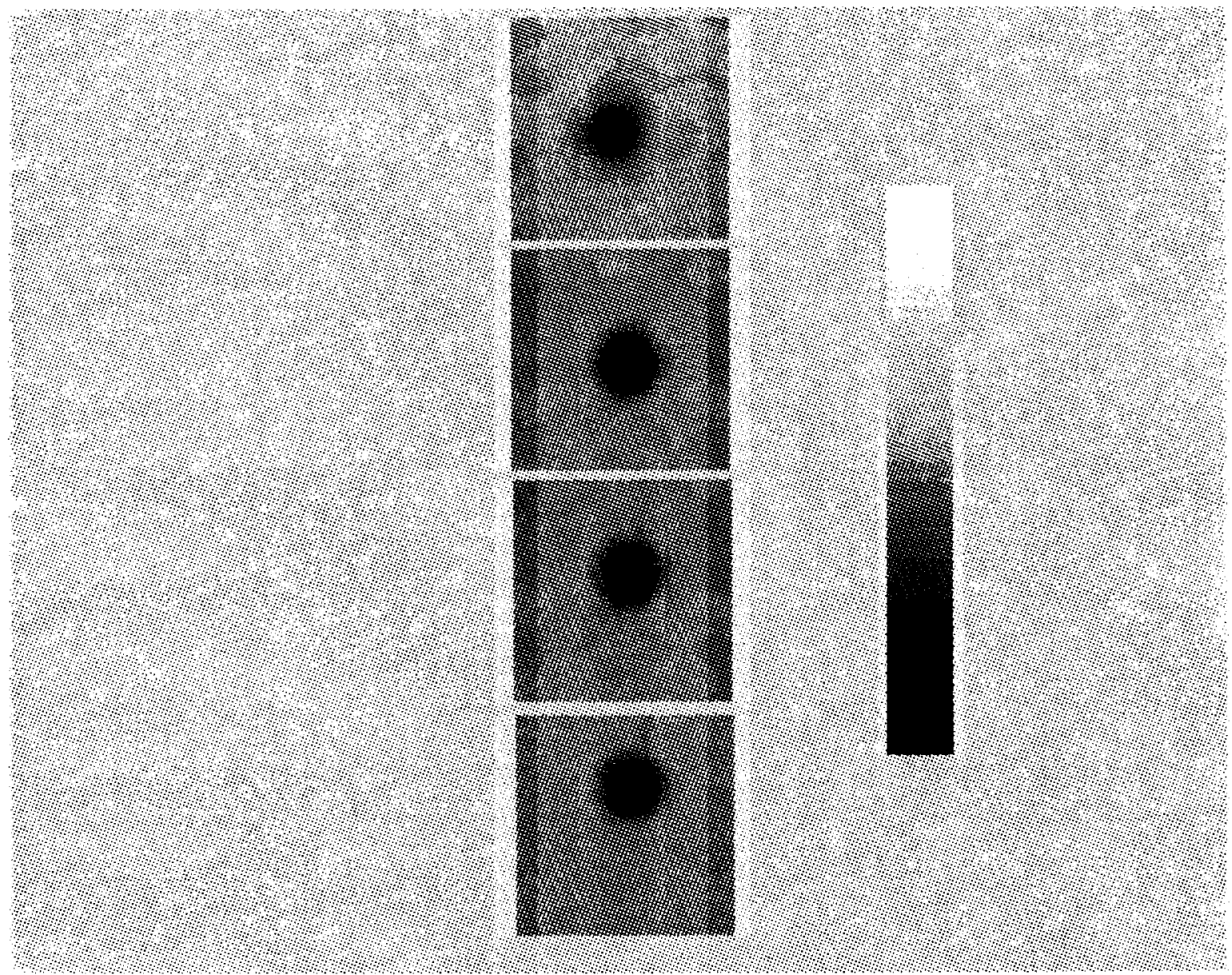

Figure 19. Immersion ultrasonic C-scan images for various specimen, transducer and reflector positions. Top to bottom C-scans correspond to (a) through (d) in Figure 18. 
There are several possible explanations for the differences in the degree of signal attentuation. First, for each transducer position, the receiver attenuation was adjusted to provide an approximately full scale peak on defect free material. This adjustment was required because signal attentuation varies with the water path length. It was difficult to achieve consistent signal amplitudes for each transducer position because the receiver attentuation could only be adjusted in two $\mathrm{dB}$ increments. Secondly, as the water path length increased, the attenuation due to the flaw became a smaller percentage of the overall signal attenuation. Finally, beam spread which typically began at the transducer's natural focus also decreased the percentage of overall attenuation due to the flaw. Beam spread applied only to the case where the specimen is in the far field.

\subsubsection{Focussed Transducers and the Pulse-Echo Technique}

With the pulse-echo technique, the data acquisition gate is set between the specimen front and back surface reflections. One problem with this technique is that the width of the front surface reflection creates what is often called the dead zone [30]. The dead zone results in an inability to detect flaws located close to the specimen front surface. As the thickness of the specimen decreases, the width of the dead zone becomes a higher percentage of the specimen thickness and reduces the percentage of material which can be inspected.

Other factors influencing the gate setup in the pulse-echo technique are background noise, surface roughness and thickness variations [30]. Background noise in composite materials is caused by low amplitude reflections from fiber/matrix interfaces, ply interfaces and irregularities such as microporosity. Usually a threshold level is set for the data acquisition gate in order to eliminate the background noise variations. The threshold is set as low as possible to insure that low amplitude reflections from small defects are not missed.

Surface roughness may result in variations in the front surface reflection width. Typically, the start of the data acquisition gate is a set delay after the front surface reflection crosses a threshold. The delay must be selected to insure that the front surface reflection does not enter the gate and mask other defects. Compensating for surface roughness variations with a gate delay can result in a broadening of the dead zone.

Finally, the gate width must compensate for variations in specimen thickness. Obviously, the time between the front and back surface reflections is a function of material thickness. The gate width must be based on the thinnest section in order to prevent the back surface reflection from entering the gate and masking defects. Compensating for the thickness variation creates a back surface dead zone.

The pulse-echo technique was used to inspect impact damage in eight ply composite specimens. The inspections were performed using a $10 \mathrm{MHz}$ focussed transducer with a 0.25 inch diameter element and a focal length of two inches. Figure 20 shows the results of $\mathrm{C}$-scans from the same impact site. One C-scan was performed using the pulse-echo technique (10 MHz focussed transducer), and the second C-scan was produced using the reflector-plate throughtransmission setup (10 MHz nonfocussed). 

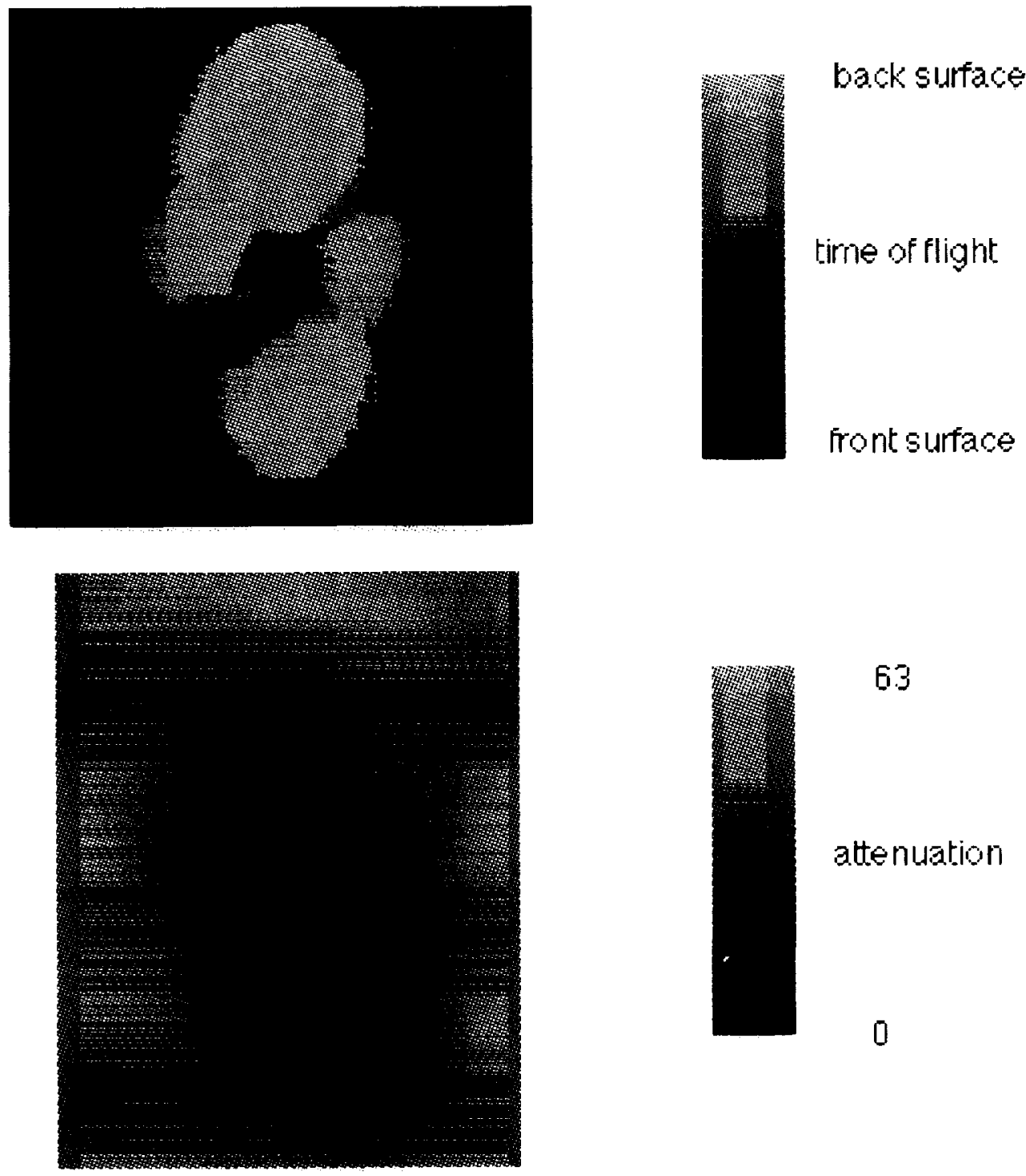

63

attenuation

Figure 20. Comparison of pulse-echo and reflector-plate throughtransmission C-scans. 
The depth data from the pulse-echo technique provided a much clearer picture of the delamination damage. The delaminations had the characteristic dumbbell shapes described by Smith et al. [24]. In addition, the size of the delaminations increased with increasing depth, and the axis of each dumbbell corresponded to the fiber direction in the underlying lamina. The section of the C-scan corresponding to the impact site (small black circle from which the dumbbells originate) incorrectly showed no defects. This was an artifact caused by the dome shaped depression on the specimen surface at the point of impact. This depression caused a large decrease in the front surface reflection.

The focussed transducer reduced the echo masking effects of background noise and surface roughness and hence, improved the resolution of time-of-flight data. The smaller diameter beam of a focussed (compared to nonfocussed) transducer reduced the area being interrogated which resulted in fewer low amplitude reflections associated with noise. The effects of surface roughness were attributed to the reflection of beam side lobe energy back to the transducer [30]. The reflected side lobe energy resulted in the broadening of the front surface reflection. Focussing reduced the deleterious effects of surface roughness by decreasing the amount of side lobe energy.

These effects are exhibited in Figure 21, which shows A-scans of front and back surface reflections from an eight ply quasi-isotropic composite specimen using the $10 \mathrm{MHz}$ focussed and nonfocussed transducers. The A-scans were acquired using a LeCroy 9420 oscilloscope. Note the reduced width of the front surface reflection and the lower level of backgound noise in the A-scan from the focussed transducer.

In order to determine the depth resolution of the $10 \mathrm{MHz}$ focussed transducer, pulse-echo/time-of-flight C-scans were acquired from a 16 ply quasiisotropic laminate containing grafoil inserts. One by one inch areas around the $1 / 4$ diameter grafoil inserts at all 15 ply interfaces were scanned. The scan step size and speed were 0.05 inches and 0.5 inches per second, respectively. This step size provided poor lateral resolution, but should not effect the depth resolution.

Figure 22 shows the depth resolution data. Some of the directly adjacent ply depths were difficult to distinguish when viewing the C-scans on the color video monitor. Distinguishing the ply depths was even more difficult in the printed image (Figure 22). However, by the accessing the individual pixel values in the NIH-lmage program, the differences in depth were detectable. The pixel values are summarized in Table 5 . Also included in Table 5 are the pixel value differences for adjacent and two ply separations. Ultrasonic pixel values which differed by three or more were visually distinguishable (Figure 23). Several of the adjacent ply pixel values varied by less than three. This explains the inability to distinguish some of the ply depths in the C-scan images. 
Table 5. Ultrasonic Depth Resolution for a 16 Ply Quasi-Isotropic Laminate

\begin{tabular}{|c|c|c|c|}
\hline \multicolumn{2}{|c|}{ Flaw Location } & \multicolumn{2}{c|}{ Pixel Value Difference } \\
\hline Ply Interface & Pixel Value & Adjacent Plies & Two Ply Spacing \\
\hline $1-2$ & 9 & - & - \\
$2-3$ & 10 & 1 & 5 \\
$3-4$ & 14 & 4 & 8 \\
$4-5$ & 18 & 5 & 9 \\
$5-6$ & 23 & 4 & 9 \\
$6-7$ & 27 & 2 & 6 \\
$7-8$ & 29 & 3 & 5 \\
$8-9$ & 32 & 4 & 7 \\
$9-10$ & 36 & 3 & 9 \\
$10-11$ & 39 & 6 & 10 \\
$11-12$ & 45 & 2 & 6 \\
$12-13$ & 49 & 3 & 4 \\
$13-14$ & 51 & 2 & \\
$14-15$ & 54 & & \\
$15-16$ & 56 & & \\
\hline
\end{tabular}




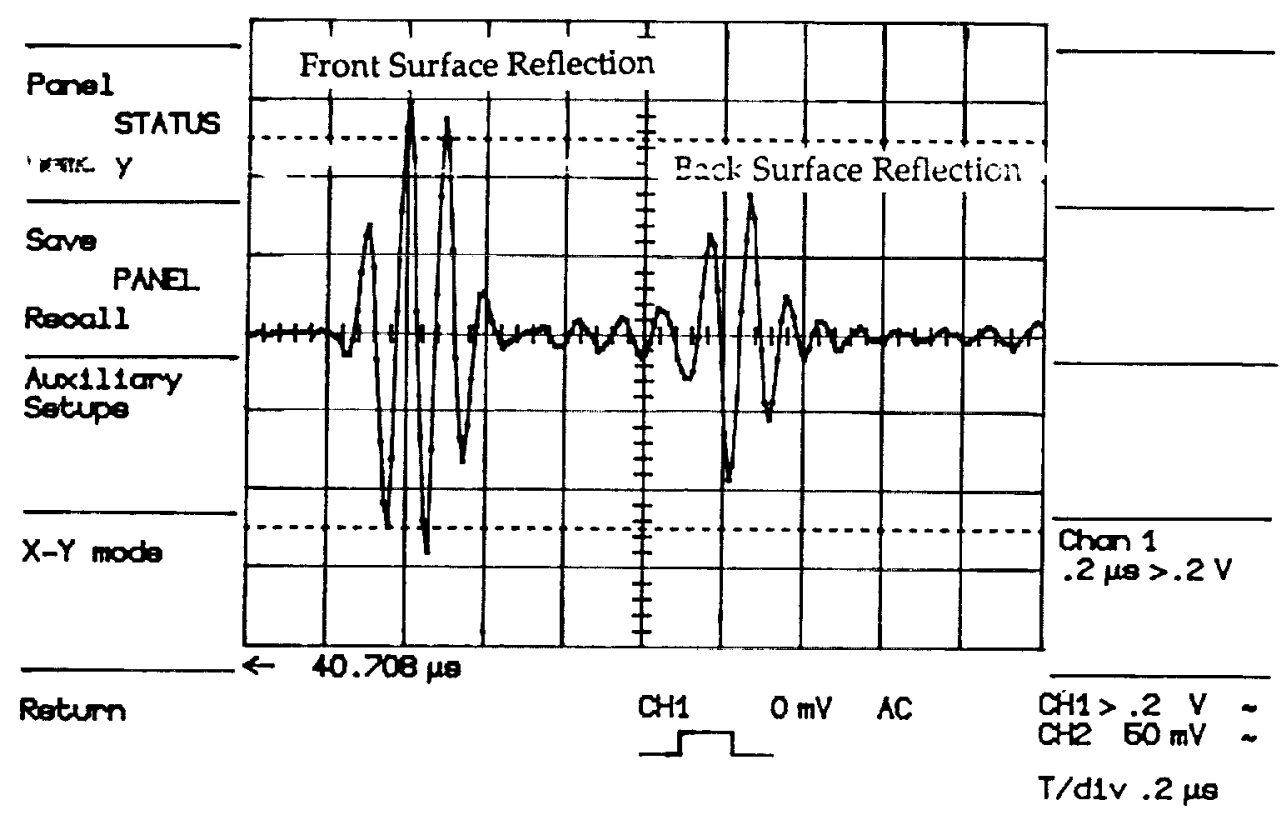

(a)

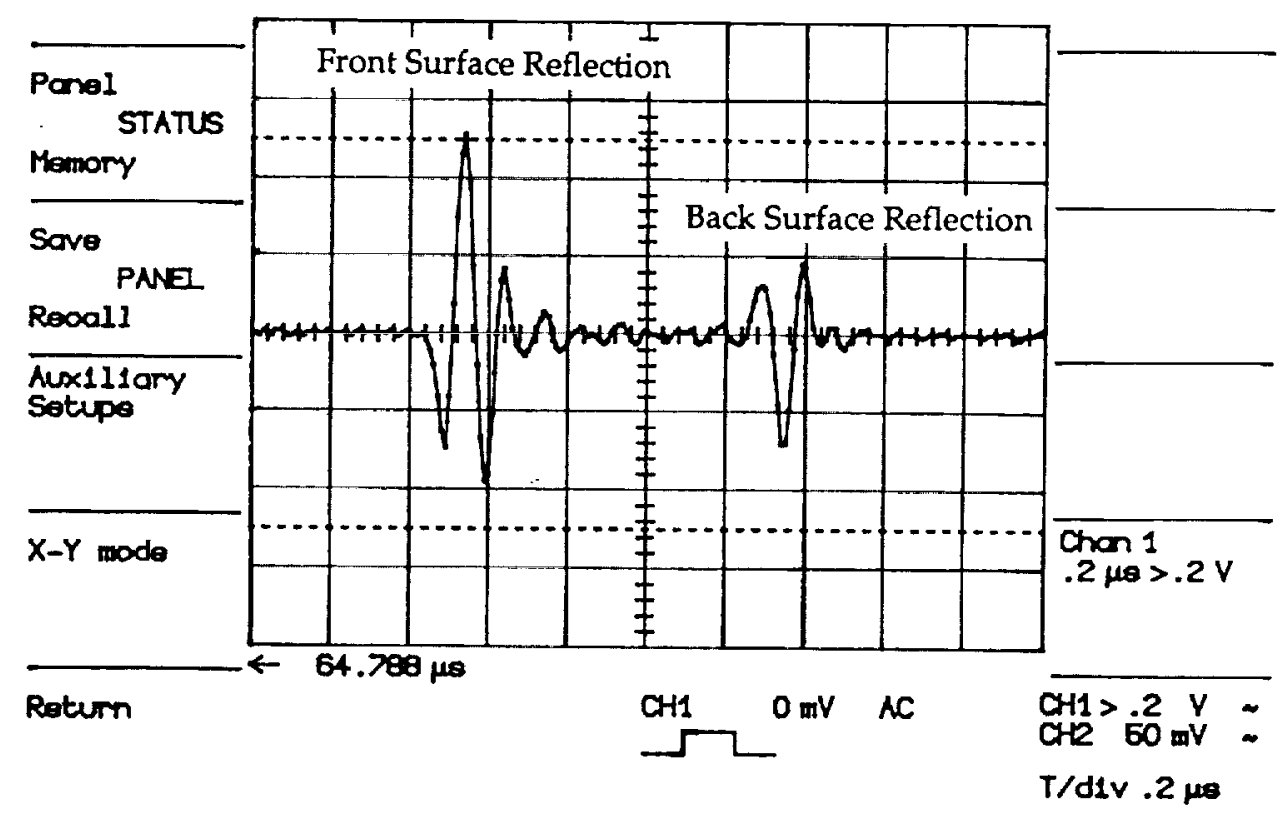

(b)

Figure 21. A-scans from focussed and nonfocussed $10 \mathrm{MHz}$ transducers. 

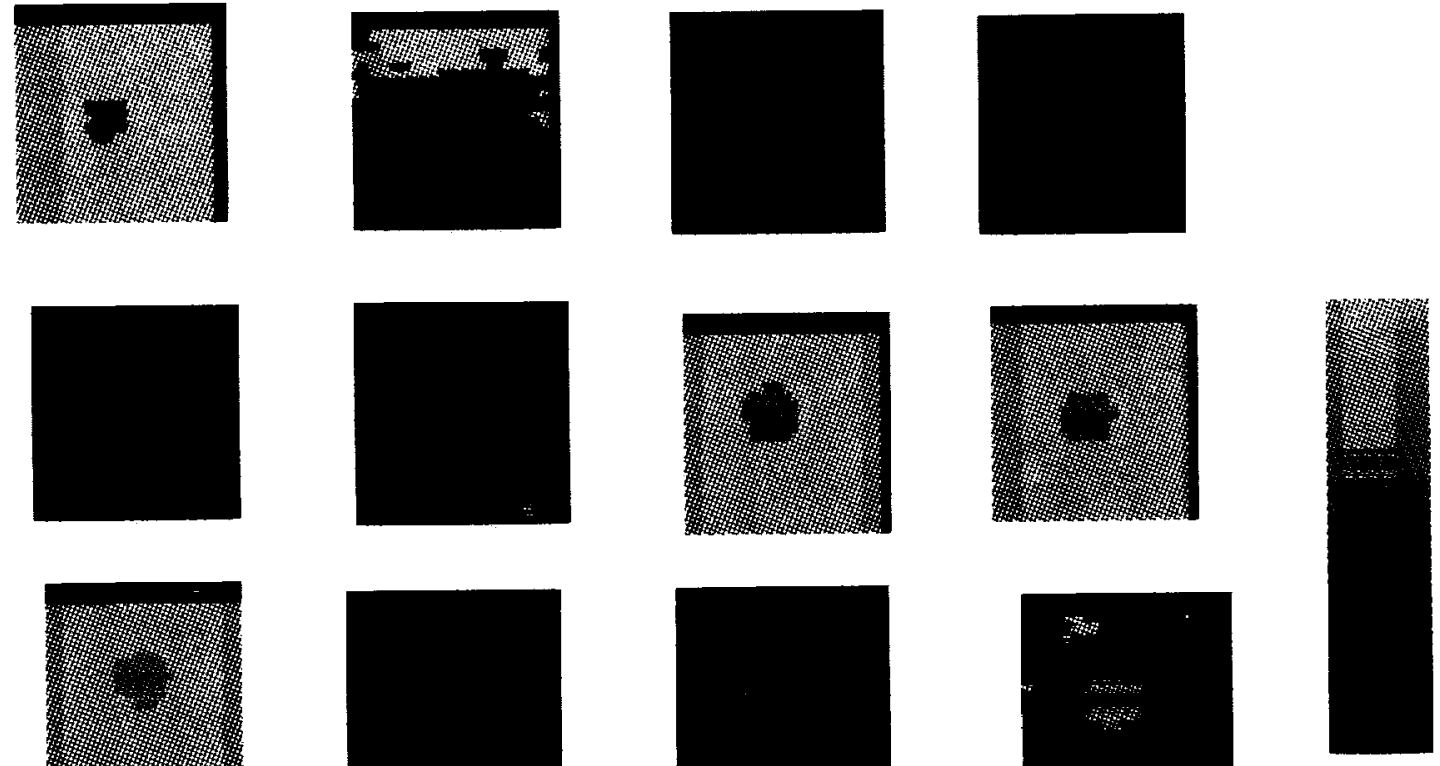

back surface
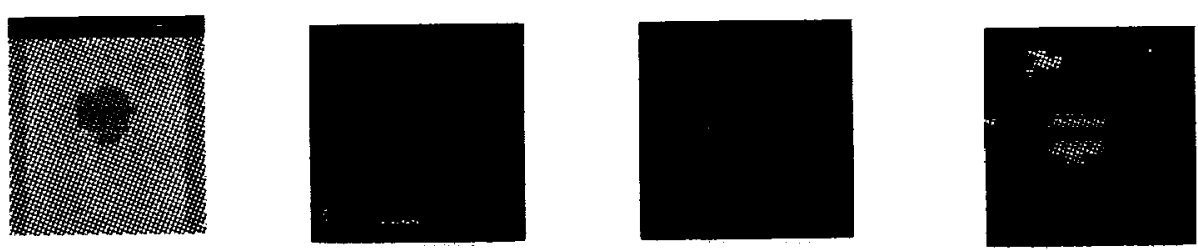

front surface
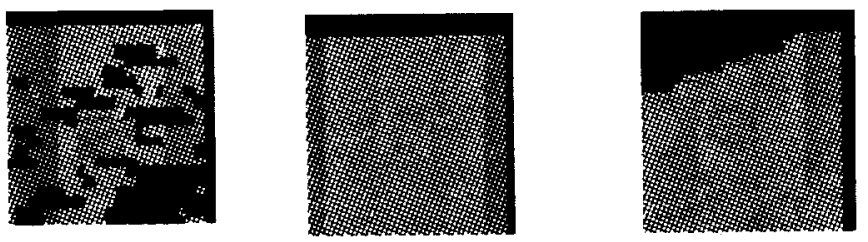

Figure 22. Pulse-echo depth resolution from a 16 ply quasi-isotropic laminate. 

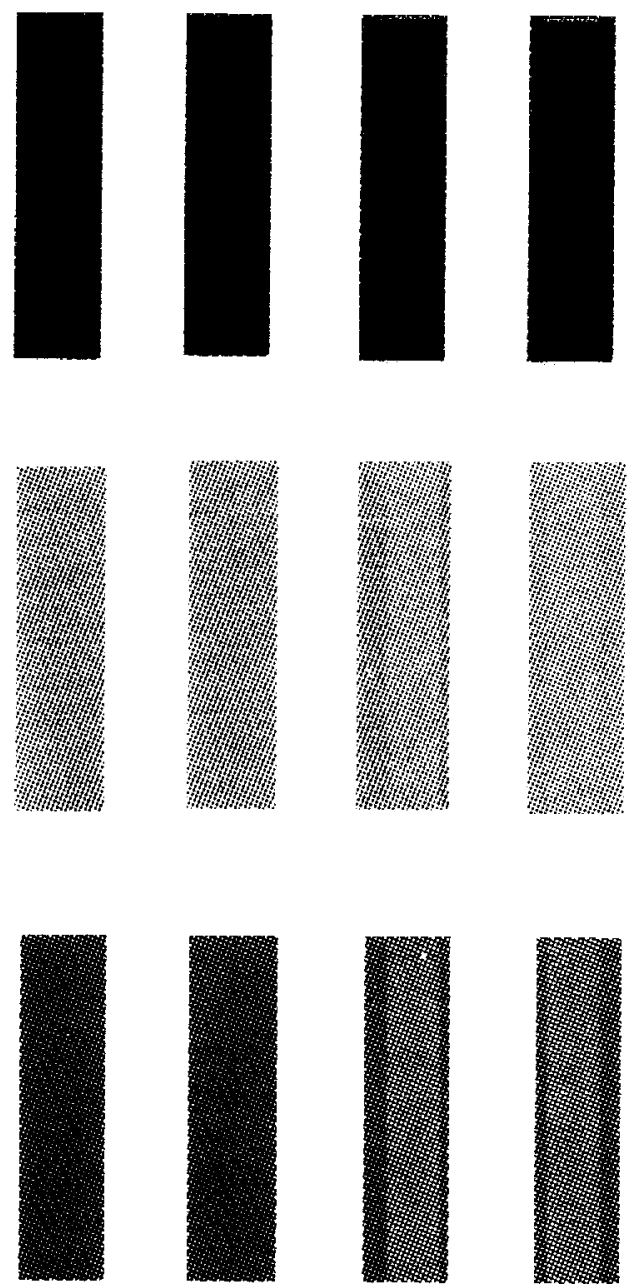

Figure 23. Pixel value color differences. Top row: difference of 1 , second row: difference of 2 , third row: difference of 3 . 


\subsection{ACOUSTIC EMISSION}

\subsection{Introduction}

$\mathrm{AE}$ is slowly gaining acceptance as a suitable material characterization and NDE technique for fiber reinforced composite materials [31]. One reason for the slow acceptance of $\mathrm{AE}$ is in contrast to conventional NDE techniques such as immersion ultrasonic and radiography, $\mathrm{AE}$ does not produce a quantitative image of a flaw. Therefore, AE must typically be used in conjunction with other NDE techniques in order to determine damage criticality. However, AE is promising because it can provide information about damage initiation and progression during loading in real-time [32].

The primary objective of this study was to investigate the use of $\mathrm{AE}$ as a structural qualification tool. During structural qualification, AE is used to locate and assess the extent of damage occurring during structural proof testing of components and assemblies. This type of application is relevant to NASA because proof testing is commonly used to screen composite structures for flaws. One disadvantage of proof testing composites is a structure may pass the test, but be damaged in the process. AE has the potential to detect damage which occurs during proof testing.

\subsection{Equipment}

The Materials Branch purchased an early version (version 1.1) of the Source Position And Real Time Analysis (SPARTAN) AE system from Physical Acoustics Corporation (PAC) in 1985. The SPARTAN was designed as a front end to the PAC $3000 \mathrm{AE}$ computer in order to separate high-speed data acquisition from the more complex requirements of data analysis and display. The SPARTAN was equipped with three Individual Channel Controllers (ICCs). Each ICC provided two data acquisition channels. The 3000 computer used a CPM operating system and had independent channel (SP/DAS version 2.1), linear location (SPL/DAS version 4.0) and planar location (SPP/DAQ version 1.3) data acquisition software. In addition, post data acquisition filtering (POSTANALYSIS) and high resolution 3-D plotting (SUPERPLOT) programs were available.

Many of the system and software upgrades developed by PAC in the late 1980 's were not compatible with the version 1.1 SPARTAN. Hence, in 1990 a new SPARTAN-AT system was purchased. The SPARTAN-AT processing architecture was still designed for raw front end data acquisition. PAC modified the Group Channel Controller (GCC) and Parametric Channel Controller (PCC) to improve location and parametric data acquisition capabilities, respectively. The SPARTAN-AT was interfaced with a IBM compatible PC, and the system software operated in the MS/DOS environment. Independent channel (SA-DAQ version 1.2) and location (SA-LOC version 1.2) software were purchased.

The SPARTAN-AT software included a program which converted PAC 3000 data files into the new DOS data format and vice versa. In order to utilize the POST-ANALYSIS and SUPERPLOT programs the DOS data files must first be converted to the old 3000 format. When using POST-ANALYSIS, the filtered data must be converted back into the DOS format for graphic display. With SUPERPLOT, the data remained in the old CPM format. Unfortunately, the 3000 computer and IBM PC system clocks were different. Thus, timing information 
required for location data acquisition was lost during the data translation. This loss of timing information compromised the ability to display the location data acquired using the new software.

The SPARTAN-AT had two ICCs which provided for a total of four data acquisition channels. The system could be expanded to 20 channels with the purchase of additional ICCs. The two current ICCs had 100-300 KHz bandpass filters and were calibrated for $150 \mathrm{KHz}$ resonance frequency transducers. According to PAC, the bandpass filters on the ICCs should not be interchanged in order to use other resonance frequency transducers. Therefore, only $150 \mathrm{KHz}$ transducers were used.

The PAC R15 $150 \mathrm{KHz}$ transducers were used in conjunction with PAC model 1220A preamplifiers. The preamplifiers featured $40 / 60 \mathrm{~dB}$ switchable gain settings and replaceable bandpass filters. PAC 100-300 KHz bandpass filters were also used in the preamplifiers.

\subsection{System Characterization}

Awerbuch [33] warned that the rate of AE events generated by the failure of composite materials may exceed the maximum data acquisition rate of most AE systems. In such a case, key data could be lost. In addition, several events separated by short time intervals could be measured as one event by the system.

In order to determine the capabilities of the SPARTAN-AT, the system was setup in the linear location mode with the same settings (gain, threshold, PDT, HDT and HLT) and hit data set (amplitude, counts and energy) used during the testing of the impacted specimens. A Panametrics Model 5052 UA pulser/receiver and a Hewlett Packard 3311-A function generator were used to create simulated AE events at various rates. The actual rates were measured using a LeCroy 9420 oscilloscope. The test setup is shown schematically in Figure 24. The rates at which hits/events were recorded by the SPARTAN-AT were determined from the slopes of cumulative hits/events versus time plots.

Figure 25 shows the relationship between actual and recorded hit/event rates. For each simulated event, the system recorded one location event and two hits, one hit at each of the two transducers in the linear array. In order to compare the hit and event rates on the same graph, the hit rate was divided by two.

The results show that at a simulated event rate of approximately 300 events per second, the system began to lose data. As the rate increased above 300 , the number of recorded hits remained relatively constant while the number of recorded events decreased. At an input rate of approximately 600 events per second, no location data was recorded. These results indicate that the SPARTAN-AT placed a priority on recording hit data.

A similar type of characterization should be performed for each new location setup, as changing the number of transducers or the location mode (linear or planar) will effect the system's data acquisition speed. 


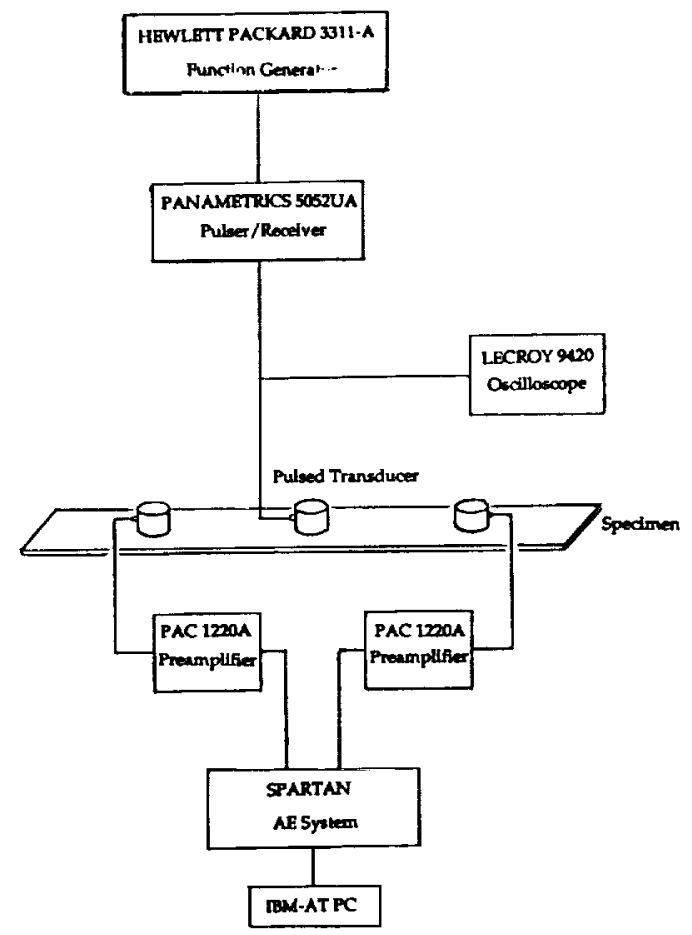

Figure 24. Acoustic emission system characterization setup.

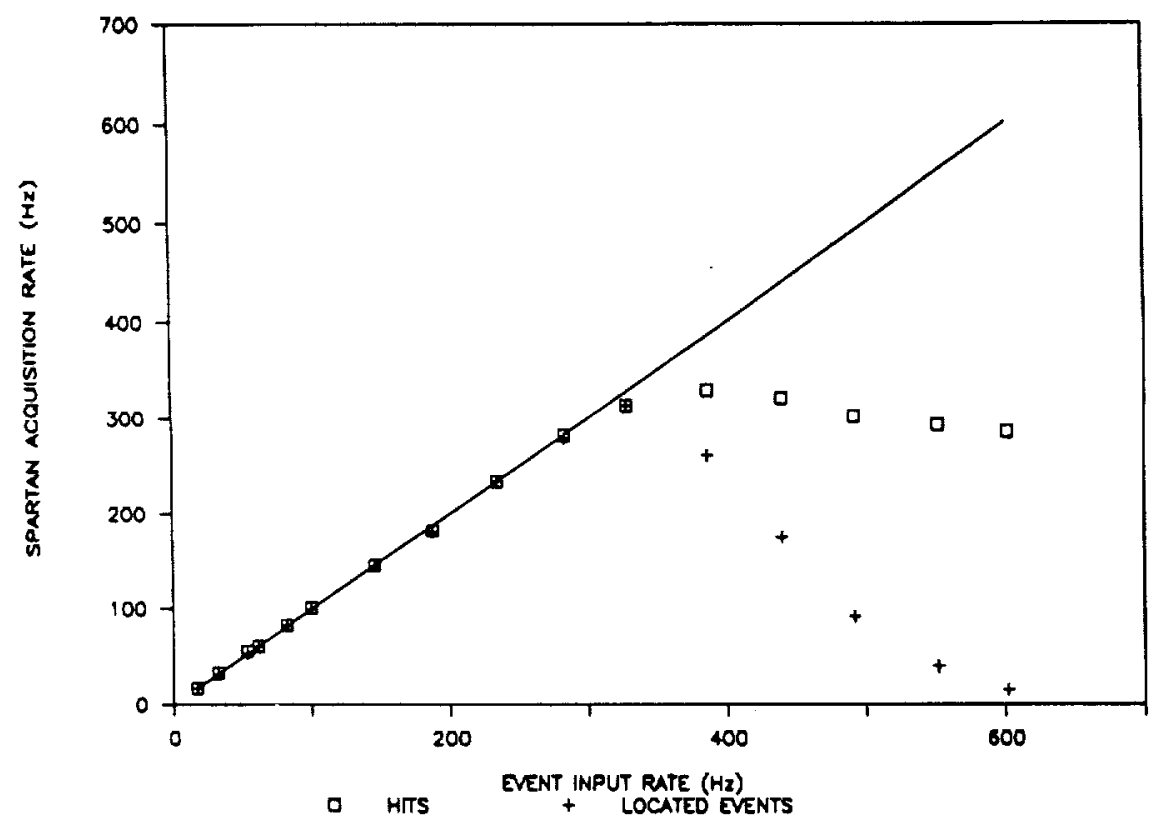

Figure 25. Relationship between actual and recorded hit and event rates. 


\subsection{Failure Mechanism Signature Analysis}

\subsubsection{Amplitude Distributions}

Amplitude distribution is the most common technique used to identify the various failure mechanisms in fiber reinforced composites. Failure mechanisms include matrix microcracking, longitudinal matrix splitting, transverse matrix cracking, delamination, fiber/matrix interface debonding, fiber failure, and fiber pull-out. Due to similarities between the matrix dominated modes, most researchers $[31,34,35,36]$ attempt to identify only matrix cracking, delamination and fiber failure.

Comparing amplitude distributions in the literature $[31,34,35,36]$ was difficult because of the different materials, lay-ups, specimen designs, frequency ranges monitored, loading profiles and AE systems, settings and processing techniques used. The only common factor in the signature analysis

investigations discussed below was that all address failure mechanisms in graphite/epoxy laminates. The different types of AE systems, frequency ranges, loading profiles, specimen configurations, etc. is not discussed. Even though these factors were different, there was general agreement in the amplitude distribution results from the reviewed studies.

Rodgers [31] reported that matrix cracking typically had low amplitudes (35-50 dB), delamination damage had medium amplitudes (50-85 dB), and fiber failure had high amplitudes (70-100 dB). Cohen and Awerbuch [34] associated a narrower range of medium amplitude events $(70-85 \mathrm{~dB})$ with delamination growth, but acknowledged that lower amplitude events typically associated with matrix cracking accompanied these medium amplitude events. Shippen and Adams [35] indicated that based solely on amplitude, delamination growth could not be distinguished from matrix cracking. The authors associated 50 to $70 \mathrm{~dB}$ events with matrix cracking and 90 to $100 \mathrm{~dB}$ events with fiber failure. The difficulty in distinguishing delamination growth from matrix cracking was possibly related to the fact that delamination growth involves failure of the matrix material.

Henneke [36] who investigated only matrix cracking and fiber failure did not provide amplitude ranges, but simply categorized matrix cracking events as low amplitude and fiber failure events as high amplitude. The matrix cracking in Henneke's study was primarily longitudinal splitting. Henneke noted that when splits rapidly progressed over an unusually long distance, high amplitude events were generated. Awerbuch [33] also recorded high amplitude events associated with longitudinal matrix splitting and attributed the events to fiber failures.

Not all high amplitude events have been directly attributed to fiber failure. Favre and Liazet [37] found that transverse matrix cracks which extended the full width of the specimen produced high amplitude events (90-100 $\mathrm{dB}$ ). The authors also found a high correlation between the number of high amplitude events and the number of transverse cracks. These high amplitude events were accompanied by a large quantity of lower amplitude events. Favre and Liazet did not address whether or not fiber failure occurred during the matrix splitting. 
These studies suggest that the high amplitude events associated with matrix splitting are due to either large crack extensions or fiber failures. Cracks or splits which extend over longer distances release more energy and therefore, produce higher amplitude events. The high amplitude events may also be attributed to fiber failures caused by fiber bridging between the fractured surfaces. There is not a consensus on the failure mechanism responsible for high amplitude events during matrix splitting.

The studies discussed above agree that AE events associated with matrix cracking have low amplitudes. However, the amplitude range could be broad and did not exclude high amplitude events in some cases. This made it difficult to reliably distinguish matrix cracking from delamination growth which typically produced medium amplitude events. The studies agree that fiber failure AE events have high amplitudes. Matrix splitting parallel to the fibers could also produce high amplitude events, but the source of the events was not completely understood.

In this program, amplitude signatures were obtained to determine if the SPARTAN-AT system produced results similar to those reported in the literature $[31,34,35,36,37]$. Optimal transducer spacing for location data acquisition is based on the amplitudes of the anticipated failure mechanisms and the attenuation characteristics of the material. Selection of transducer spacing involves a trade-off between the number of transducers and the types of damage progression which is detectable. As the transducer spacing increases, there is a higher probability that some amplitude events associated with matrix cracking are be attenuated enough to avoid detection.

The specimens used for signature analysis were previously described in the Materials section of this report. The specimens were monitored using three $150 \mathrm{KHz}$ transducers. One transducer was placed as close as possible to the failure site, and the remaining two transducers were progressively spaced away from the failure site in order to acquire attenuation information. The preamplifier gain was $40 \mathrm{~dB}$, and the system gain and threshold were 20 and 40 $\mathrm{dB}$, respectively. The peak definition time (PDT), hit definition time (HDT) and the hit lock-out time (HLT) were 50, 150, and 300 microseconds, respectively. These were the values recommended by PAC for monitoring composite materials. The Activity Graph-High Speed data acquisition mode was selected because it provides the highest data acquisition rate. The stored data was then replayed for interpretation. The discussion below focusses on the event amplitudes at the failure site. Attenuation of the AE activity is addressed in the section on Attenuation.

The strip specimens designed for matrix microcracking and transverse matrix cracking were loaded in four point bending on an Instron Model 1125 testing machine at a crosshead rate of 0.02 inches per minute. The compression and tension side loading spans were one and three inches, respectively. The specimen lay-up and loading were selected to produce matrix splitting parallel to the fibers in the 90 degree outer ply on the tensile surface. An alarm on the SPARTAN-AT was setup to be triggerd by events with amplitudes greater than $90 \mathrm{~dB}$. The alarm had a manual reset on the SPARTAN-AT front panel. Thus, it was possible to miss high amplitude events which occurred before the alarm could be reset. The data was replayed to determine the actual number of high amplitude events. 
The following is a discussion of the results obtained from one specimen. Similar results were obtained from two additional specimens. When the first alarm sounded, the test was stopped, and the specimen was unloaded. The AE data showed only one low amplitude event $(39 \mathrm{~dB})$ prior to the burst of activity which triggered the alarm. The burst consisted of three events with amplitudes of 100,82 and $49 \mathrm{~dB}$. Examination of the tensile side of the specimen at high magnification revealed one transverse matrix crack which extended over the full one inch width of the specimen.

The specimen loading was continued. When two additional alarms had sounded, the test was again stopped. At this point, over 600 events were detected. The amplitude distribution, which is shown in Figure 26, revealed that the majority of events had amplitudes between 40 and $70 \mathrm{~dB}$. These events were assumed to be associated with matrix microcracking. The distribution also showed that two $100 \mathrm{~dB}$ events were recorded. Each of the $100 \mathrm{~dB}$ events was accompanied by a large number of lower amplitude events. This result is exhibited in Figure 27, which is a point plot of amplitude versus time for a 30 second window.

Two additional full width transverse matrix cracks were identified when the specimen was microscopically examined. This finding suggests that there is a one-to-one correlation between high amplitude events (100 dB) and large transverse matrix cracks. The correlation began to decrease as the number of cracks in the outer ply increased. This was attributed to the development of cracks in the adjacent subsurface plies. These cracks, which were observed during an edgewise microscopic examination, were difficult to reliably count. These findings are consistent with the results reported by Favre and Laizet [37].

The amplitude distribution results suggest that matrix microcracking produces events with amplitudes between 40 and $70 \mathrm{~dB}$. The majority of the events were in the 40 to $60 \mathrm{~dB}$ range. This result is consistent with the findings reported in the literature $[31,33,35,36]$.

The mode I delamination specimens were loaded at a crosshead rate of 0.005 inches per minute. Wedge grips were used to grip the hinges. Thin rubber pads were placed between the grip teeth and the hinge to minimize the amount of noise generated at the grips. The load levels required to extend the delamination were less than $30 \mathrm{lbs}$. At this relatively low load level, slippage in the grips was not a problem.

The level of AE activity during delamination progression was extremely high. Hence, the testing was stopped periodically to keep the data files in sizes which were easy to manage in terms of playback and interpretation. Typical amplitude distributions are shown in Figures 28 and 29. The distributions are bimodal with peaks at approximately 40 and $70 \mathrm{~dB}$. The majority of the events are in the low and medium amplitude ranges $(40$ to $80 \mathrm{~dB})$. This result is consistent with the findings reported in the literature $[31,33,35,36]$.

As in the case of the matrix cracking specimens, the higher and medium amplitude events were accompanied by numerous low amplitude events. This phenomenon is displayed in Figure 30, which is a point plot of amplitude versus load for a portion of the test. 


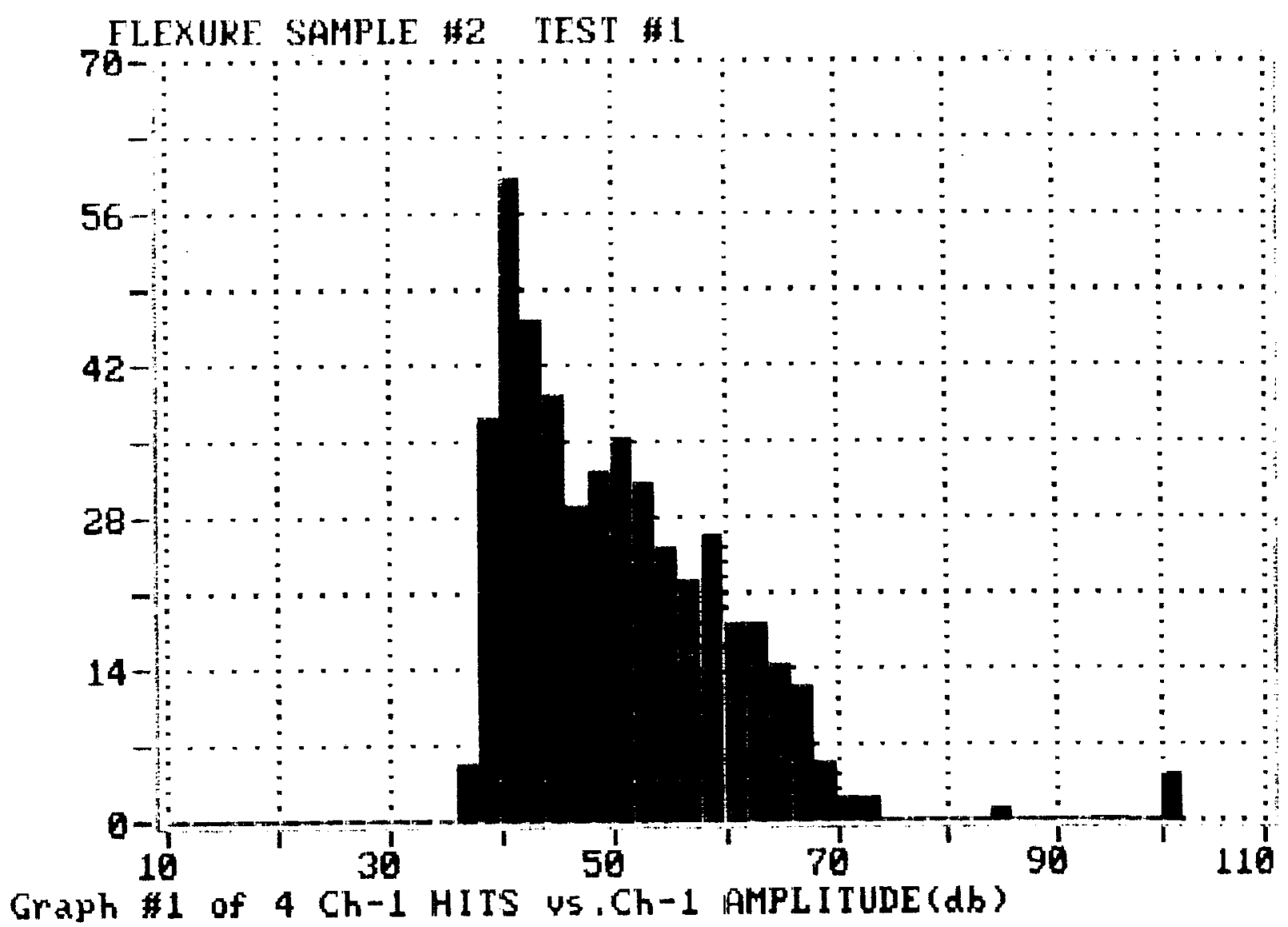

Figure 26. Amplitude distribution from matrix microcracking specimen. 


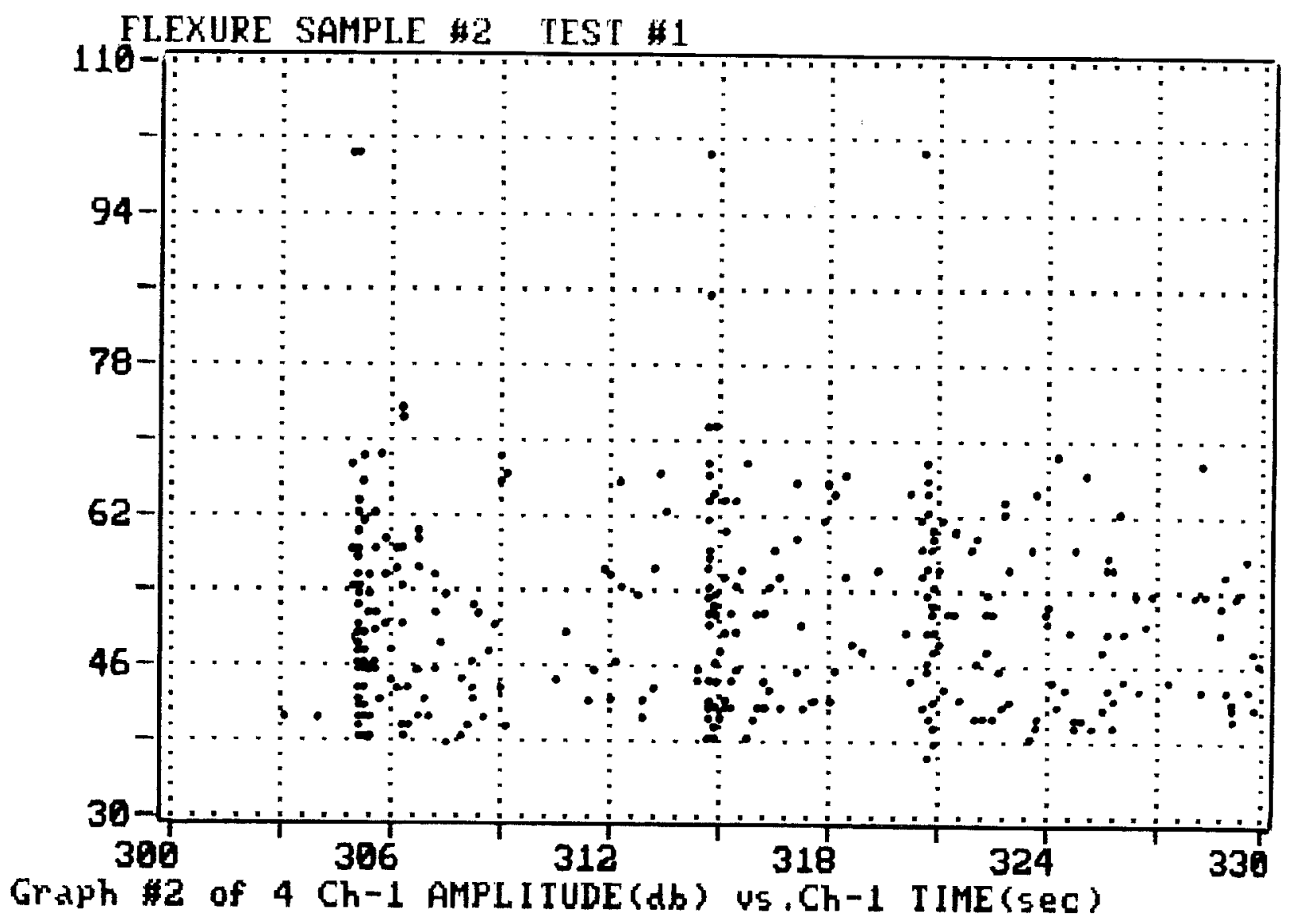

Figure 27. Point plot of amplitude versus time for matrix micro-cracking specimen. 


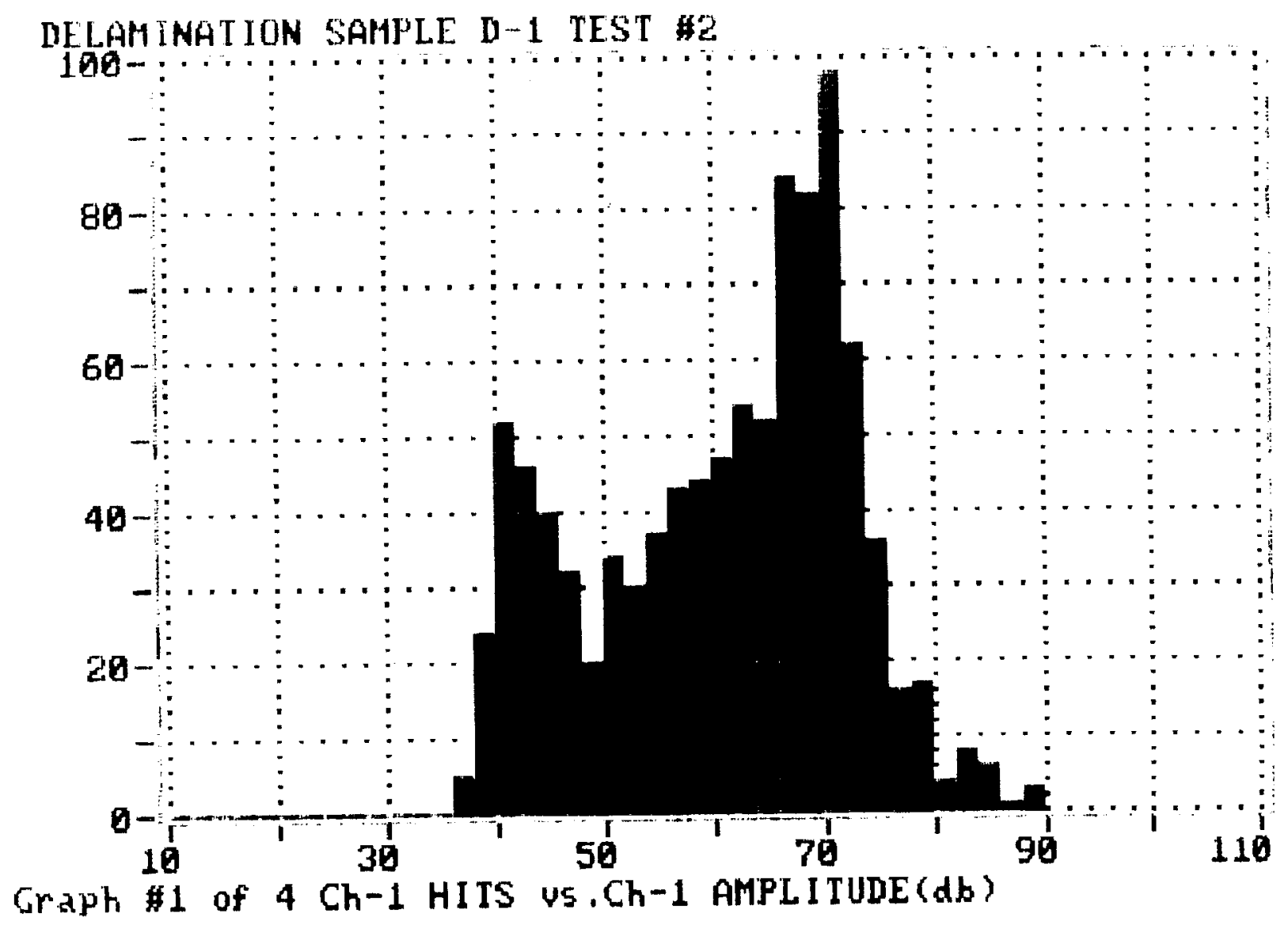

Figure 28. Amplitude distribution from delamination specimen. 


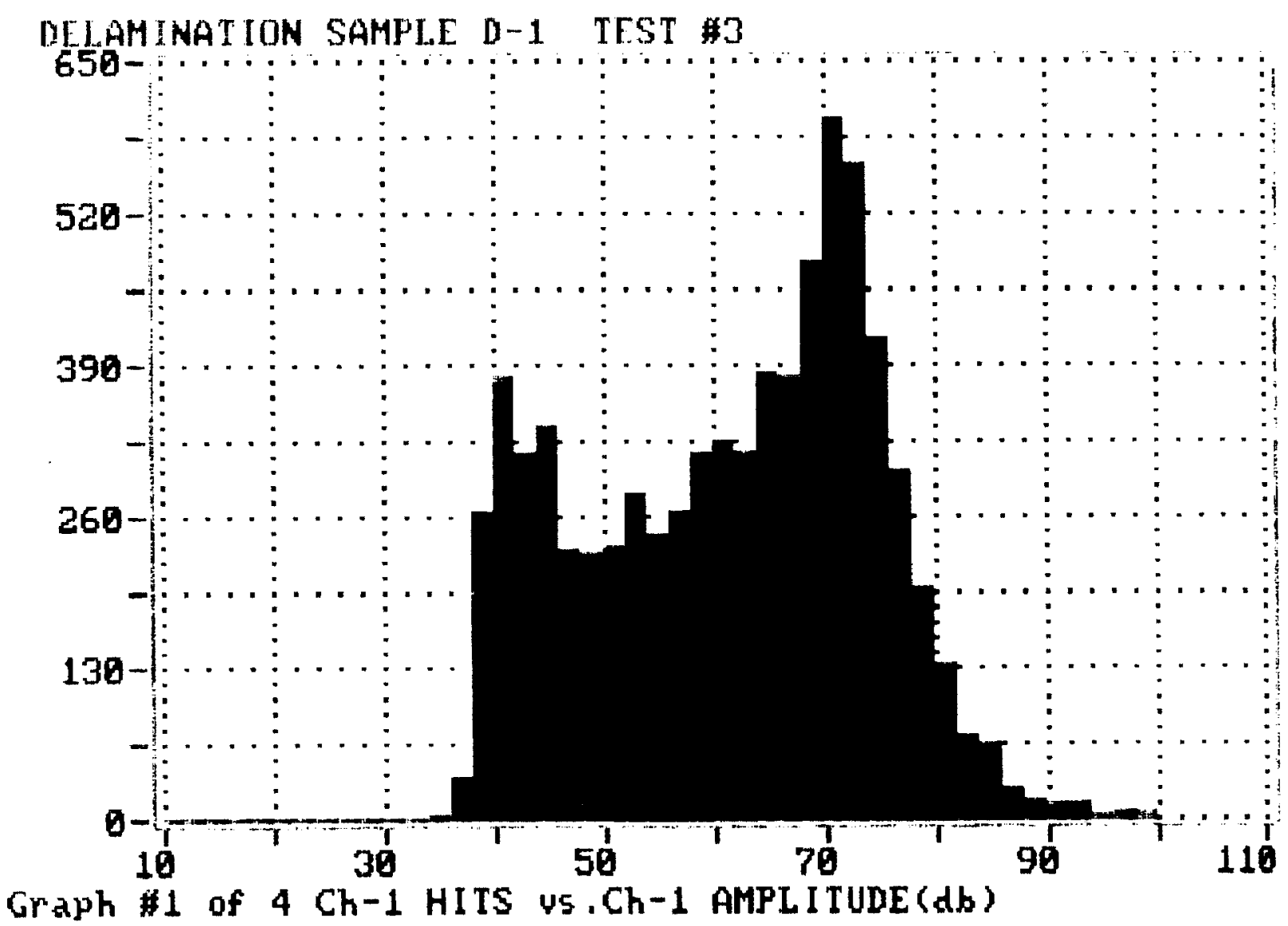

Figure 29. Amplitude distribution from delamination specimen. 


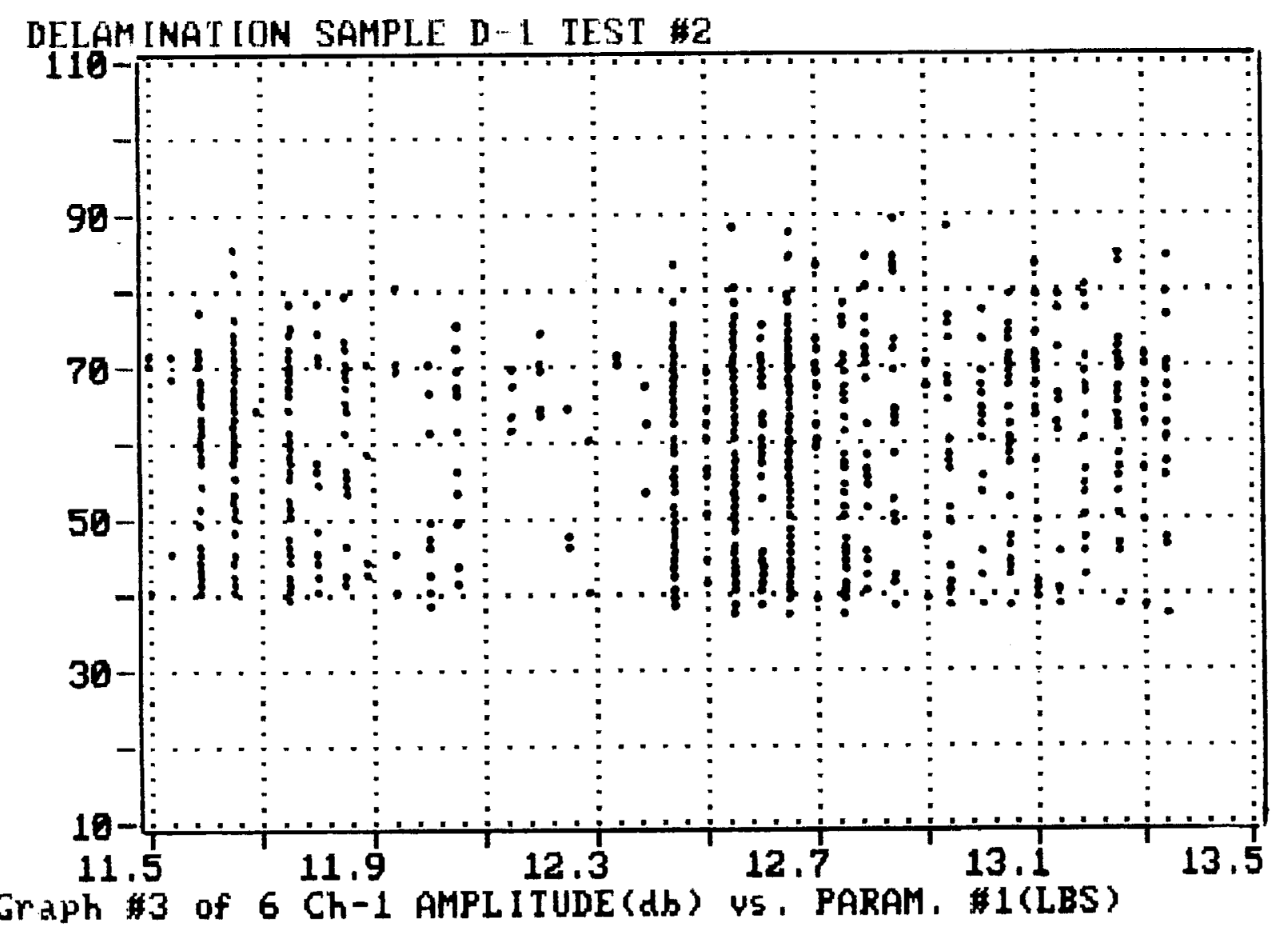

Figure 30. Point plot of amplitude versus load for a delamination specimen. 
There are some high amplitude events in the amplitude distributions. Some fiber bridging was observed between the fractured surfaces. Fiber bridging for mode I delamination was also reported by Bascom [38]. Microscopic examination of the surfaces after complete specimen failure revealed some areas of fiber failure. Thus, the high amplitude events were associated with fiber failure.

This finding suggests that fiber bridging and fiber failure may occur during longitudinal and transverse matrix splitting parallel to the fibers. Delamination growth also involves matrix splitting parallel to the fibers. The difference is that delamination occurs in the plane orthogonal to the plane in which longitudinal and transverse matrix splitting occur. Hence, the high amplitude events associated with matrix splitting may be produced by fiber failure.

The results from both the matrix cracking and delamination specimens are consistent with the findings reported in the literature $[31,33,35,36]$. The results suggest that events associated with matrix dominated failure modes typically have low and medium amplitudes. These findings in combination with the attenuation results discussed below are key to understanding the effects of the linear location transducer spacing used in this program.

\subsubsection{Frequency Spectra Analysis}

Some researchers $[36,39,40]$ have attempted to distinguish failure mechanisms based on frequency spectra. Henneke [36] concluded that frequency spectra are relatively independent of the failure mechanism and are primarily composed of the natural frequencies of the specimen, transducer and overall system. Henneke did note slight differences in how these natural frequencies were excited, as well as minor differences in the overall frequency envelope.

Frequency spectra were obtained using a PAC WD broadband transducer in conjunction with a $30 \mathrm{KHz}$ high pass filter and LeCroy 9420 digital oscilloscope. The LeCroy 9420 is equipped with fast Fourier transform (FFT) and waveform processing software. The FFT software package was used to obtain power density frequency spectra, which according to LeCroy is the most suitable type of spectra for characterizing broadband noise. The waveform processing software was used to average hundreds of individual spectra.

The primary reason for obtaining the frequency data was not to identify various failure mechanisms, but to compare the typical frequency spectra of real failures to the spectra from simulated $A E$ events. The most common simulated $\mathrm{AE}$ events, which are used to calibrate $\mathrm{AE}$ systems and setup location arrays, are $0.5 \mathrm{~mm}$ Pentel mechanical pencil lead breaks and pulsed transducer events.

Before obtaining frequency spectra from simulated $\mathrm{AE}$ events, a technique described by Henneke [36] was used to determine if the PAC-WD transducer had a flat response to broadband noise. The transducer was coupled to an aluminum plate which was abraded by 60 grit sandpaper in order to create broadband noise. Figure 31 shows several spectra which are the average of 200 individual abrasion event spectra. The spectra appear to peak at the high pass filter cut-off of $30 \mathrm{KHz}$. Otherwise, the results show the transducer had a relatively flat response. 

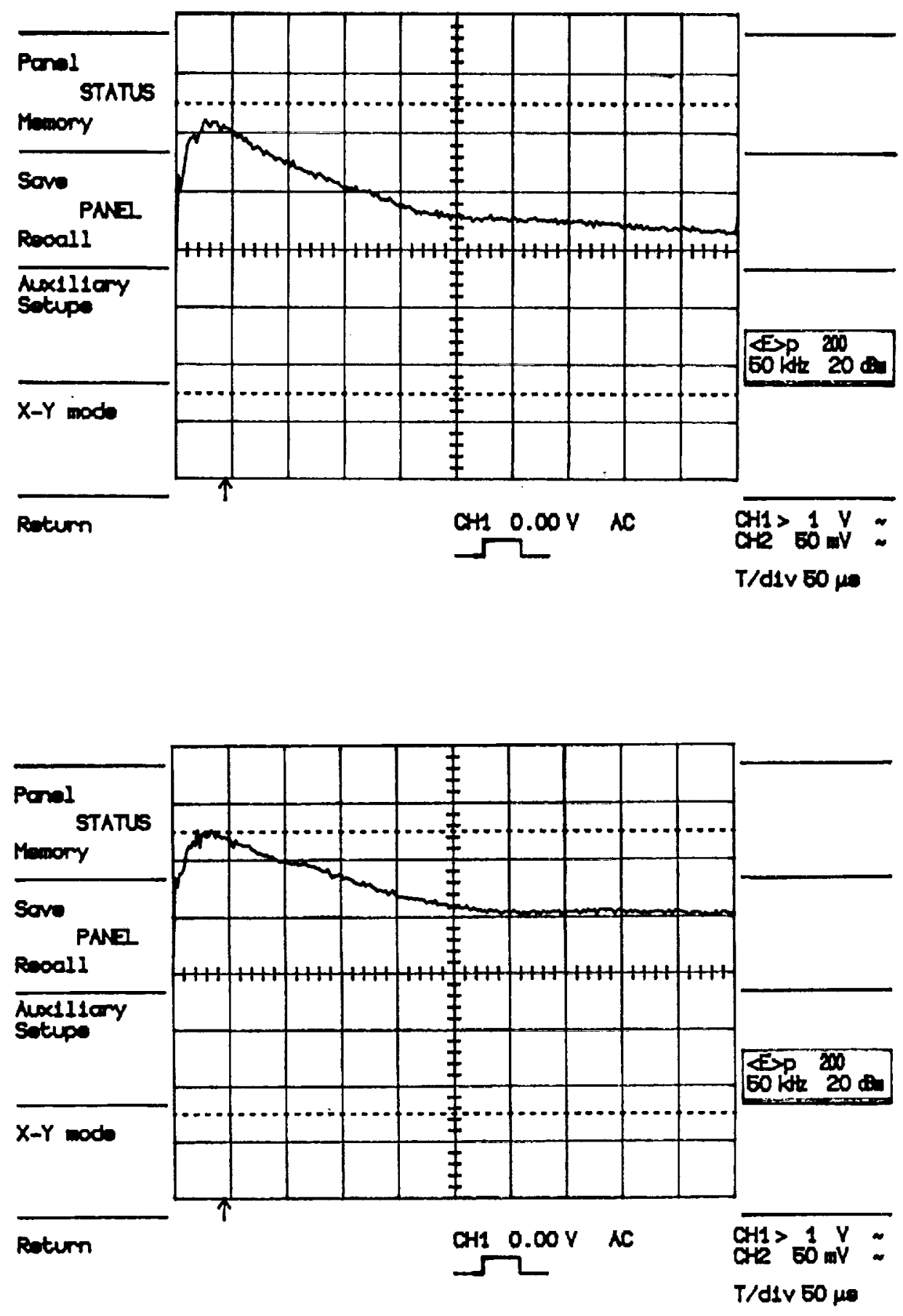

Figure 31. Response of PAC-WD transducer to broadband noise. Power density frequency spectra from 0 to $500 \mathrm{KHz}$. 
Frequency data was obtained from both matrix cracking and delamination specimens. The average frequency spectra corresponded to events with the amplitude distributions discussed above, i.e., no attempt was made to obtain spectra from individual (low, medium or high) amplitude ranges.

Typical average spectra from the matrix cracking specimens are shown in Figure 32. The spectra have peaks at approximately 30 and $100 \mathrm{KHz}$ with a relatively flat response at frequencies greater than $250 \mathrm{KHz}$. Figure 33 shows averaged spectra from a delamination specimen. These spectra also have peaks at approximately 30 and $100 \mathrm{KHz}$. Several spectra exhibit an additional peak at approximately $225 \mathrm{KHz}$. The response is relatively flat at frequencies greater than $250 \mathrm{KHz}$. In conclusion, the matrix cracking and delamination failures produced approximately the same frequency peaks and overall spectral envelope.

Several factors may have contributed to the minor spectral differences. First, the lay-ups for the two types of specimens were $[90, \pm 45,90]_{2 \mathrm{~s}}$ and $[0]_{16}$ for the matrix cracking and delamination specimens, respectively. In addition, the broadband transducer was coupled to surfaces with different states of stress, i.e., bending tension and slight bending compression for matrix cracking and delamination specimens, respectively. Finally, the amplitude distributions from the two types of specimens were different.

Averaged frequency spectra were then obtained for lead break and pulser events on specimens with the same two lay-ups. The specimens were supported as double cantilever beams with no applied stress. In retrospect, it might have been more informative to obtain the spectra with the specimens in their actual loading configurations.

Spectra from the lead break events for the $[90, \pm 45,90]_{2 \mathrm{~s}}$ and $[0]_{16}$ lay-ups are shown in Figures 34 and 35,respectively. The spectra from the two lay-ups were essentially identical. In addition, both were similar to the spectra corresponding to actual matrix failures. The pulser events from the two lay-ups are shown in Figures 36 and 37. These spectra, which have peaks between 100 and $200 \mathrm{KHz}$ and at approximately $250 \mathrm{KHz}$, were significantly different from the matrix failure spectra.

These results suggest that lead break events are a better simulation of actual failure events. Lead breaks and not pulser events should be used for location array setup and for determination of material attenuation characteristics. The waveforms of the individual lead breaks show dramatic differences compared to individual pulser events (Figures 38 and 39). Hence, pulser events may be more suitable for checking or comparing the response of transducers.

\subsection{Attenuation}

The attenuation of AE waves is due to a complex combination of geometric attenuation, dispersion, scattering, diffraction and energy loss mechanisms [41]. Because of the complexity of composites, it is usually impossible to analytically predict the attenuation. Attenuation can be empirically measured using simulated $\mathrm{AE}$ events.

In this program, the attenuation of simulated $\mathrm{AE}$ events $(0.5 \mathrm{~mm}$ lead breaks), as well as the attenuation of actual delamination and matrix cracking 

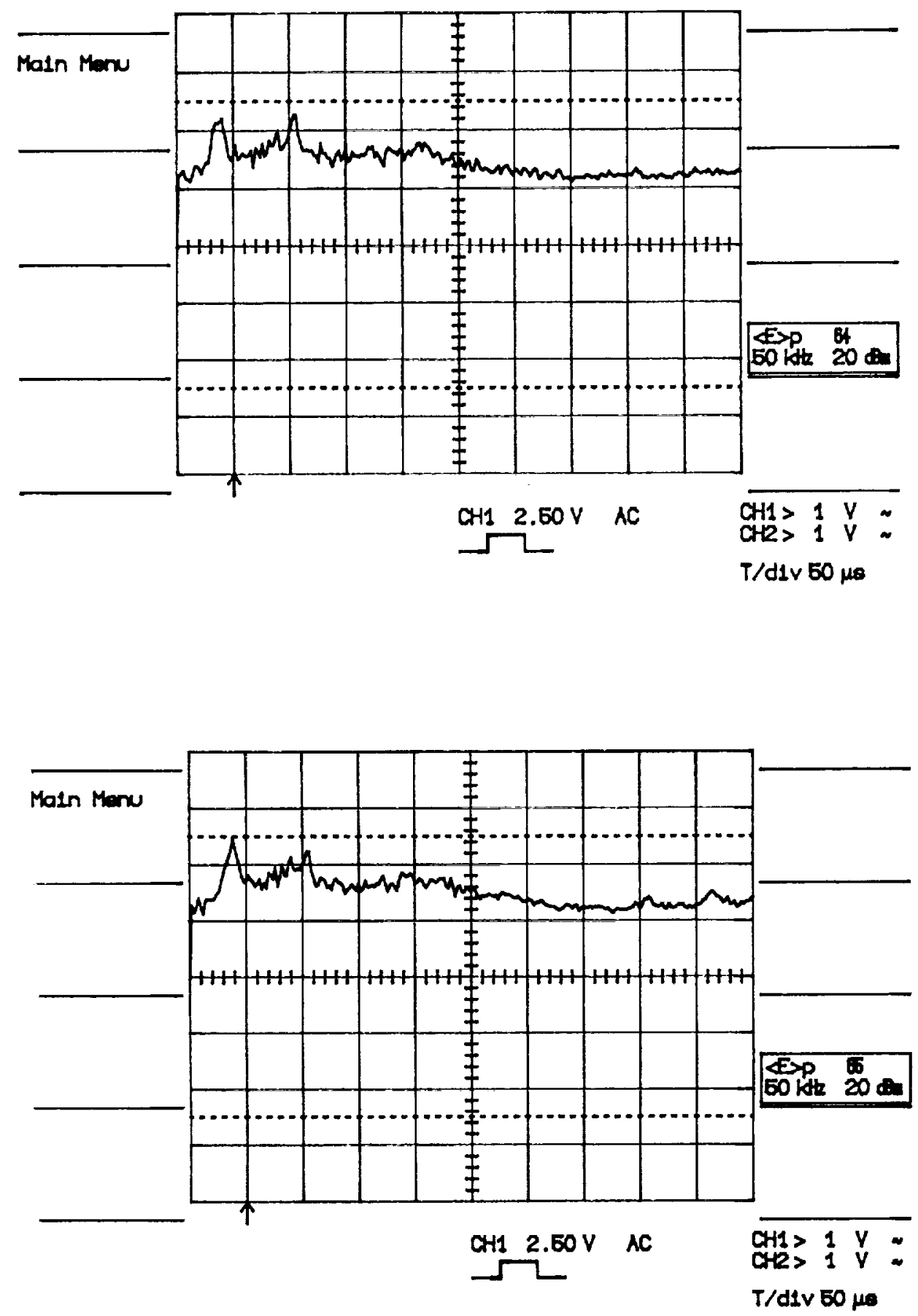

Figure 32. Power density frequency spectra for matrix microcracking. 

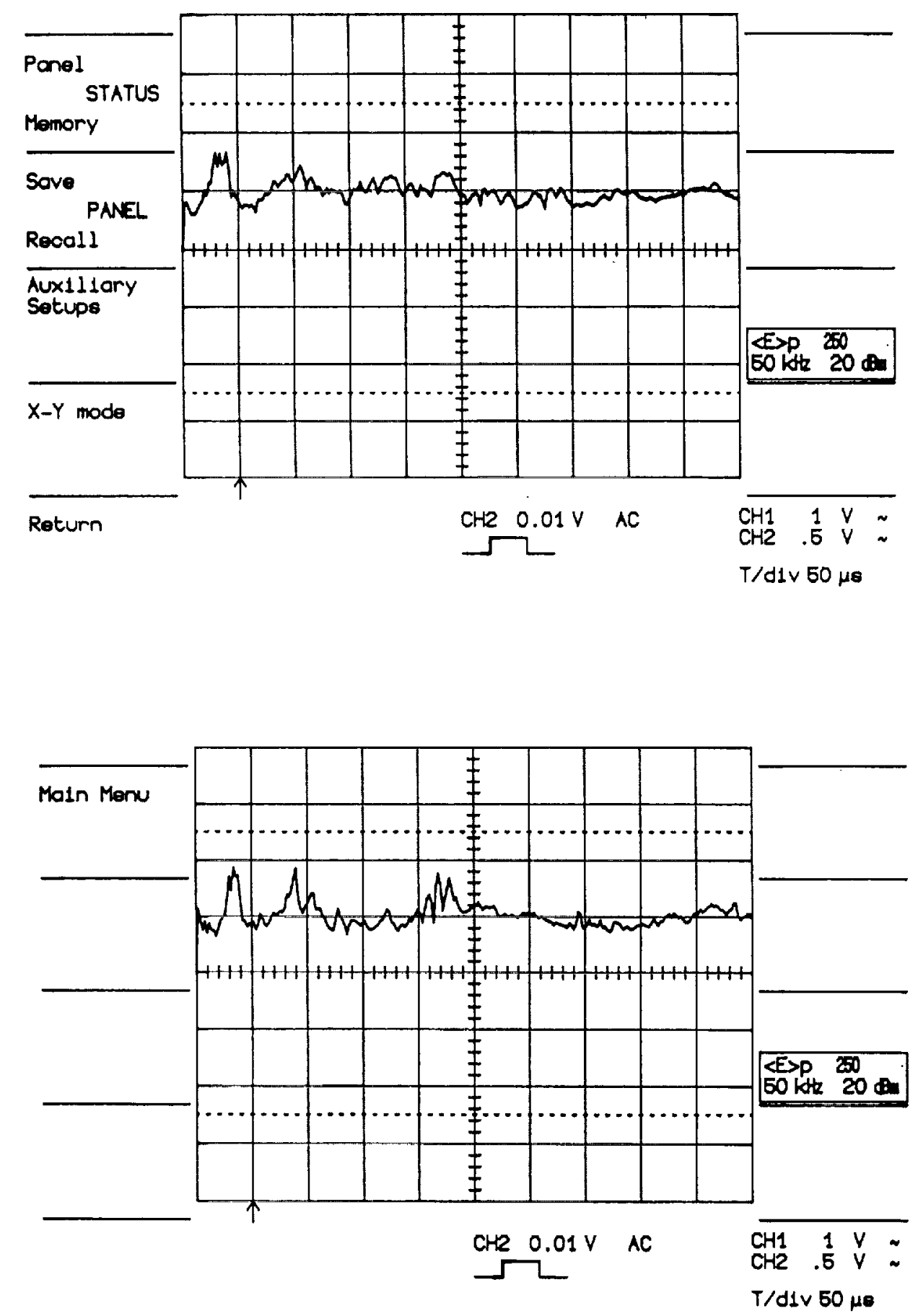

Figure 33. Power density frequency spectra for delamination. 

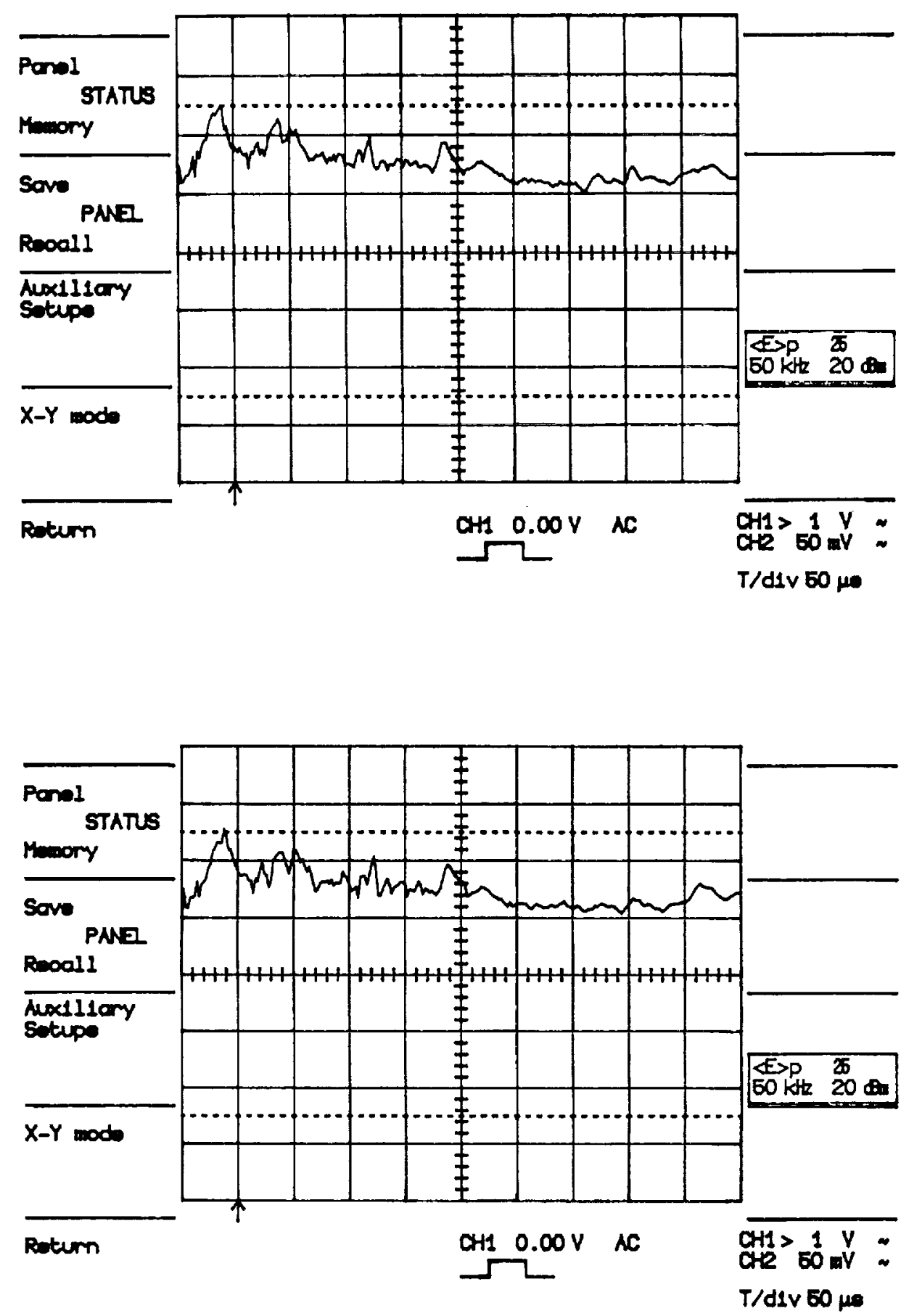

Figure 34. Power density frequency spectra for lead break events on $[90, \pm 45,90]_{2 s}$ laminate. 

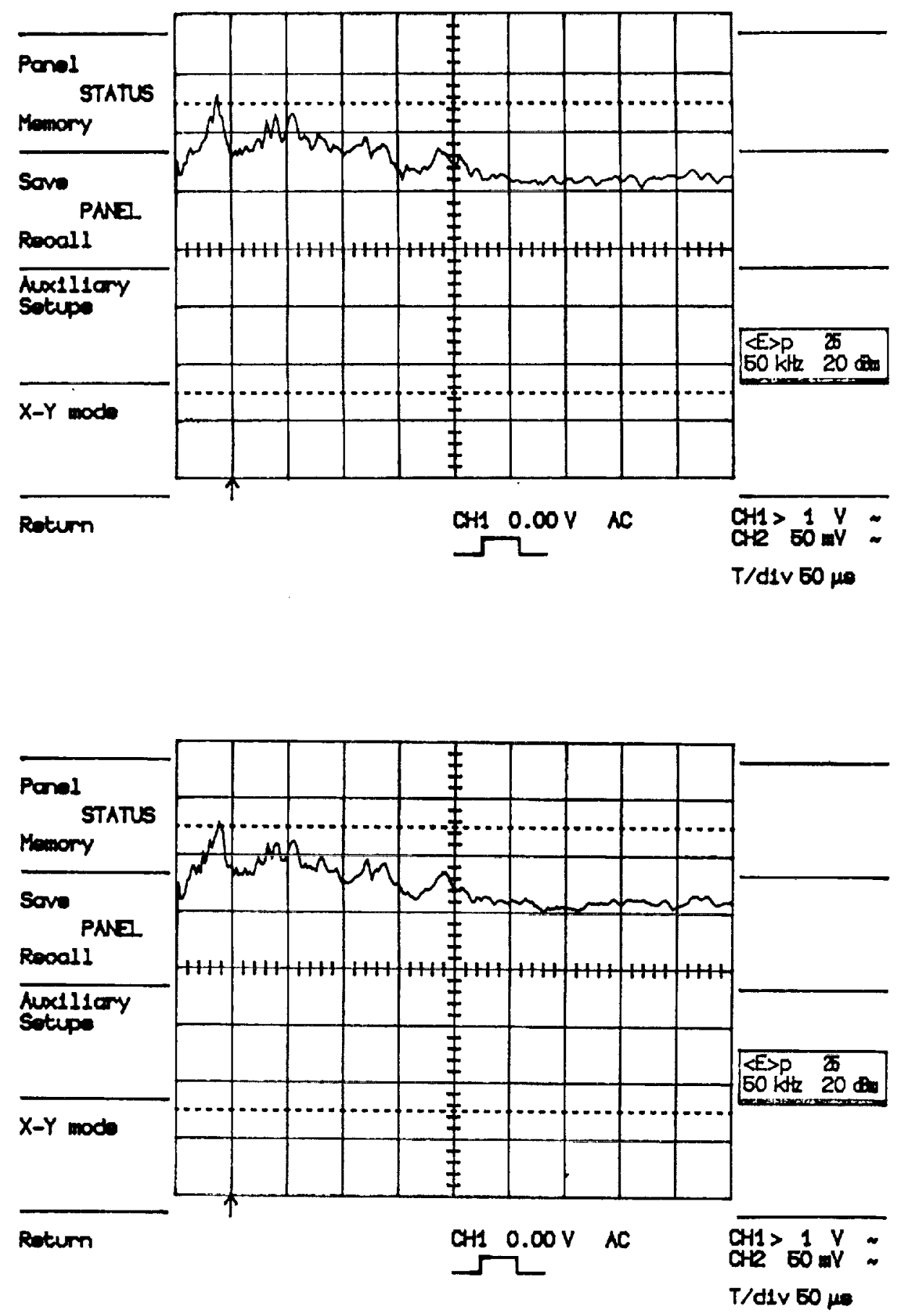

Figure 35. Power density frequency spectra for lead break events on $[0]_{16}$ laminate. 

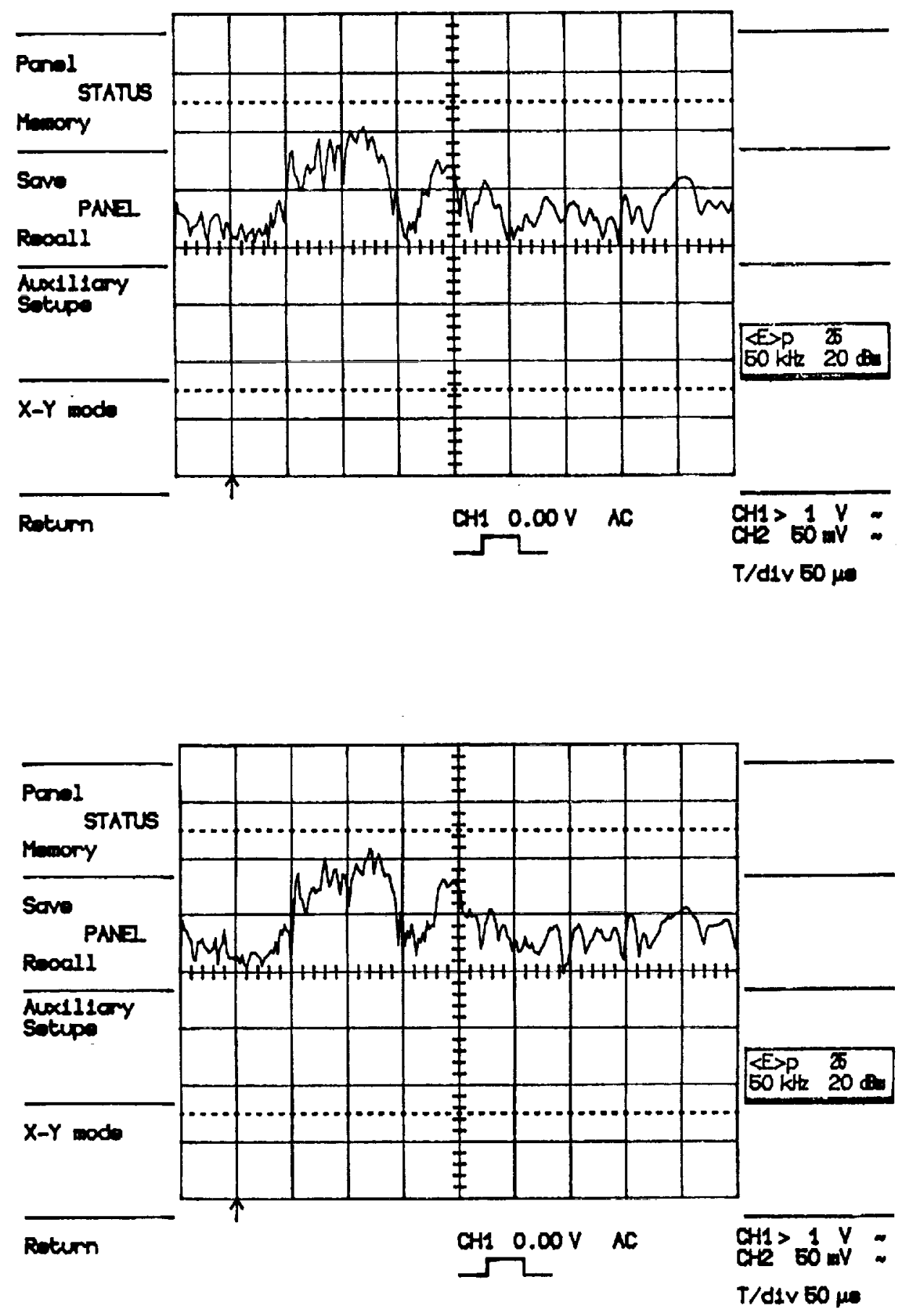

Figure 36. Power density frequency spectra for pulser events on $[90, \pm 45,90]_{2 \mathrm{~s}}$ laminate. 

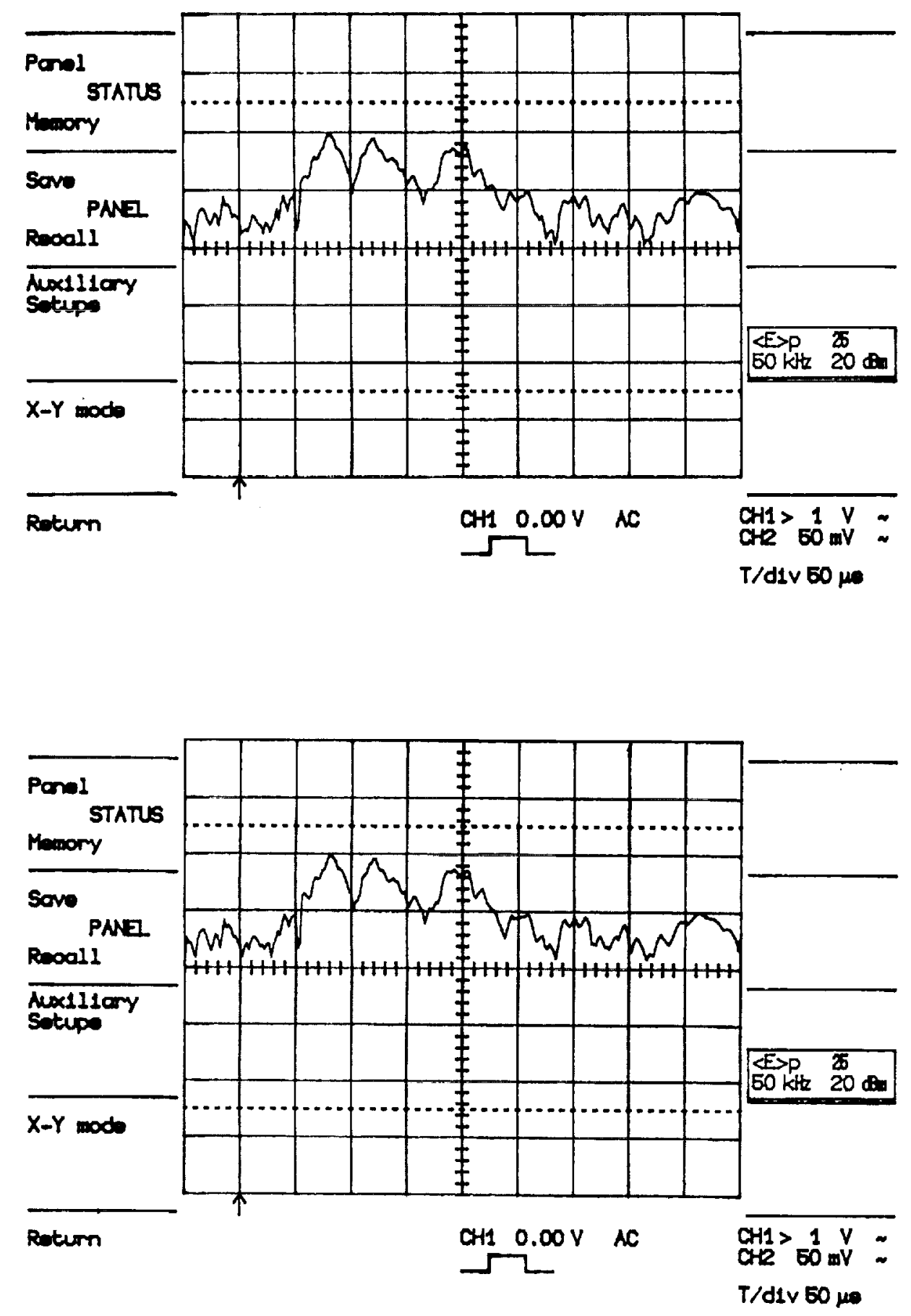

Figure 37. Power density frequency spectra for pulser events on $[0]_{16}$ laminate. 

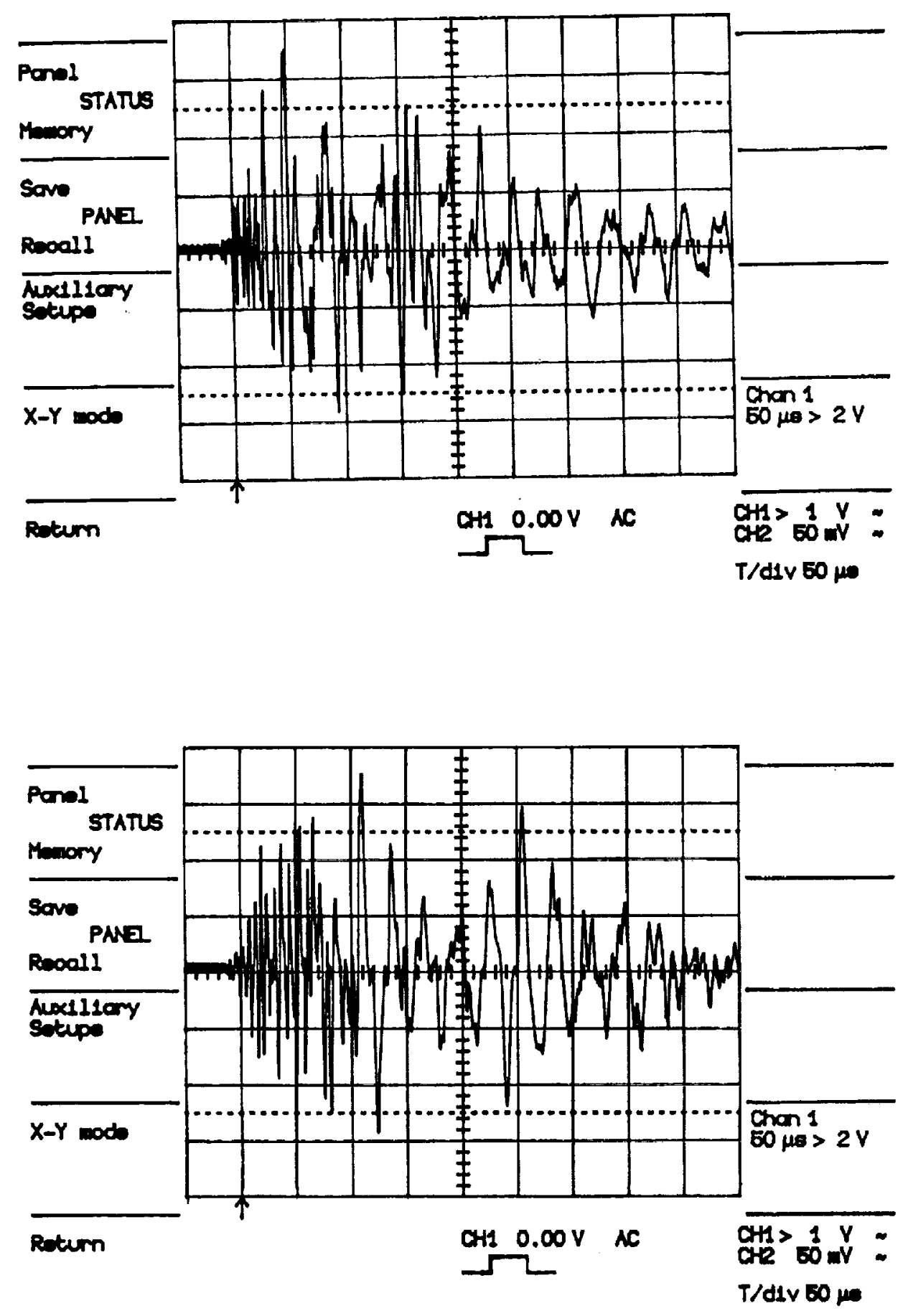

Figure 38. Typical lead break voltage versus time signals. 

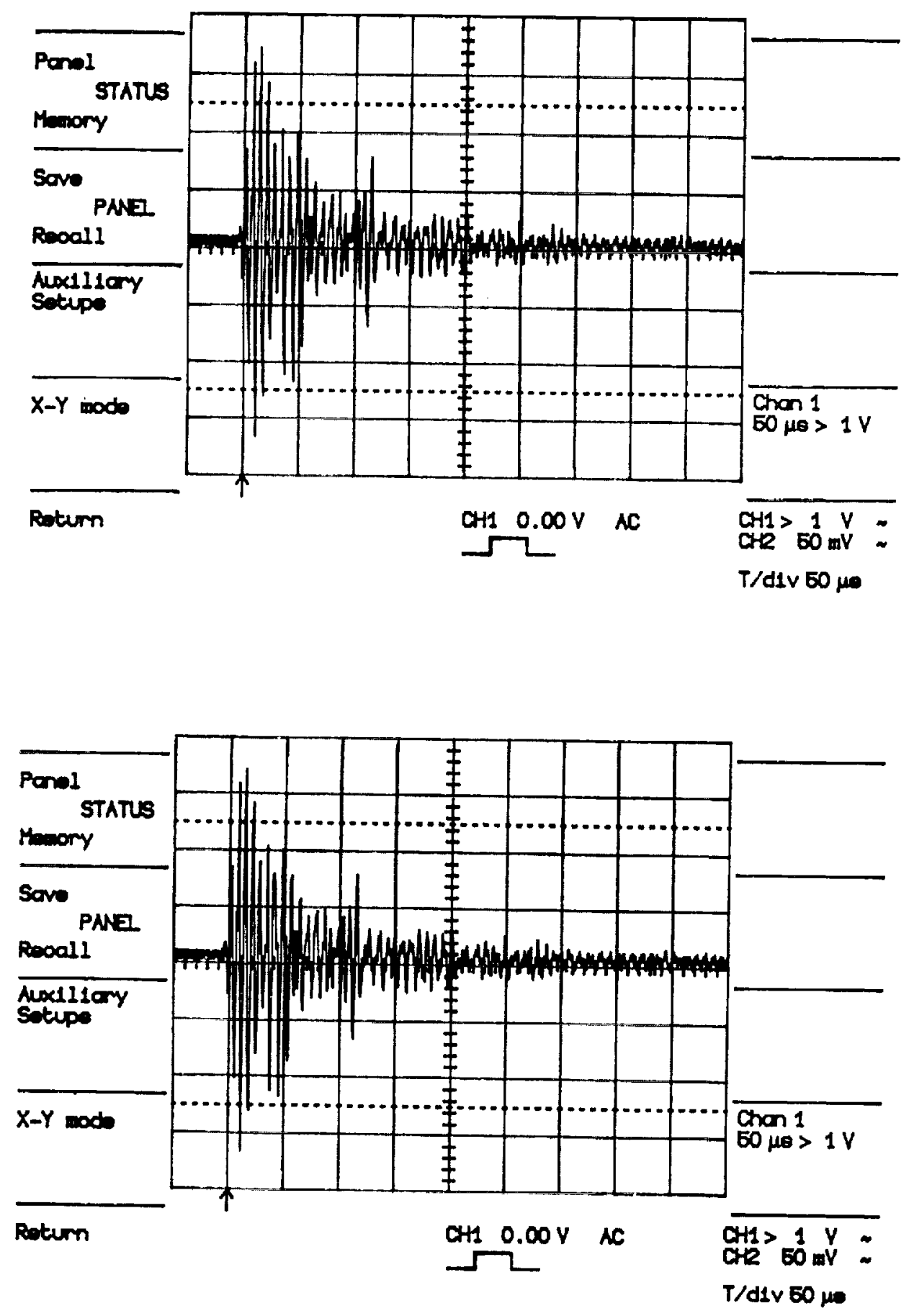

Figure 39. Typical pulser voltage versus time signals. 
failure events was measured. The primary objective was to measure the attenuation of low amplitude matrix cracking events. Matrix cracking is typically the first mode of failure to occur in composites during quasi-static tensile loading. Low amplitude events such as matrix cracking can be attenuated below the system's threshold in a relatively short distance.

Figure 40 shows the attenuation of lead break events for an eight ply Hexcel T-300/F-155 quasi-isotropic laminate. Each data point is the average amplitude of 10 lead breaks. The data shows a change in slope at approximately six inches. Linear regression yielded slopes of -3.4 and $-1.4 \mathrm{~dB}$ per inch for the distances up to and beyond six inches, respectively.

Attenuation due to scattering, diffraction and energy loss mechanisms should be active in both regions of wave travel. The higher rate of attenuation in the first six inches was probably due to dispersion, which can be significant in the wave components of typical AE events [41]. Dispersion was caused by the frequency dependence of wave speed. The variable wave speeds caused the wave components to spread as the wave propagated outward from the source. Due to the dimensions of the specimen ( $1^{\prime \prime}$ by $0.05^{\prime \prime}$ by $\left.24^{\prime \prime}\right)$, geometric attenuation should be limited to the near field. At some relatively short distance from the source, the waveguide nature of the specimens should effectively eliminate the geometric attenuation. There could be other mechanisms responsible for the differing rates of attenuation, but their analyses is beyond the scope of this report.

Attenuation data was also obtained from the matrix cracking and delamination signature analysis specimens. Recall that the matrix cracking specimens and delamination specimens were 16 ply T-300/934 laminates with $[90, \pm 45,90]_{2 s}$ and $[0]_{16}$ lay-ups, respectively. The transducer spacing for the matrix cracking and delamination specimens was 2.3 and 3.2 inches, respectively. A shorter spacing was used for the matrix cracking specimens because the majority of events are low amplitude and may be rapidly attenuated below the system threshold $(40 \mathrm{~dB})$.

Figures 41,42 and 43 show the amplitude distributions corresponding to the three transducers on a matrix cracking specimen. The distributions have the same general shape. There is a decreased number of events in the 60 to $70 \mathrm{~dB}$ range as the distance from the source increases. In addition, the total number of detected events decreases as the transducer spacing from the source increases. Approximately 49 and 64 percent of the total number of events detected by the transducer closest to the source were attenuated below the $40 \mathrm{~dB}$ system threshold within the first 2.3 and 4.6 inches of specimen, respectively.

Examination of the data in a numerical format revealed that approximately 88 percent of the events with amplitudes between 40 and $49 \mathrm{~dB}$ at the source were attenuated below the threshold in the first 4.6 inches. Approximately 48 percent of the events between 50 and $59 \mathrm{~dB}$ were attenuated enough to avoid detection at the transducer farthest from the source. All events with amplitudes greater than $60 \mathrm{~dB}$ were detected at all three transducers.

Figure 44 which is a plot of event amplitude versus specimen distance also shows the attenuation of the matrix cracking events. The data was grouped according to the event amplitude at the transducer closest to the source. The selected ranges were 50 to 59,60 to 69 and 70 to $79 \mathrm{~dB}$. Events in the 40 to $49 \mathrm{~dB}$ 


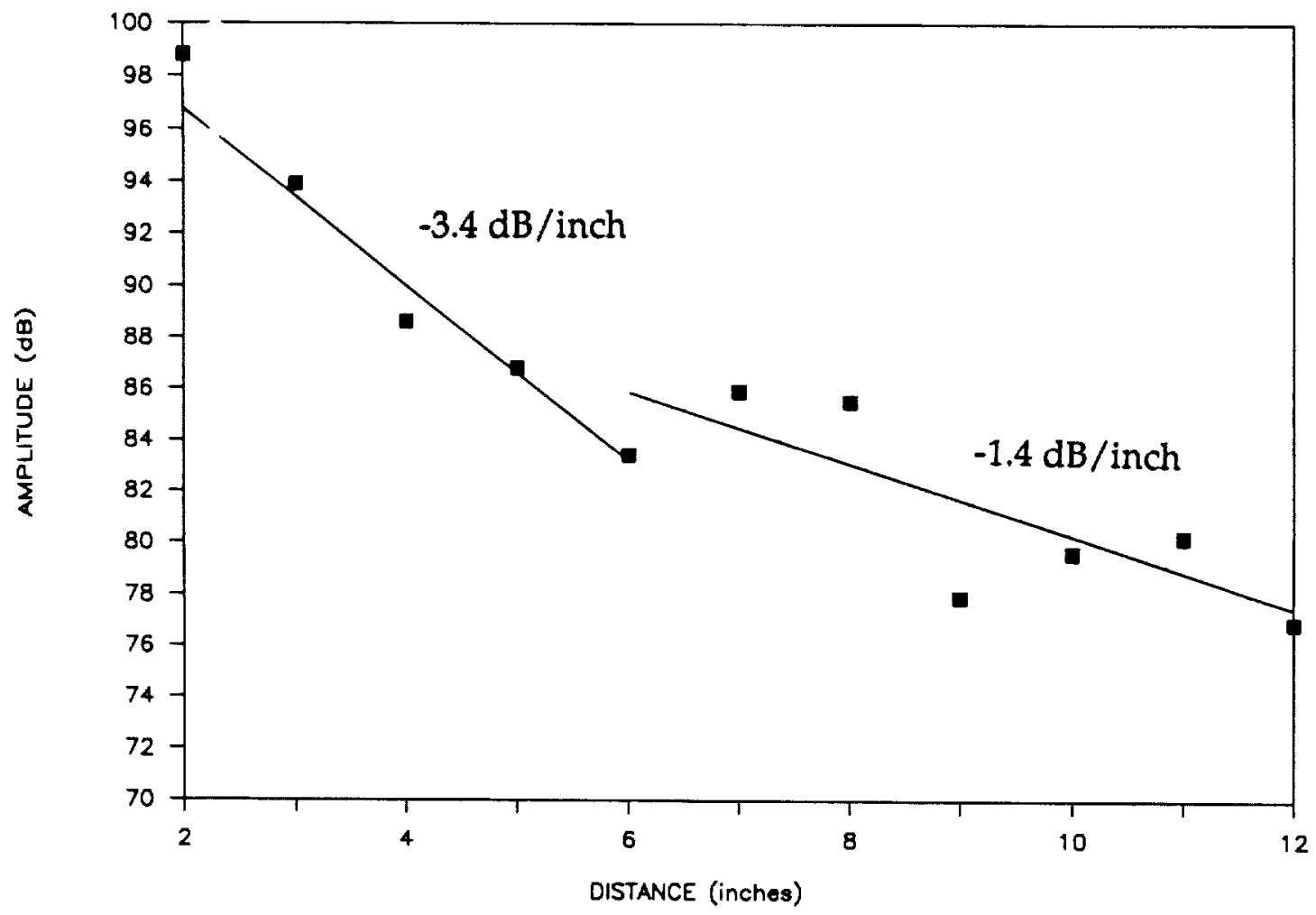

Figure 40. Attenuation of lead break events for an eight ply quasiisotropic laminate. 


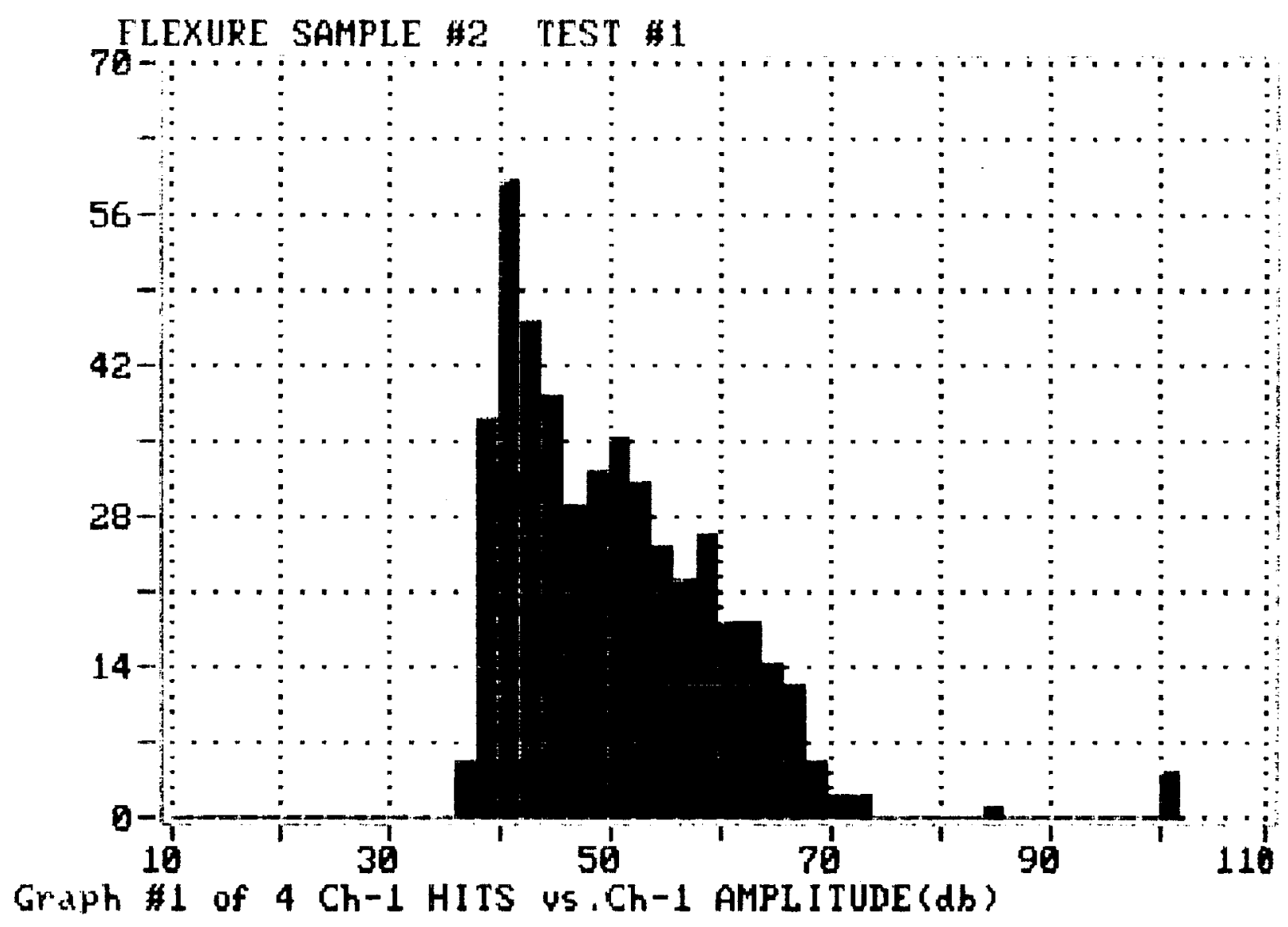

Figure 41. Amplitude distribution from matrix cracking specimen. Transducer \#1, closest to source. 


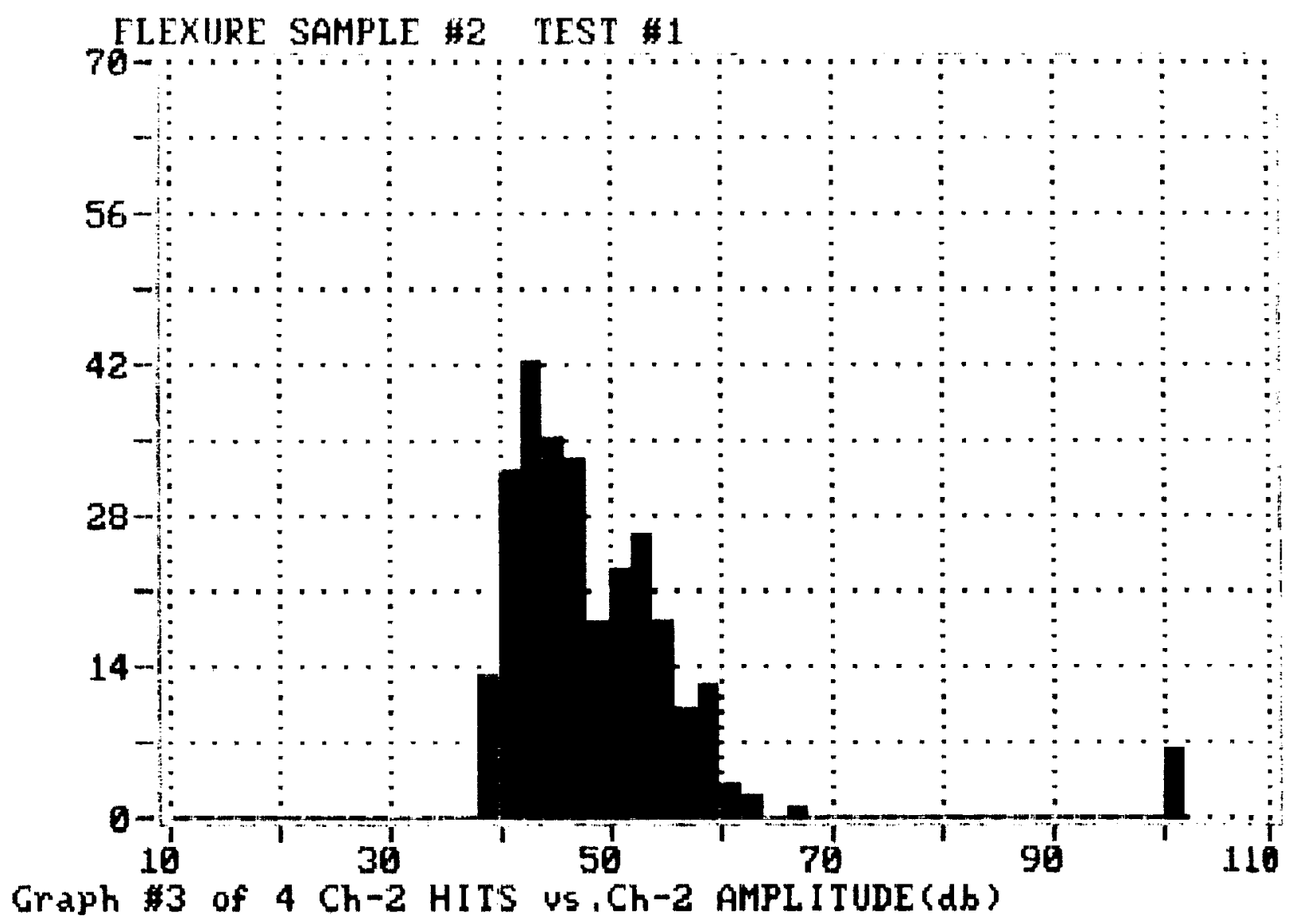

Figure 42. Amplitude distribution from matrix cracking specimen. Transducer $\# 2,2.3$ inches from the source. 


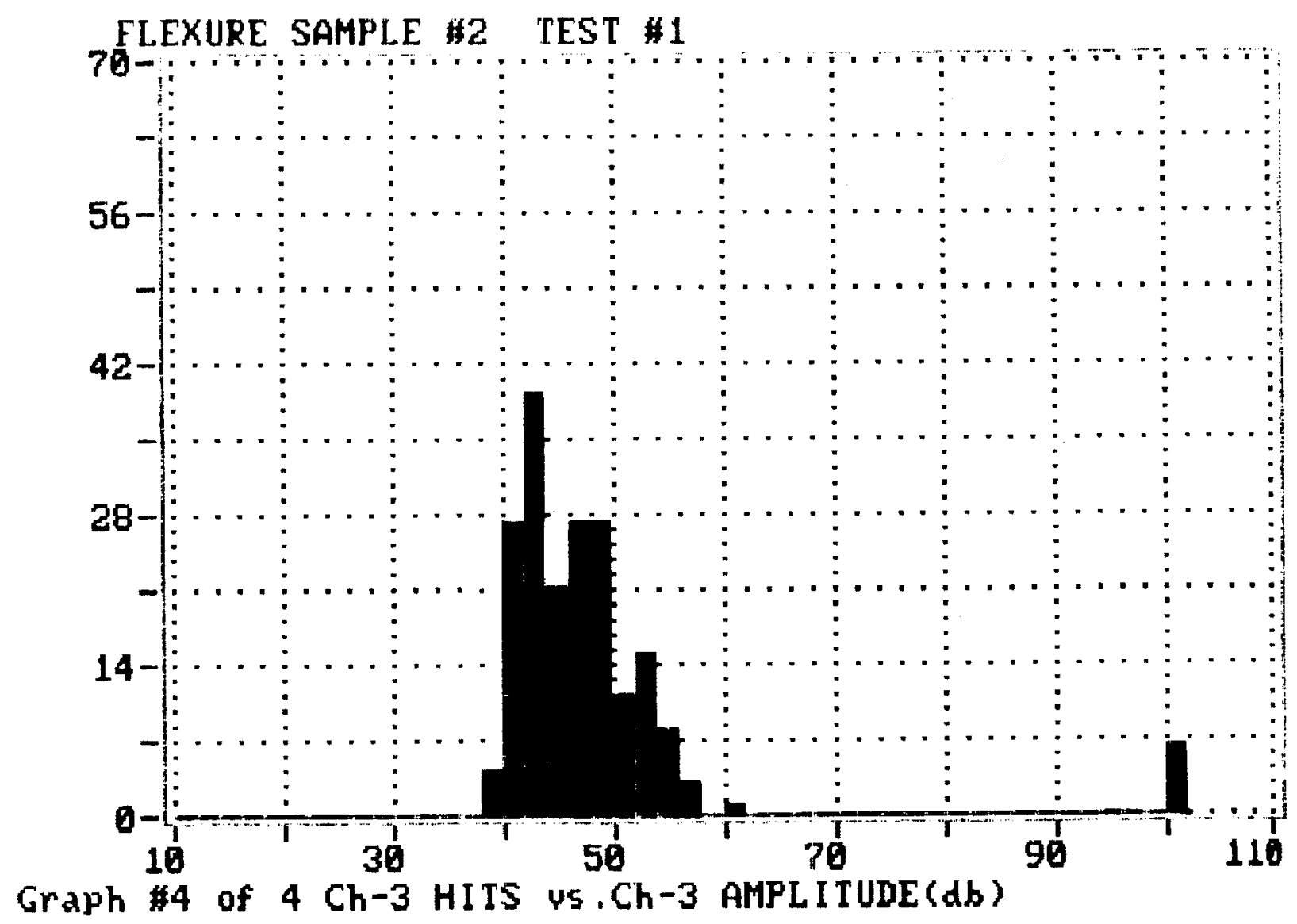

Figure 43. Amplitude distribution from matrix cracking specimen. Transducer \#3, 4.6 inches from the source. 


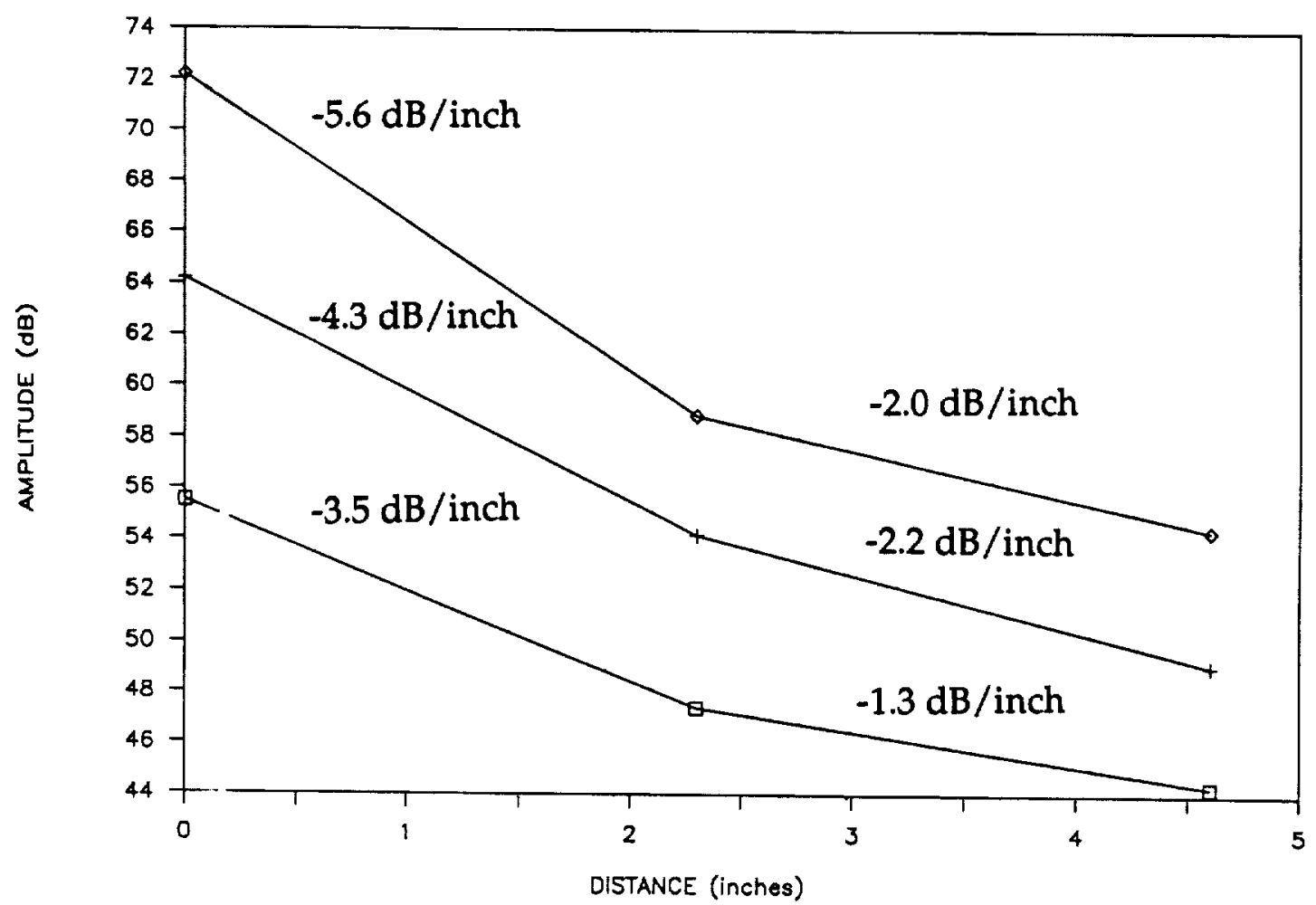

Figure 44. Attenuation of matrix microcracking events. 
range were not included because the majority of these events were attenuated below the threshold within the first 2.3 inches. The plot was generated by averaging the individual amplitudes of 25 events which had source amplitudes (transducer closest to source) within the selected ranges. Only events which were detected at all three transducers were included. The plot suggests that within the first 2.3 inches of specimen travel, the rate of signal attenuation is a function of the source event amplitude. As the source amplitude increased, the rate of attenuation increased. Beyond 2.3 inches, the rates of attenuation were approximately equal.

Attenuation data from the delamination specimens was handled in a similar manner. Figures 45,46 and 47 show the amplitude distributions corresponding to the three transducers. Approximately 30 and 34 percent of the delamination events were attenuated below the threshold in the first 3.2 and 6.4 inches, respectively. Due to the attenuation, the group of source events in the 70 to $85 \mathrm{~dB}$ range showed up in progressively lower amplitude ranges at the two transducers spaced away from the source. As a consequence, the delamination distributions changed shape.

Examination of the data in a numerical format indicated that nearly 100 percent of the events in the 40 to $49 \mathrm{~dB}$ range at the source were attenuated below the system threshold in the first 3.2 inches of specimen travel. Approximately 16 and 36 percent of the events in the 50 to $59 \mathrm{~dB}$ range were attenuated below the threshold within 3.2 and 6.4 inches, respectively. None of the events with amplitudes greater than $60 \mathrm{~dB}$ were attenuated below the threshold.

The delamination events were also grouped according to the source amplitude in order to produce a plot of amplitude versus distance. Figure 48 shows that the rate of attenuation in the delamination specimens is independent of source amplitude. The approximate rates of attenuation up to and beyond 3.2 inches are -3.8 and $-0.7 \mathrm{~dB}$ per inch, respectively.

The attenuation results indicate that a high percentage of the low amplitude events ( 40 to $59 \mathrm{~dB}$ ) typically associated with matrix cracking were attenuated below the $40 \mathrm{~dB}$ system threshold within five to seven inches of specimen travel. The five and seven inch distances corresponded to the source to transducer spacing for centrally located damage in 10 and 14 inch linear location arrays, respectively. AE events from damage progression which is not centrally located experiences a higher degree of attenuation in one direction. As a result, some medium amplitude events may not be located.

Clearly, attenuation is important in determining and understanding the effects of the transducer spacing in location data acquisition. Location data acquisition is typically used during quality control proof testing of relatively large structures. However, Awerbuch $[32,33,34]$ used a linear location array of two transducers separated by eight inches during material characterization studies. Awerbuch did not address attenuation when discussing the detection of damage progression or when discussing signature analysis amplitude distribution results. The attenuation results in this program show that even for relatively short distances (four inches), the amplitude distributions associated with a particular failure mechanism can be dramatically changed. 


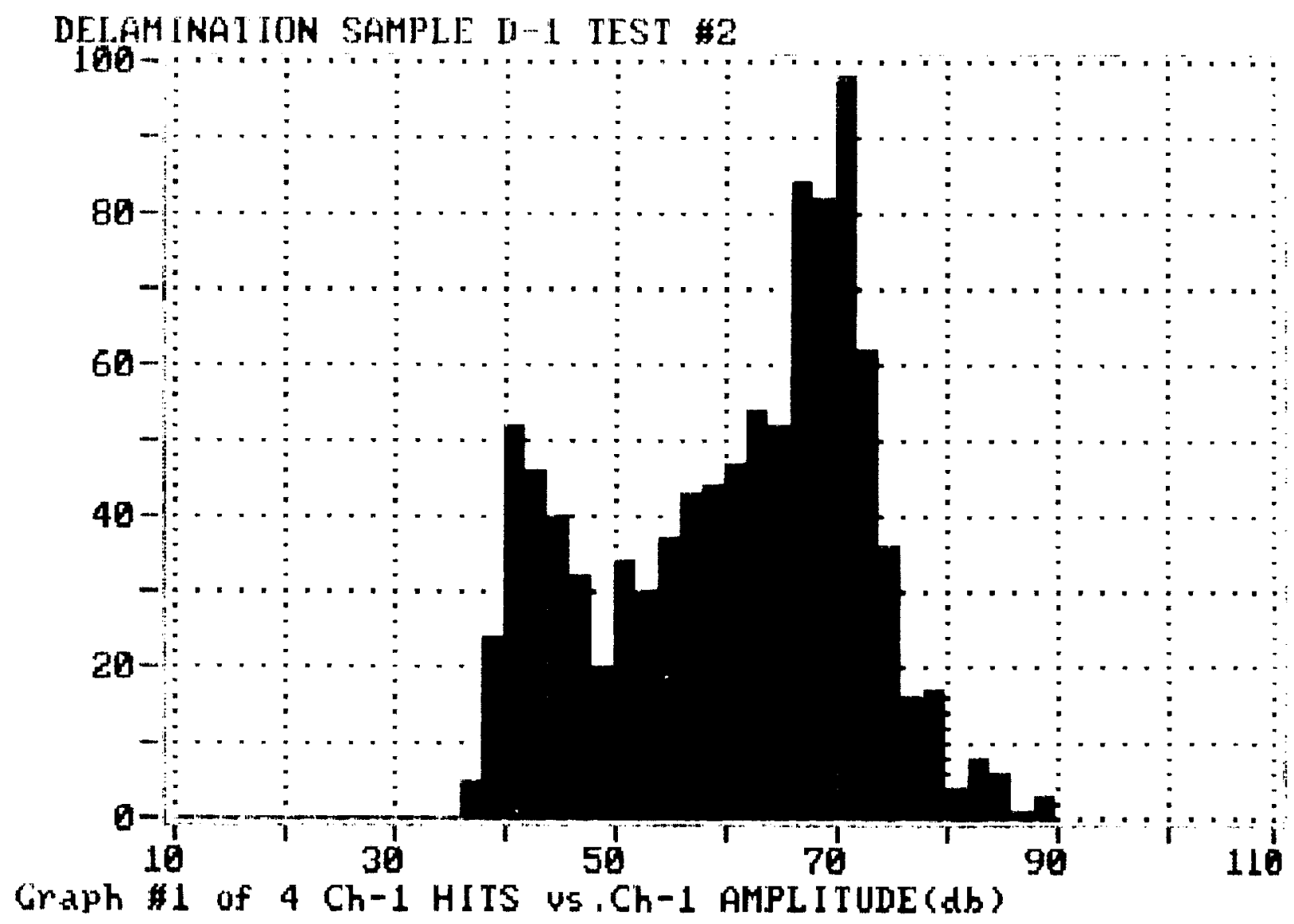

Figure 45. Amplitude distribution from delamination specimen. Transducer \#1, closest to source. 


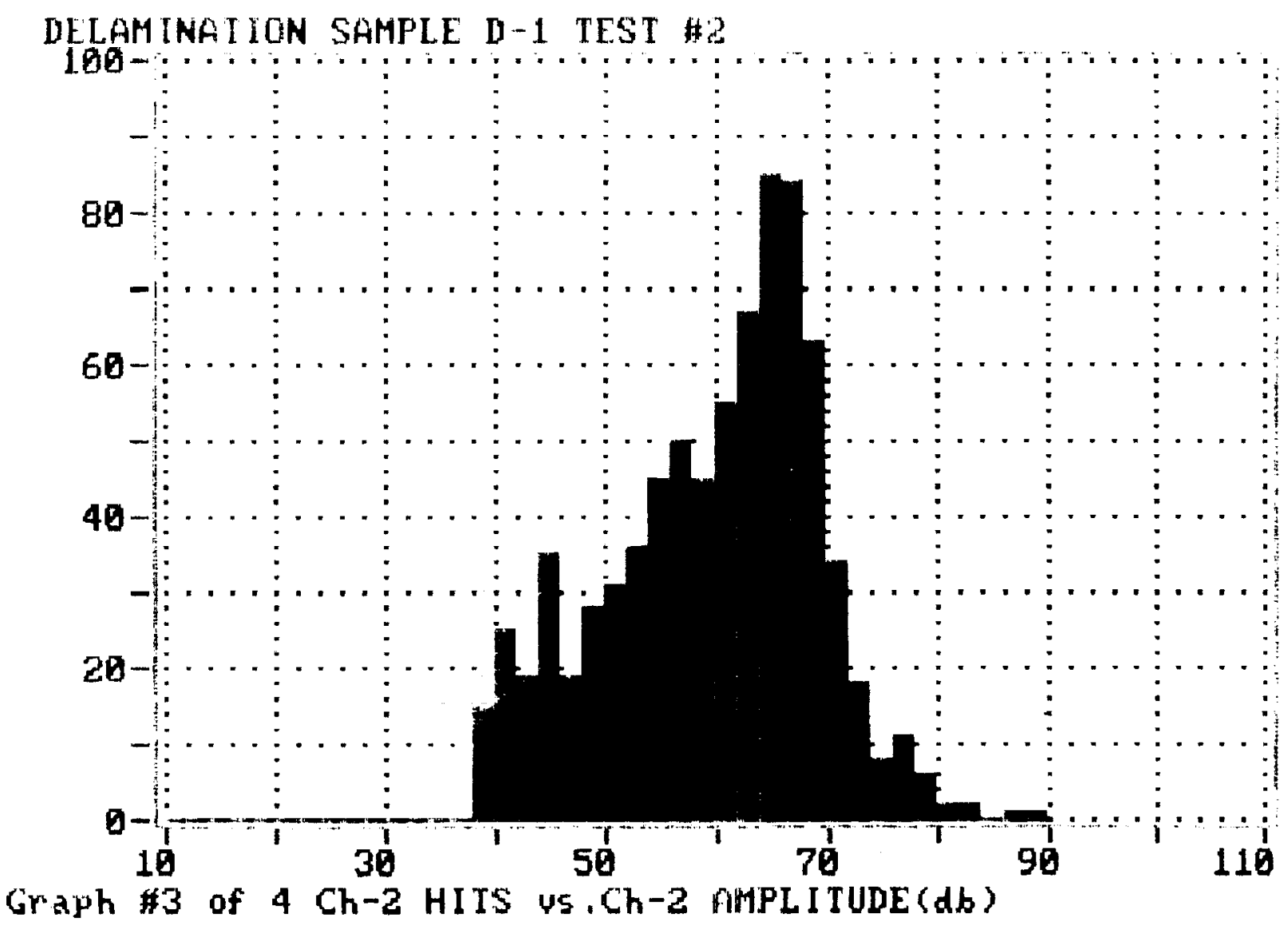

Figure 46. Amplitude distribution from delamination specimen. Transducer \#2, 3.2 inches from the source. 


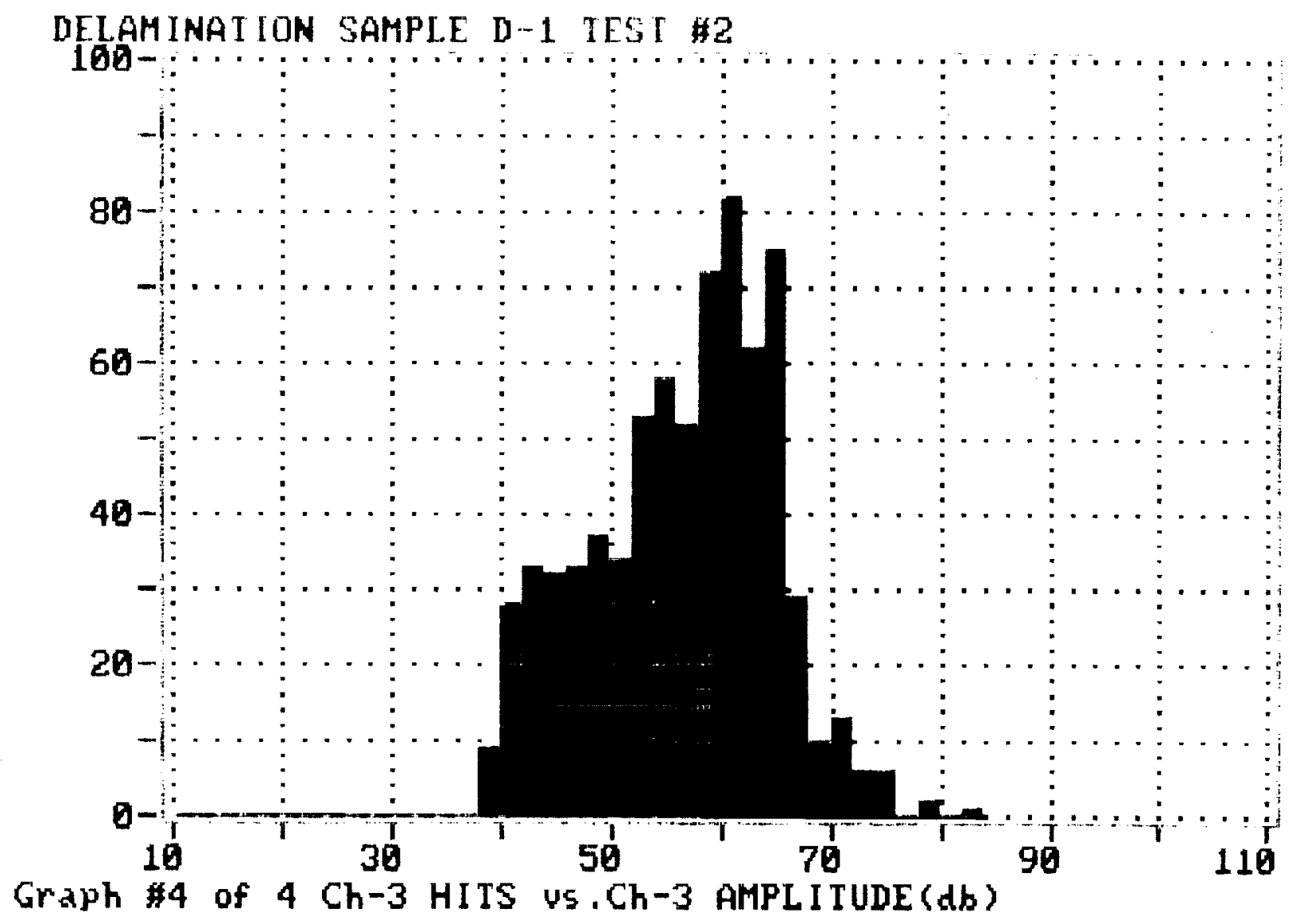

Figure 47. Amplitude distribution from delamination specimen. Transducer $\$ 3,6.4$ inches from the source. 


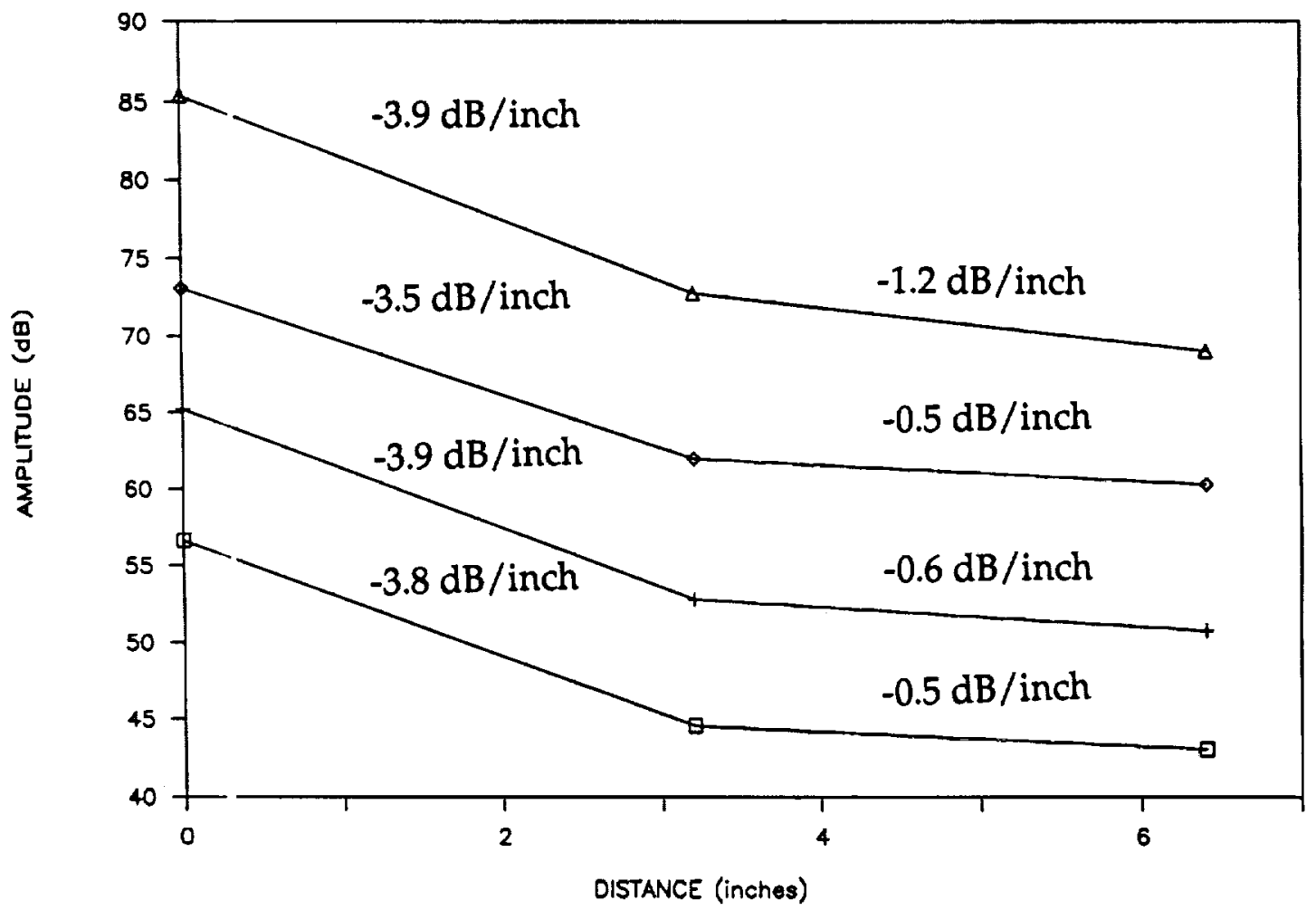

Figure 48. Attenuation of delamination events. 


\subsection{Linear Location}

\subsubsection{Introduction}

Several studies have demonstrated the capability of AE to locate damage initiation and monitor damage progression in composites $[8,32,33,34,42$, $43,44,45,46]$. Many of these investigations were performed by Awerbuch in collaboration with other investigators $[32,33,34,42,44,45]$. The studies performed by Awerbuch utilized a two transducer linear location array and could be categorized as material characterization studies.

Ghaffari and Awerbuch [45] successfully detected the initiation and monitored the progression of longitudinal matrix splitting in unidirectional laminates during quasi-static tension and tension-tension fatigue loading. In a similar study, Cohen and Awerbuch [34] monitored delamination progression during tension-tension fatigue loading. The investigators were able to isolate damage progression events by filtering out friction or grating $\mathrm{AE}$ events caused by the rubbing of existing fracture surfaces. The filtering was based on event amplitude and energy, duration and count intensities.

Awerbuch and Ghaffari [32] addressed the use of AE to locate high velocity impact damage in a 16 ply quasi-isotropic laminate. The specimens were supported as a double cantilever beam and impacted by a $1 / 2$ diameter aluminum sphere at velocities between 90 and $2,800 \mathrm{ft} / \mathrm{sec}$. The investigators were able to locate the impact sites in specimens with non-visual damage during the early stages of quasi-static tension loading (at approximately 30 percent of ultimate strength). However, at higher load levels AE events from the accumulation of matrix cracking damage throughout the specimen length and events associated with the outward damage progression from the impact site dominated the events generated at the impact site. Surprisingly, the authors also found that for specimens with visually detectable back surface damage, it was more difficult to locate the damage site during the early stages of loading. This was attributed to the large number of friction events generated from relatively long longitudinal matrix splits produced during impact. Awerbuch and Ghaffari concluded that the damage site could not be reliably located using quasi-static tension proof loading. However, they did reliably locate the impact damage by detecting friction $\mathrm{AE}$ events generated during tension-tension fatigue loading.

Several articles by Awerbuch $[32,34,45]$ address the AE signatures of friction events. Awerbuch found that the majority of friction events had amplitudes between 40 and $60 \mathrm{~dB}$. In addition, Awerbuch established Friction Emission Threshold (FRET) intensity values for event duration, energy and counts.

As was previously discussed in this report, a high percentage of events in the 40 to 49 and 50 to $59 \mathrm{~dB}$ ranges were attenuated below the AE system's $40 \mathrm{~dB}$ threshold within approximately five inches of specimen travel. This suggests that Awerbuch and Ghaffari's success in using low amplitude friction events to locate the damage was contingent on a relatively short transducer spacing. The transducer spacing used by these authors was eight inches with centrally located damage. This configuration results in a four inch distance between the AE source and transducer. 
In this program, a linear location array similar to that used by Awerbach was selected to detect and locate low velocity impact damage in composites. Only quasi-static tension loading was investigated. One goal of this program was to determine whether or not $\mathrm{AE}$ could improve the reliability of proof tests.

\subsubsection{Specimens Impacted With an Aluminum Support Configuration}

During the first phase of the program, two PAC R-15 $150 \mathrm{KHz}$ resonance frequency transducers were placed on the specimens in a linear array. One transducer was placed at each end of the specimen gauge length approximately one inch from the aluminum tab. The transducer spacing was 10 inches. The transducers were coupled to the specimen using Apiezon $H$ vacuum grease and were held in place using rubber bands.

The SPARTAN/3000 AE system was setup in the linear location data acquisition mode using the SPL/DAS software. The time difference between the transducers, which was empirically determined using lead break events, was approximately 60 microseconds. The impact site was at the center of the transducer spacing for all specimens.

The PAC $1220 \mathrm{~A}$ preamplifiers had $100-300 \mathrm{KHz}$ plug-in bandpass filters, and the gain was $40 \mathrm{~dB}$. The system gain and threshold were 20 and $40 \mathrm{~dB}$, respectively. The Rise Time Out (RTTO), Single Channel Event Time Out (SCETO) and Rearm Time Out (RTO) were 20,50 and 50 microseconds, respectively. At the end of an event, the system automatically inhibits data acquisition in order to rearm (reset ICC counters). The time required for the SPARTAN to rearm is approximately 300 to 500 microseconds. A RTO less than 300 microseconds was selected to insure that the system rearm was as fast as possible.

The specimens were loaded in tension using a pin loading configuration at a crosshead rate of 0.01 inches per minute on an Instron Model 1125 Universal Testing Machine. The test setup is shown in Figure 49. Clumps of plasticine were used to damp out noise events emanating from the grips.

The AE system was first used to monitor the tension loading of a specimen without impact damage. At a stress of approximately 20 thousand pounds per square inch (ksi), the system began to detect a large number of nonlocated events (hits). This AE activity was attributed to tab bond failure. Loading was continued until one of the tab bonds completely failed.

During the test 1,568 hits were recorded, but only 21 events were located. The majority of hits were associated with tab bond failures. Figure 50 , which is a 3 -D histogram plot of events versus location versus time, shows the 21 located events. The plot shows that 13 of the 21 events were located at the ends of the specimen. These 13 events were also associated with tab bond failure.

The SPARTAN PCC was used to monitor the voltage signal from the Instron 1125 load cell. The PCC had a 10 volt offset which could not be changed by the system software. The voltage offset made it impossible to generate location histograms as a function of load or stress. Hence, the $z$-axis in all the 3$D$ plots was time. The Instron 1125 load versus time plots were used to determine the stress levels corresponding to time values in the 3-D plots. 

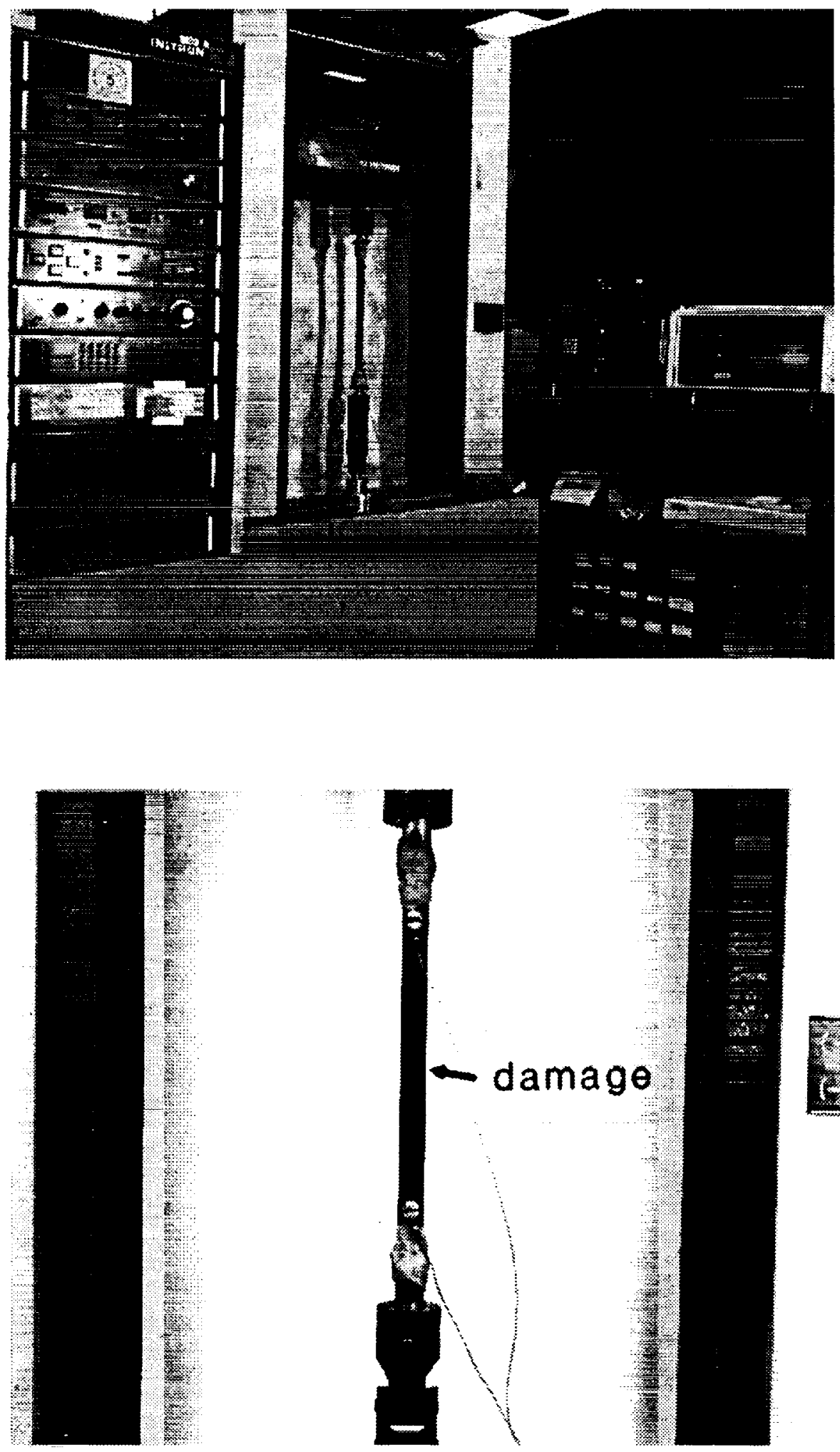

Figure 49. Linear location test setup. 


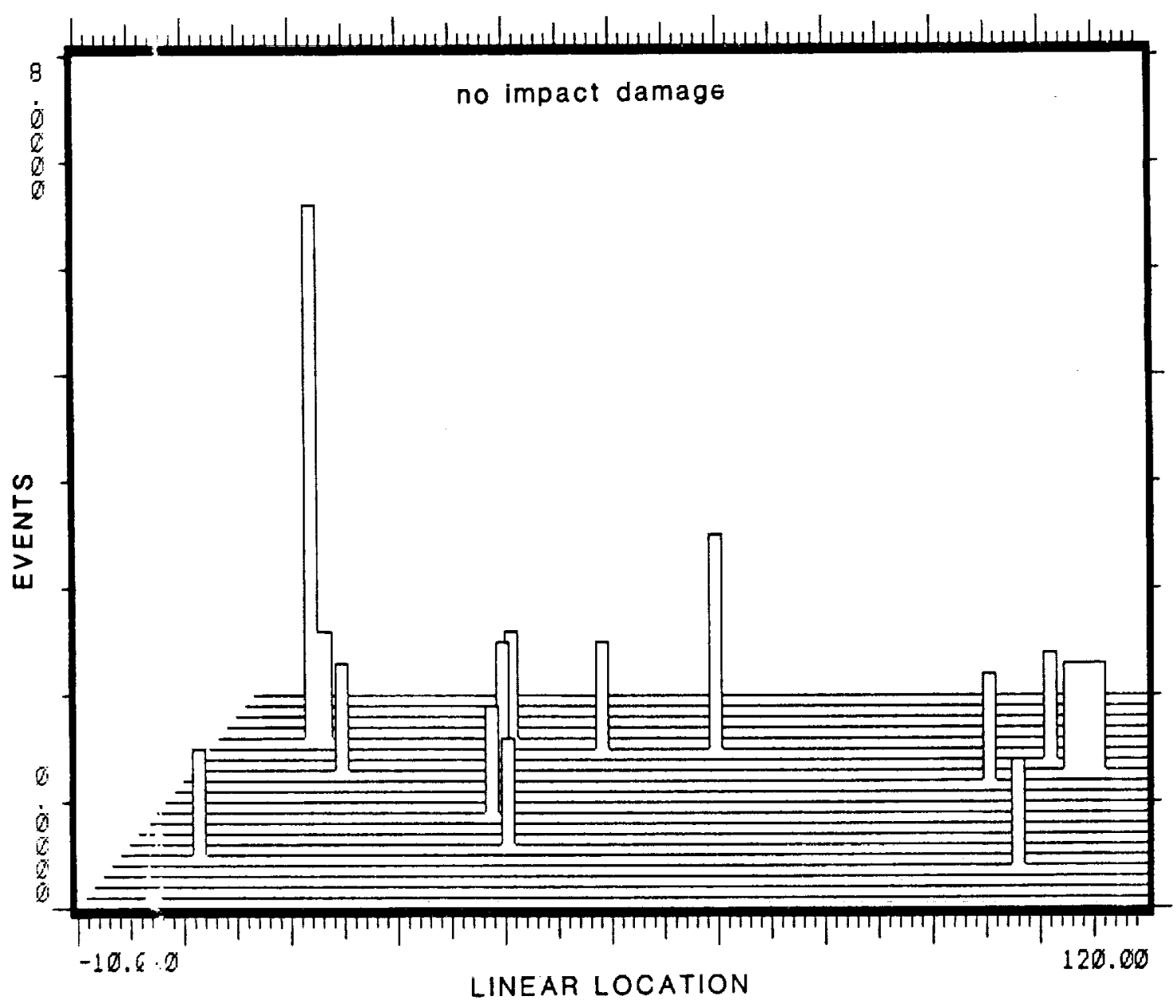

Figure 50. Three-dimensional location histogram from specimen with no damage. 
One of the specimens with a $6.8 \mathrm{ft}-\mathrm{lb}$ impact was then loaded to $2,100 \mathrm{lbs}$ (approximately $42 \mathrm{ksi}$ tensile stress). Figure 51 shows the 3 -D histogram of the located events. The first time interval in the z-axis of the 3-D plot was six minutes. The stress at this time was approximately $20 \mathrm{ksi}$. Each time interval in the plot corresponded to approximately $1.5 \mathrm{ksi}$ stress.

The location histogram clearly demonstrates the system's ability to locate impact damage consisting of fiber failure, delamination and matrix cracking. The first impact site event was located at approximately $26 \mathrm{ksi}$. The data shows that as the stress level increased above $26 \mathrm{ksi}$, the number of correctly located events increased. There was also a considerable amount of AE activity located at the ends of the specimen. This activity was associated with tab bond failure. Similar results were obtained from an additional specimen with a $6.8 \mathrm{ft}-\mathrm{lb}$ impact.

The AE system also correctly located the impact damage sites in specimens impacted at 3.4 and $1.7 \mathrm{ft}-\mathrm{lbs}$. Location histograms for specimens impacted at these energies are shown in Figures 52 and 53. Damage progression at the 3.4 and $1.7 \mathrm{ft}$-lb impact sites began at approximately 27 and $32 \mathrm{ksi}$ stress, respectively. Again, there was an increase in the number of correctly located damage progression events as the stress level increased. In contrast to the histogram from the $6.8 \mathrm{ft}-\mathrm{lb}$ specimen, these histograms showed numerous events located away from the damage site. This finding suggests that as the impact energy decreased, the tendency for damage initiation throughout the specimen length increased.

After the impact sites were correctly located, all of the specimens were loaded to failure. In order to avoid damage, the transducers were removed from the specimens. All specimens failed at the impact site. Examples of the failures are shown in Figure 54. The average tensile strengths for the impacted specimens were 46,50 , and $54 \mathrm{ksi}$ for $6.8,3.4$ and $1.7 \mathrm{ft}$-lbs, respectively. The ultimate tensile strength (UTS) of the quasi-isotropic laminate was approximately $82 \mathrm{ksi}$. The impact damage, which is primarily in the form of matrix cracking and fiber failure, significantly reduced the UTS of the graphite/epoxy specimens.

All three levels of impact damage were reliably located at tensile stress levels which were less than 50 percent of the laminate's UTS. Immersion ultrasonics only detected the highest level of damage (6.8 ft-lb impact). These results suggest that $\mathrm{AE}$ monitoring during tensile proof loading was more effective than immersion ultrasonics for detecting fiber failure damage.

\subsubsection{Specimens Impacted With a Membrane Support Configuration}

The SPARTAN-AT was used during the second phase of the program. Specimens were again monitored during quasi-static tensile loading using a linear array of two $150 \mathrm{KHz}$ transducers. The transducer spacing was increased from 10 to 14 inches. The transducers were coupled to the specimens using vacuum grease and rubber bands.

The PAC 1220A preamplifier gain was $40 \mathrm{~dB}$, and the system gain and threshold were 20 and $40 \mathrm{~dB}$, respectively. The PDT, HDT and HLT were 50, 150 , and 300 microseconds, respectively. These timing values were slightly 


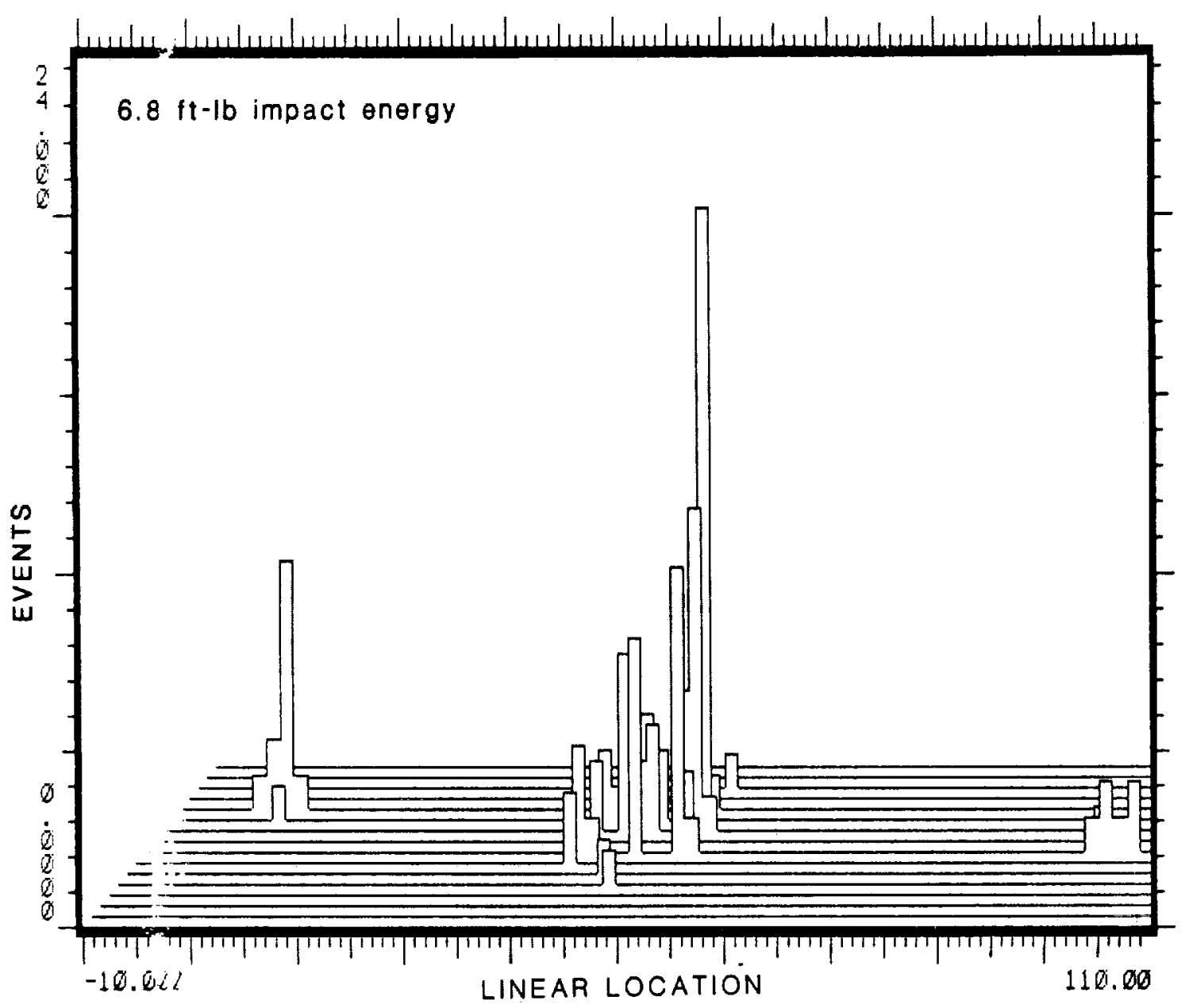

Figure 51. Three-dimensional location histogram from specimen with $6.8 \mathrm{ft}$-lb impact event. 


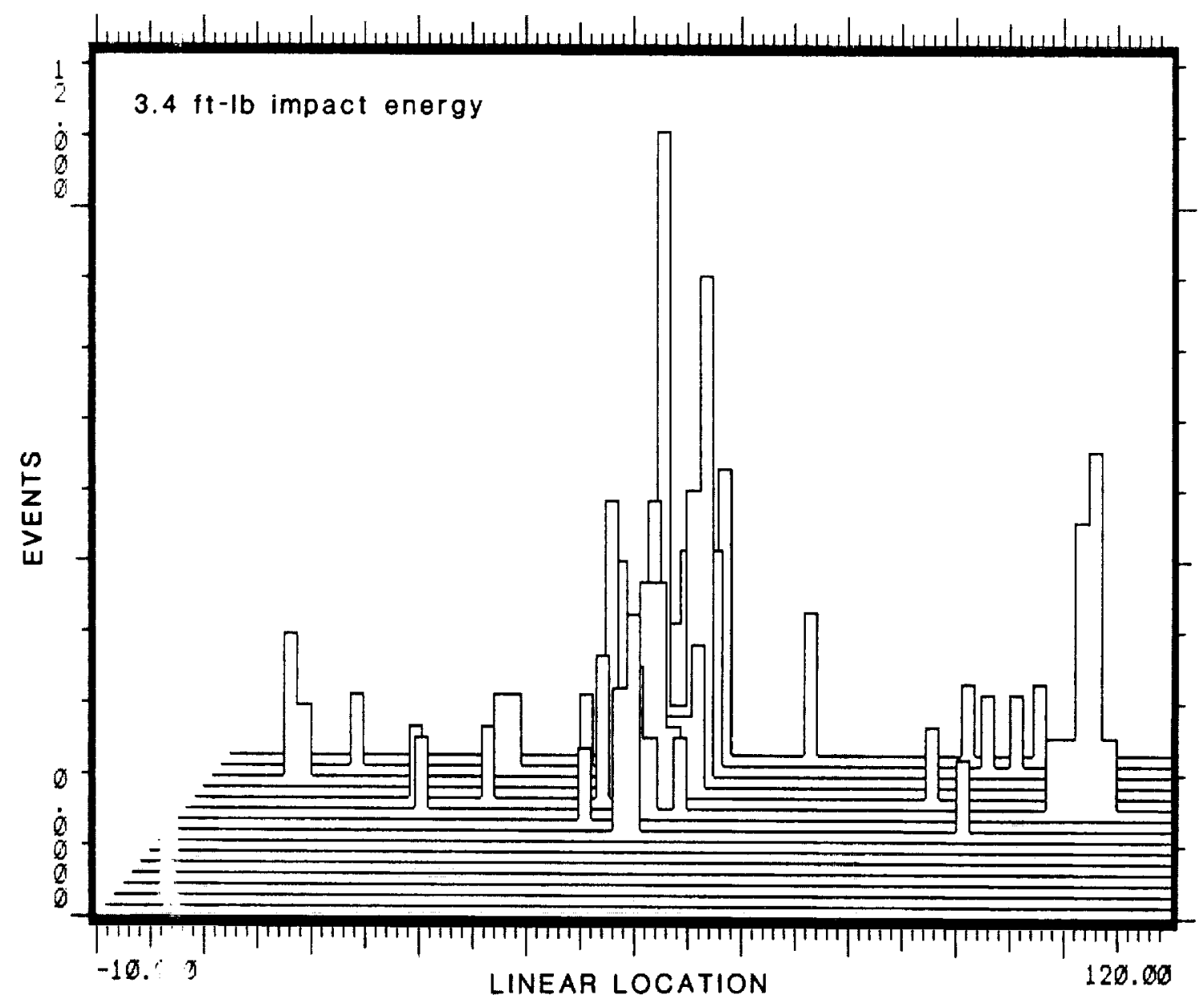

Figure 52. Three-dimensional location histogram from specimen with $3.4 \mathrm{ft}-\mathrm{lb}$ impact event. 


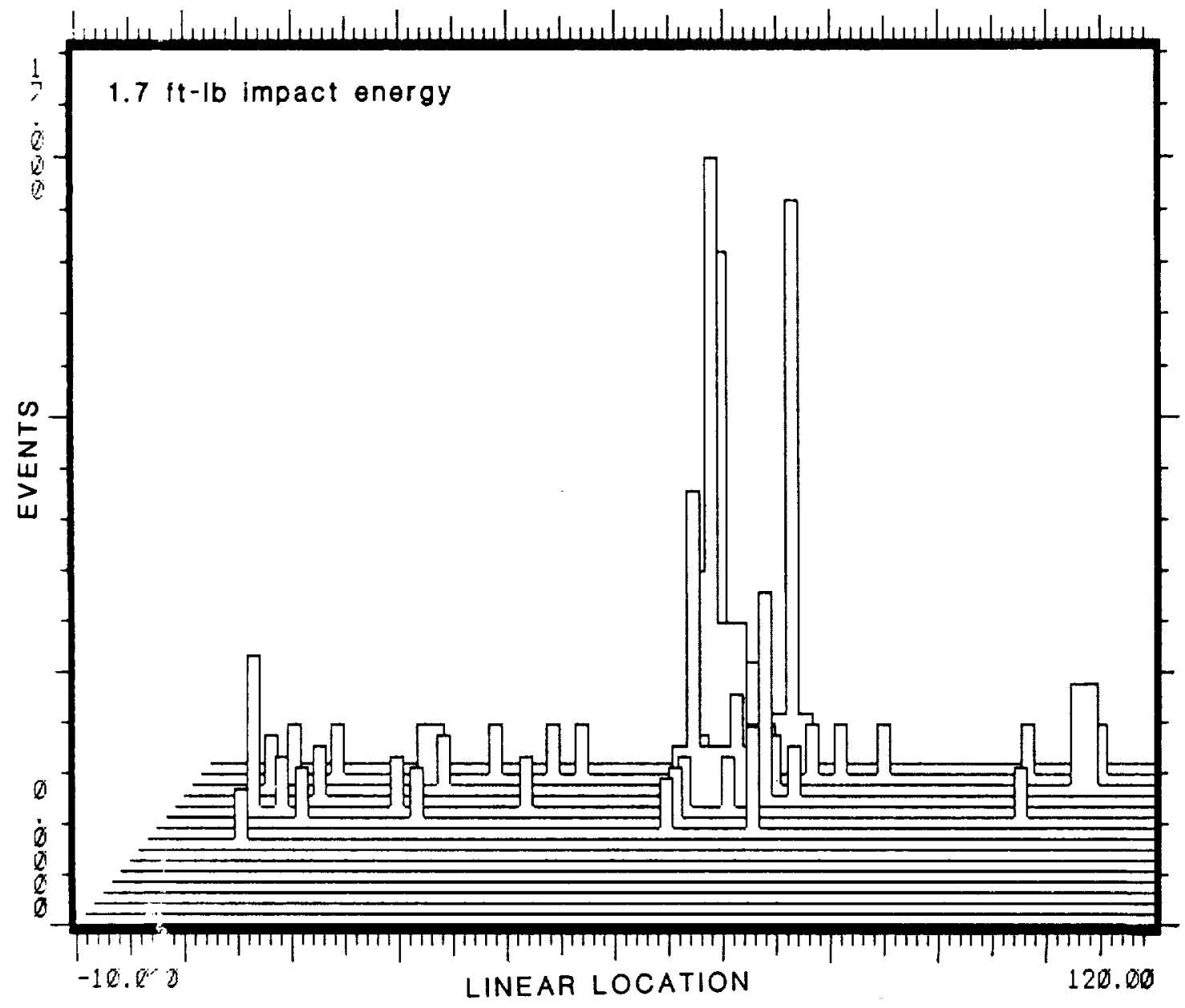

Figure 53. Three-dimensional location histogram from specimen with $1.7 \mathrm{ft}-\mathrm{lb}$ impact event. 

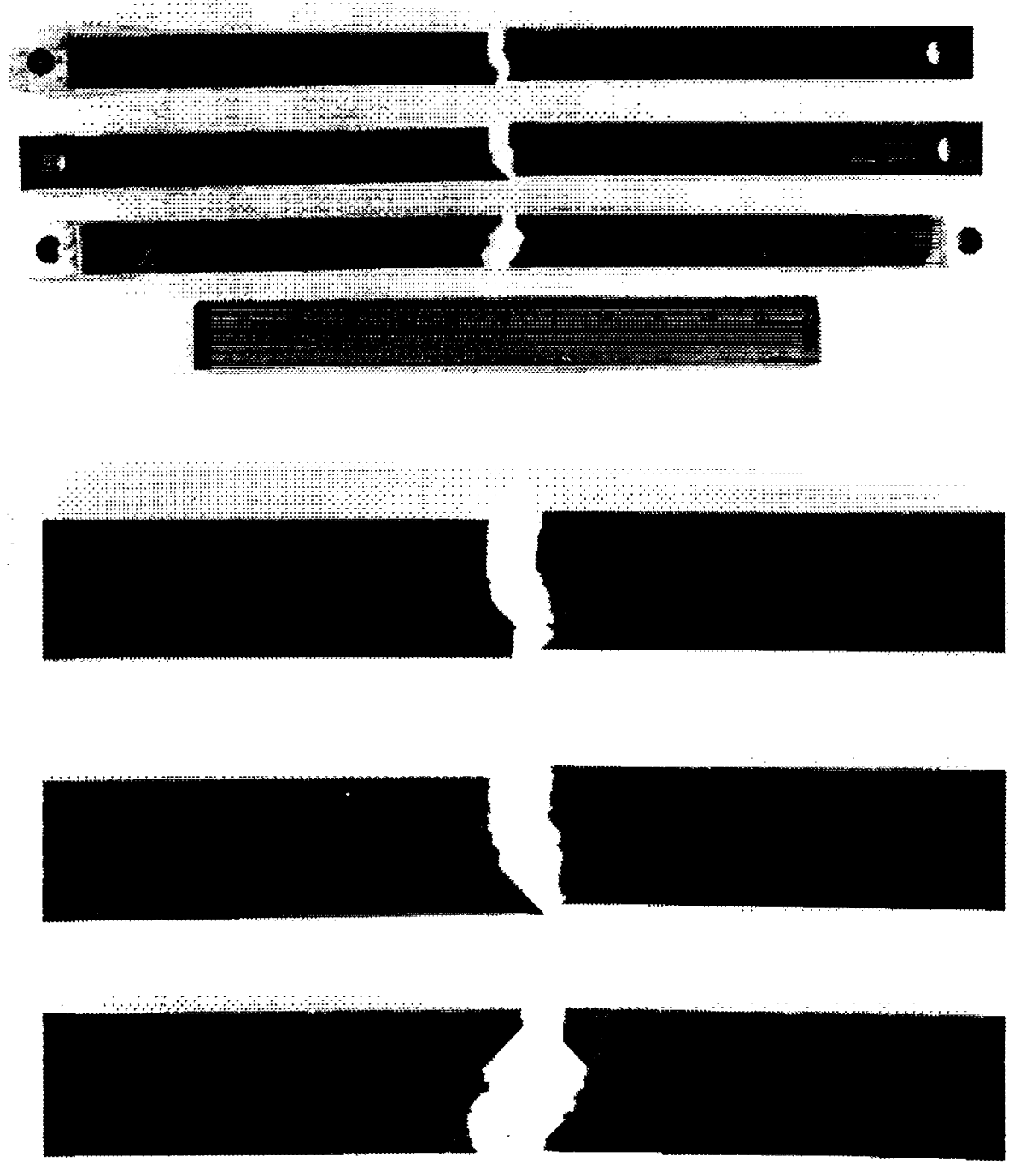

Figure 54. Examples of failure sites in impacted specimens.

ORIGINAL PAGE IS
OF POOR QUALITY 
different than the RTTO, SCETO and RTO values used during the first phase of the program.

The test setup on the Instron 1125 was identical to that shown in Figure 49. The specimens were loaded at a crosshead rate of 0.02 inches per minute. This was twice the rate used in the first phase of the program.

The $[90, \pm 45,0]_{\mathrm{S}}$ specimens impacted at the highest energy ( $0.8 \mathrm{ft}$-lbs) were tested first. Two of the specimens experienced catastrophic tab bond failures before there was detectable damage progression at the impact sites. The tab bonds failed at stresses of 48 and $53 \mathrm{ksi}$. The AE system correctly located the tab bond failures. Figure 55, which is a location histogram from a specimen with centrally located impact damage, shows that the majority of events were located at the end of the specimen at which the tab failed.

The location histogram also shows low levels of detected $\mathrm{AE}$ activity throughout the specimen gauge length. Figure 56, which is a point plot of location versus amplitude, shows that these located events had amplitudes ranging from approximately 40 to $75 \mathrm{~dB}$. Microscopic examination of the specimen surfaces revealed a large number of full width transverse matrix splits in the outer plies. The matrix splits probably generated the majority of located events.

Assuming an attenuation rate of approximately three $\mathrm{dB}$ per inch, the events at the center of the gauge length would have had source amplitudes between 60 and $95 \mathrm{~dB}$. These amplitudes are consistent with the amplitude distribution obtained for full width transverse matrix splits.

The third specimen impacted at $0.8 \mathrm{ft}-\mathrm{lbs}$ failed at one end of the specimen within the gauge length. The failure occurred at $81 \mathrm{ksi}$, which is the approximate UTS of the laminate. There was extensive damage initiation located throughout the gauge length, but the impact site was not located. Microscopic examination revealed an extremely large number of matrix splits in the outer plies. In some areas there were more than 25 full width matrix splits per inch of specimen length. Again, the majority of detected AE activity was associated with this matrix cracking.

Next, the specimens impacted at $0.6 \mathrm{ft}$-lbs were tested. The impact site in one of the three specimens was located prior to tab bond failure. Figure 57 shows a series of location histograms which correspond to increasing stress levels. The results show that the impact site was reliably located at a stress level which was less than 50 percent of the laminate's UTS. The results also show a significant amount of detectable $\mathrm{AE}$ activity throughout the gauge length. In addition, the histogram at $50 \mathrm{ksi}$ shows detectable damage progression at one of the tab bonds.

The damage sites were not located in the remaining two specimens impacted at $0.6 \mathrm{ft}$-lbs. Figure 58 shows the location histogram from one of these specimens. The majority of located events were from a tab bond failure. Again, there were events located throughout the specimen gauge length. Figure 59 shows a point plot of location versus amplitude. The majority of these events had low amplitudes ( 40 to $50 \mathrm{~dB}$ ) and were associated with full width matrix splits in the specimen outer plies. The loading was stopped at $54 \mathrm{ksi}$. 


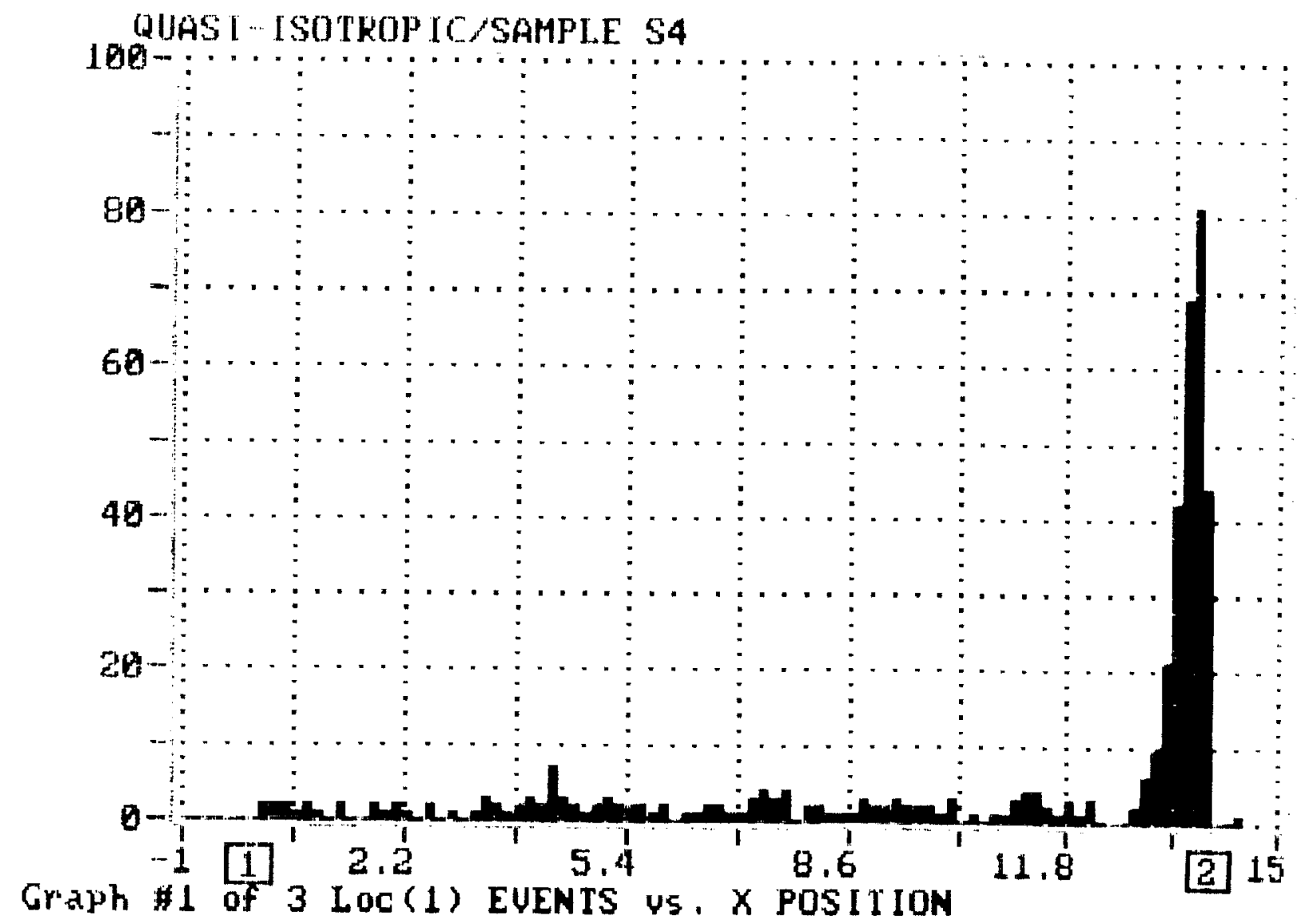

Figure 55. Location histogram from $[90, \pm 45,0]_{S}$ specimen which experienced catastrophic tab bond failure prior to location of impact site. Specimen impacted at $0.8 \mathrm{ft}-\mathrm{lbs}$. 


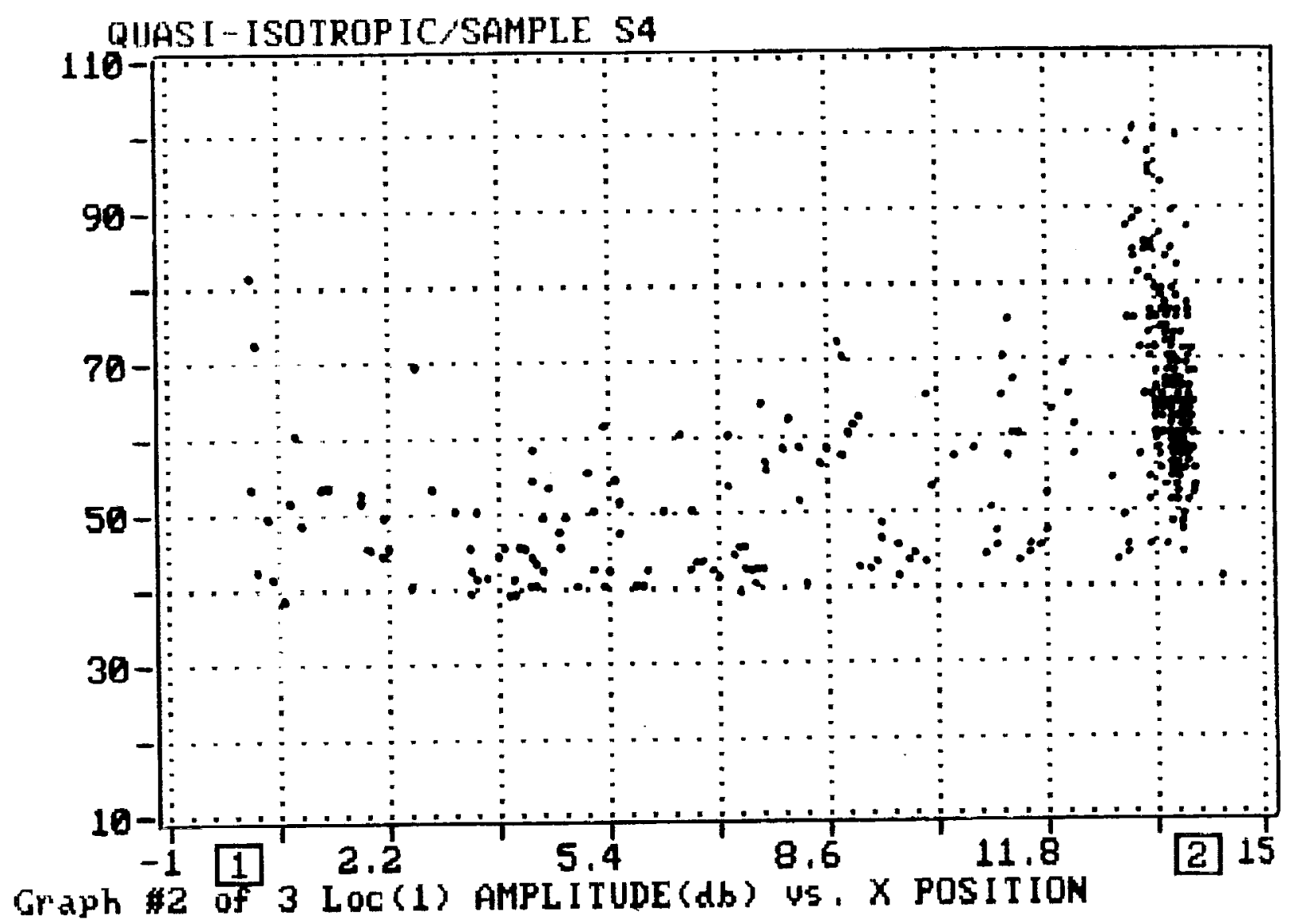

Figure 56. Point plot of amplitude versus location for events shown in Figure 55. 


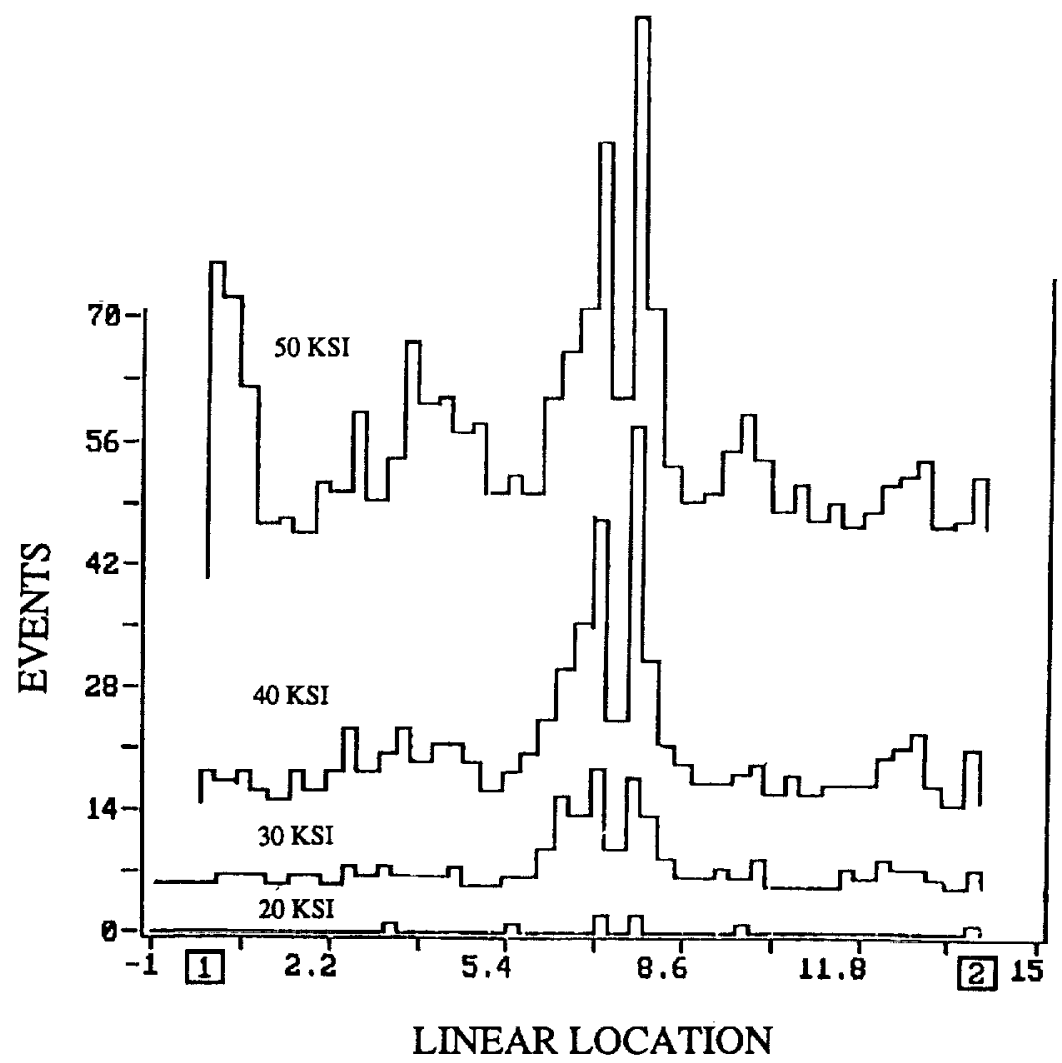

Figure 57. Series of location histograms for specimen impacted at $0.6 \mathrm{ft}-\mathrm{lbs}$. 


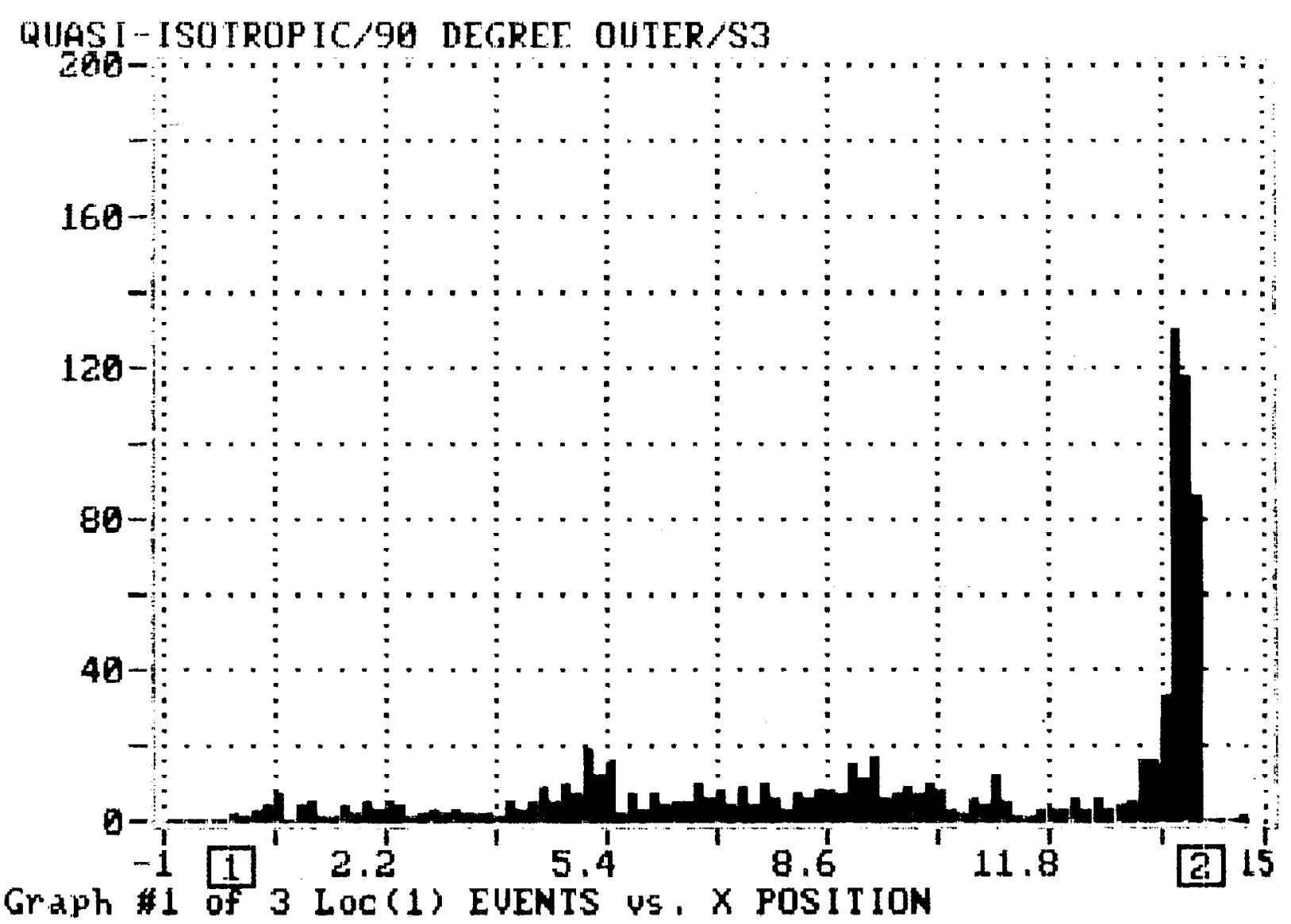

Figure 58. Location histogram from $[90, \pm 45,0]_{S}$ specimen which experienced catastrophic tab bond failure prior to location of impact site. Specimen impacted at $0.6 \mathrm{ft}-\mathrm{lbs}$. 


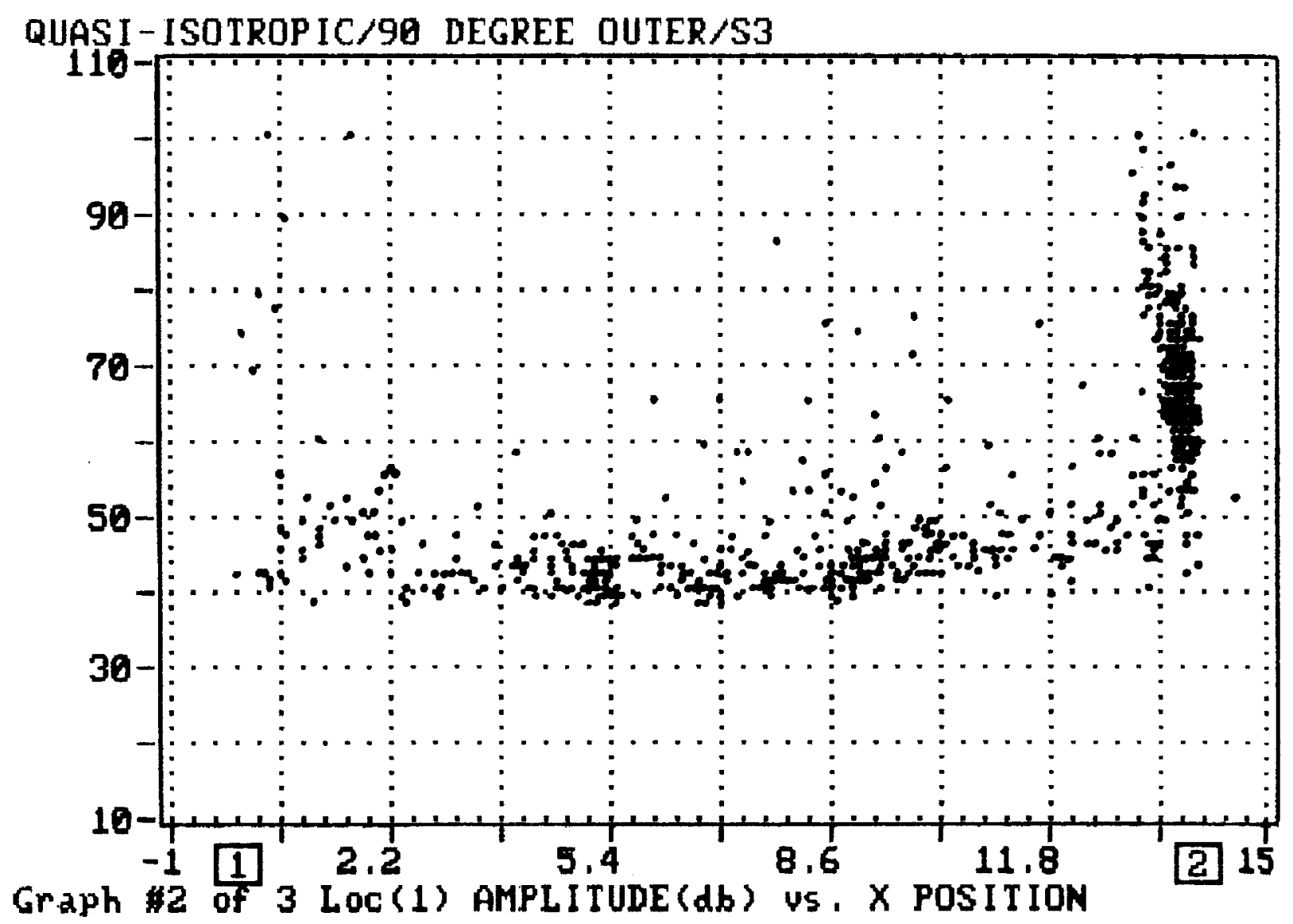

Figure 59. Point plot of amplitude versus location for events shown in Figure 58. 
In summary, only one of the six impact sites in the specimens impacted at 0.6 and $0.8 \mathrm{ft}-\mathrm{lbs}$ was located. Four of the six specimens experienced catastrophic tab bond failures at stress levels between 48 and $54 \mathrm{ksi}$. For each of these specimens, the AE system located the tab bond which failed. One specimen failed within the gauge length near one tab, but the impact site was not located. All the specimens exhibited extensive transverse matrix splitting in the 90 degree outer plies. Based on these results, the testing of specimens impacted at $0.3 \mathrm{ft}-\mathrm{lb}$ was not warranted.

The results suggest that $\mathrm{AE}$ cannot reliably detect and locate low velocity impact damage which is primarily in the form of matrix cracking and delamination. Several factors may have compromised the tests. First, stress concentrations produced by the pin loading configuration resulted in premature tab bond failures in the majority of specimens. Due to the tab bond failures, the maximum achievable tensile stress was approximately $50 \mathrm{ksi}$. In addition, the specimens from the second phase of the program exhibited excessive porosity (Figure 60). During tensile loading, porosity produces stress concentrations and promotes matrix cracking. The porosity may have contributed to the relatively large amount of $\mathrm{AE}$ activity located throughout the specimen gauge lengths.

Another reason for the lack of detectable damage progression at the impact sites was the state of stress in the specimens. Uniaxial tension loading produces plane stress in each ply of a laminate. The only interlaminar stresses (three-dimensional states of stress) are at the free edges of the laminate [47]. The primary mode of failure away from the specimen edges should be either translaminar matrix cracking or fiber failure. In theory, there should be no interlaminar stresses and hence, no driving force for delamination growth.

The presence of damage in the specimens may produce localized threedimensional states of stress. The absence of detectable damage progression at the impact sites suggests that these interlaminar stresses were insufficient to produce delamination growth.

The impact damage in the specimen which exhibited damage progression may have been different from the damage in the remaining five specimens. The difference is shown in the immersion ultrasonic C-scan images (Figure 11). The area of delamination damage in this specimen was significantly smaller that the areas in the other specimens impacted at $0.6 \mathrm{ft}-\mathrm{lbs}$. This result suggests that a higher portion of the impact energy was transferred into matrix cracking and possibly fiber failure. This type of damage has a higher probability for progression during tension loading.

The problems produced by the pin loading configuration prompted the use of alternate specimen gripping techniques during the testing of the $[0, \pm 45,90]_{s}$ specimens. In order to use the alternate gripping techniques, the tabbed sections of the specimens were removed using a diamond cut-off wheel. The remaining specimen length was approximately 16 inches. The reduced length resulted in a decreased transducer spacing (nine inches).

The specimens impacted at $0.8 \mathrm{ft}$-lbs were loaded using Instron Model 10FA wedge-action grips. In order to minimize the amount of specimen damage, thin rubber pads were placed between the diamond wedge faces and the specimen. The specimens were loaded at a crosshead rate of 0.05 inches per 


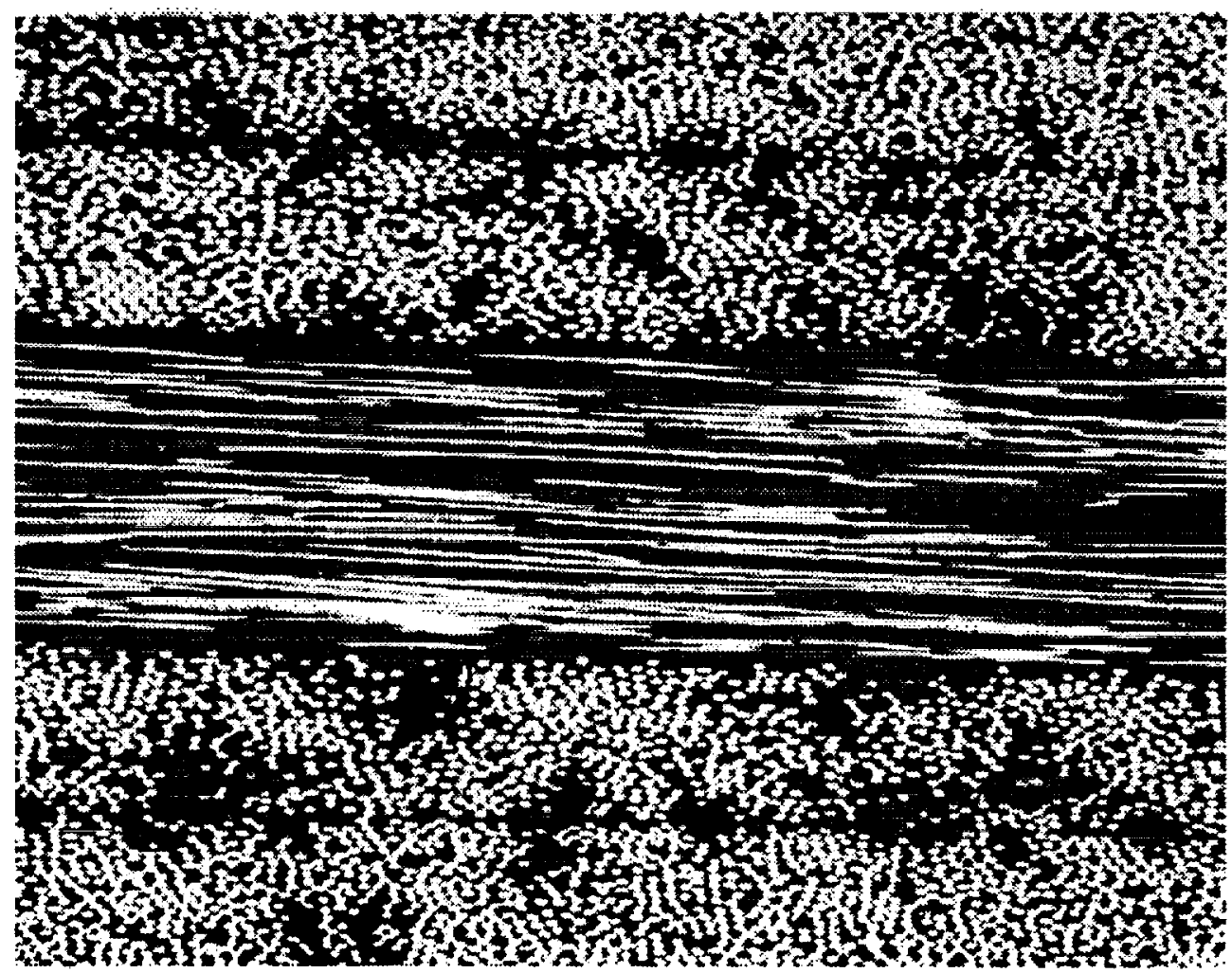

Figure 60. Micrograph at $100 \mathrm{X}$ magnification showing specimen porosity. 
minute. The higher rate was used to minimize specimen slippage between the rubber pads.

The rubber pads did not prevent the diamond wedge faces from crushing the outer plies of the laminate. The crushing created relatively high rates of $\mathrm{AE}$ activity. The maximum recorded hit rate for all specimens was approximately 450 hits per second. Based on the $\mathrm{AE}$ system characterization, this hit rate should not have resulted in lost data.

None of the impact sites were located during tension loading. Figure 61 shows the location histogram for one of the specimens. The majority of the located AE activity was at the ends of the specimen. This activity was attributed to laminate crushing by the grips. There is no evidence of the centrally located impact site. The loading was stopped at approximately $70 \mathrm{ksi}$.

The location histogram also shows that considerable damage initiation was detected throughout the specimen gauge length. Figure 62 , which is a point plot of amplitude versus location, shows that the majority of events located in the gauge length have amplitudes between 40 and $60 \mathrm{~dB}$. Assuming an attenuation rate of approximately three $\mathrm{dB}$ per inch, those events located near the center of the specimen would have had source amplitudes between 55 and 75 $\mathrm{dB}$. Events located closer to the ends of the specimen would have had even lower source amplitudes. This result suggests that all of the damage initiation within the gauge length was due to matrix dominated failures.

Similar results were obtained from the remaining two specimens impacted at $0.8 \mathrm{ft}$-lbs. Each of the specimens simultaneously failed at one grip/specimen interface and within the gauge length (away from the impact site). The failure stresses were 66 and $69 \mathrm{ksi}$. These stresses were significantly lower than the laminate's UTS (approximately $82 \mathrm{ksi}$ ). This suggests that the crushing damage at the grips weakened the specimens.

The specimens impacted at $0.6 \mathrm{ft}$-lbs were gripped using MTS Systems Corporation Model 647.10 hydraulic wedge grips. Surfalloy wedge faces were used without an interface between the specimen and wedge face. The grip. pressure was $2,000 \mathrm{psi}$. The surfalloy wedges, which were specifically designed for testing polymeric and composite materials, rely on a high contact area to prevent specimen slippage. In contrast, diamond faces rely on biting action to prevent specimen slippage.

The specimens were loaded using a crosshead rate of 0.01 inches per minute. The surfalloy wedges did not completely eliminate slippage, and as a consequence, there was some AE activity generated at the grips. The activity rate increased as the stress level increased. The rate remained below 200 hits per second for stress levels up to approximately $45 \mathrm{ksi}$. At stresses above $50 \mathrm{ksi}$, the rate jumped to over 450 hits per second. Again, based on the system characterization, these activity rates should not have resulted in lost data.

One of the three $0.6 \mathrm{ft}-\mathrm{lb}$ impact sites was located during tension loading. Figure 63 shows a series of location histograms which correspond to increasing stress levels for a specimen with a centrally located impact site. At each stress level, the greatest number of located events was at the center of the location array. However, there were large levels of $\mathrm{AE}$ activity located throughout the 


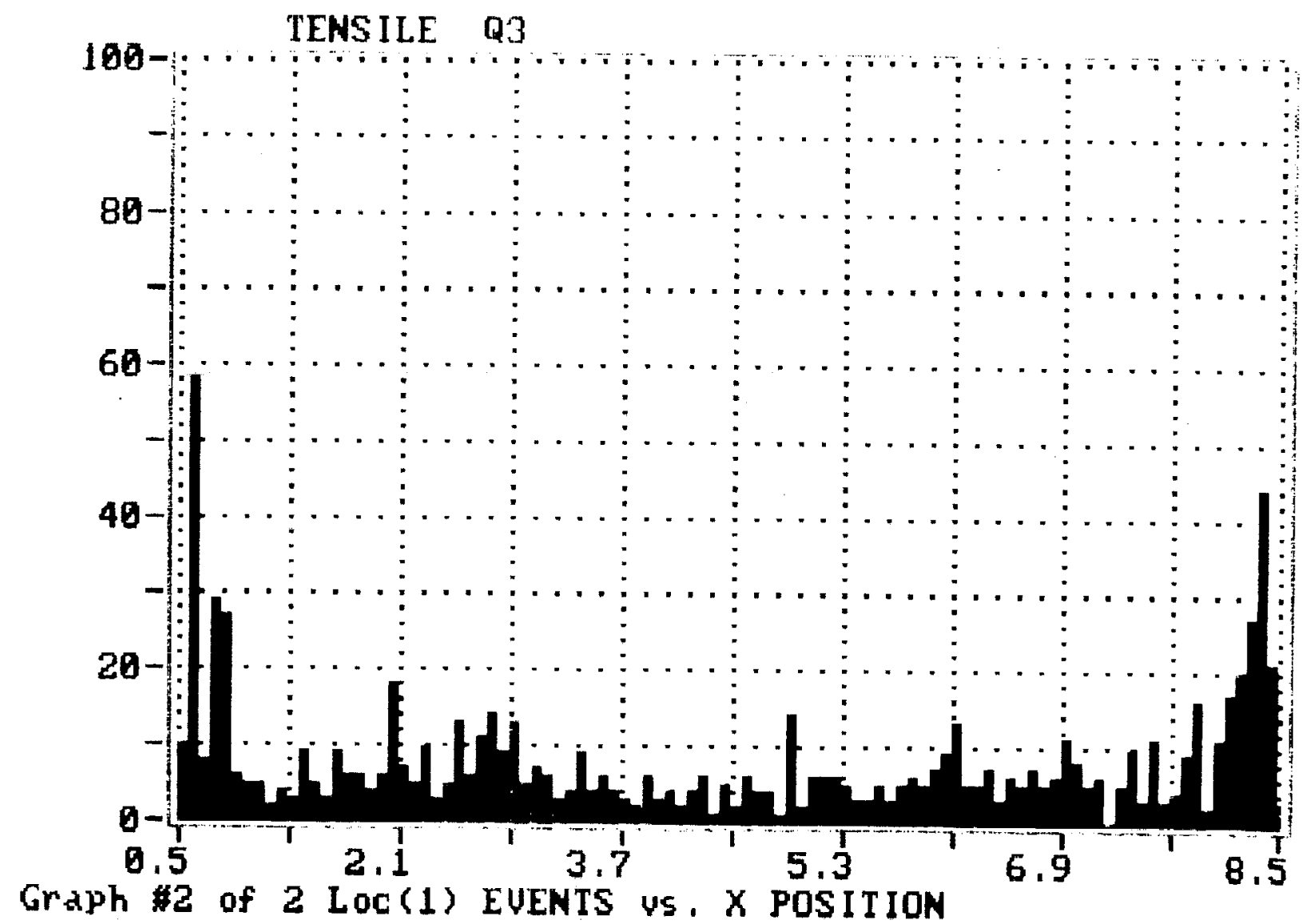

Figure 61. Location histogram from $[0,+45,90]_{S}$ specimen impacted at 0.8 $\mathrm{ft}$-lbs and loaded using Instron Model 10FA wedge grips. 


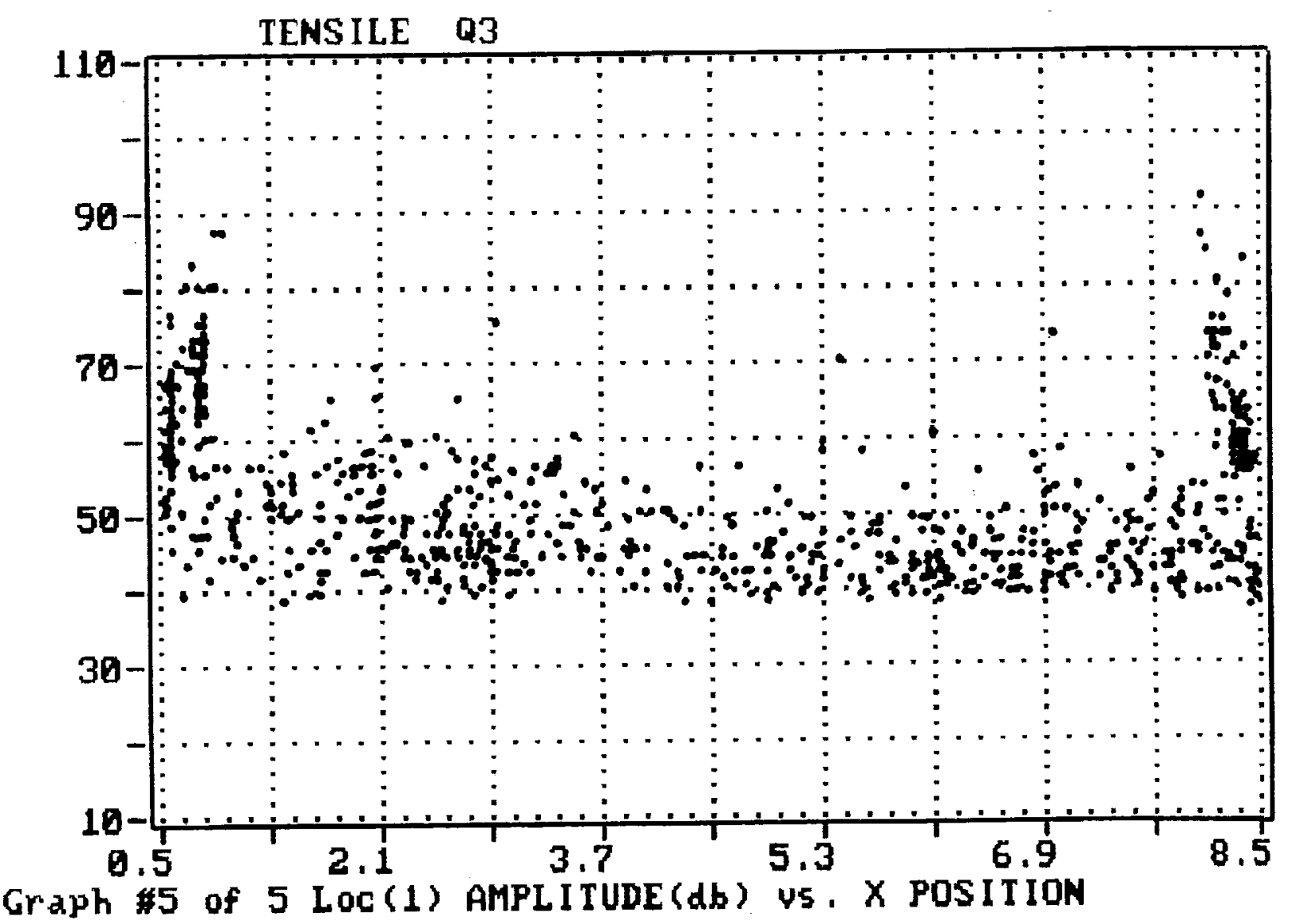

Figure 62. Point plot of amplitude versus location for events shown in Figure 61. 


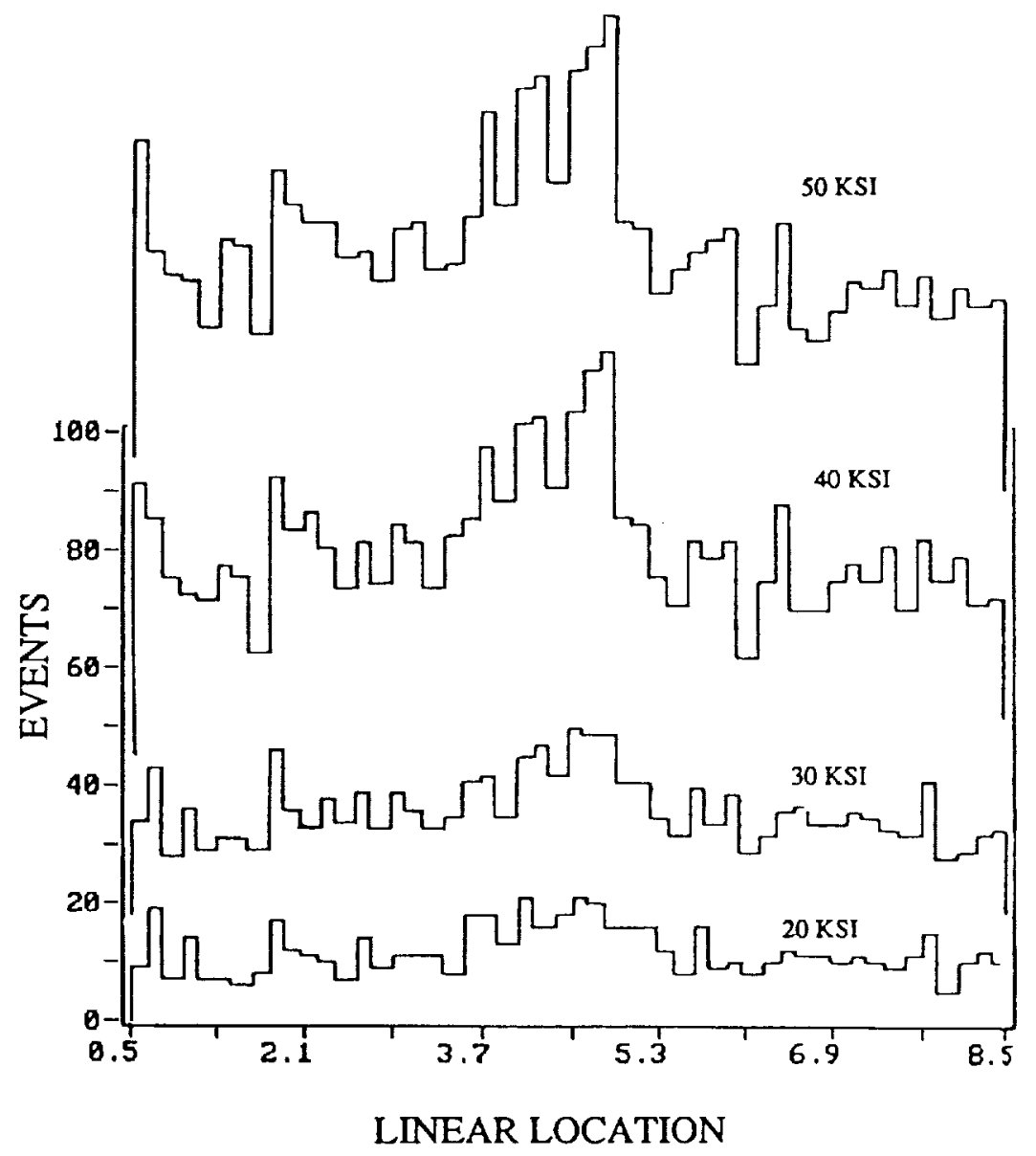

Figure 63. Series of location histograms for specimen impacted at $0.6 \mathrm{ft}$-lbs and loaded using MTS Model 647.10 hydraulic wedge grips. Impact site centrally located. 
specimen gauge length. This activity made it difficult to reliably locate the damage site.

The impact site in the second specimen was approximately two inches from one of the transducers. The series of location histograms in Figure 64 show a peak at the impact site. However, the $\mathrm{AE}$ activity generated throughout the gauge length at higher stress levels was more dominant than the activity at the damage site. Hence, the damage location was unreliable.

In conclusion, the alternate gripping techniques did not improve the location reliability during tension loading. This confirms that tension loading does not produce sufficient interlaminar stress to promote detectable delamination progression. Again, the extensive damage initiation throughout the specimen gauge length dominated the location histograms. These events were probably due in part to excessive porosity. These results suggest that immersion ultrasonics is a more effective technique than $\mathrm{AE}$ for detecting delamination damage. 


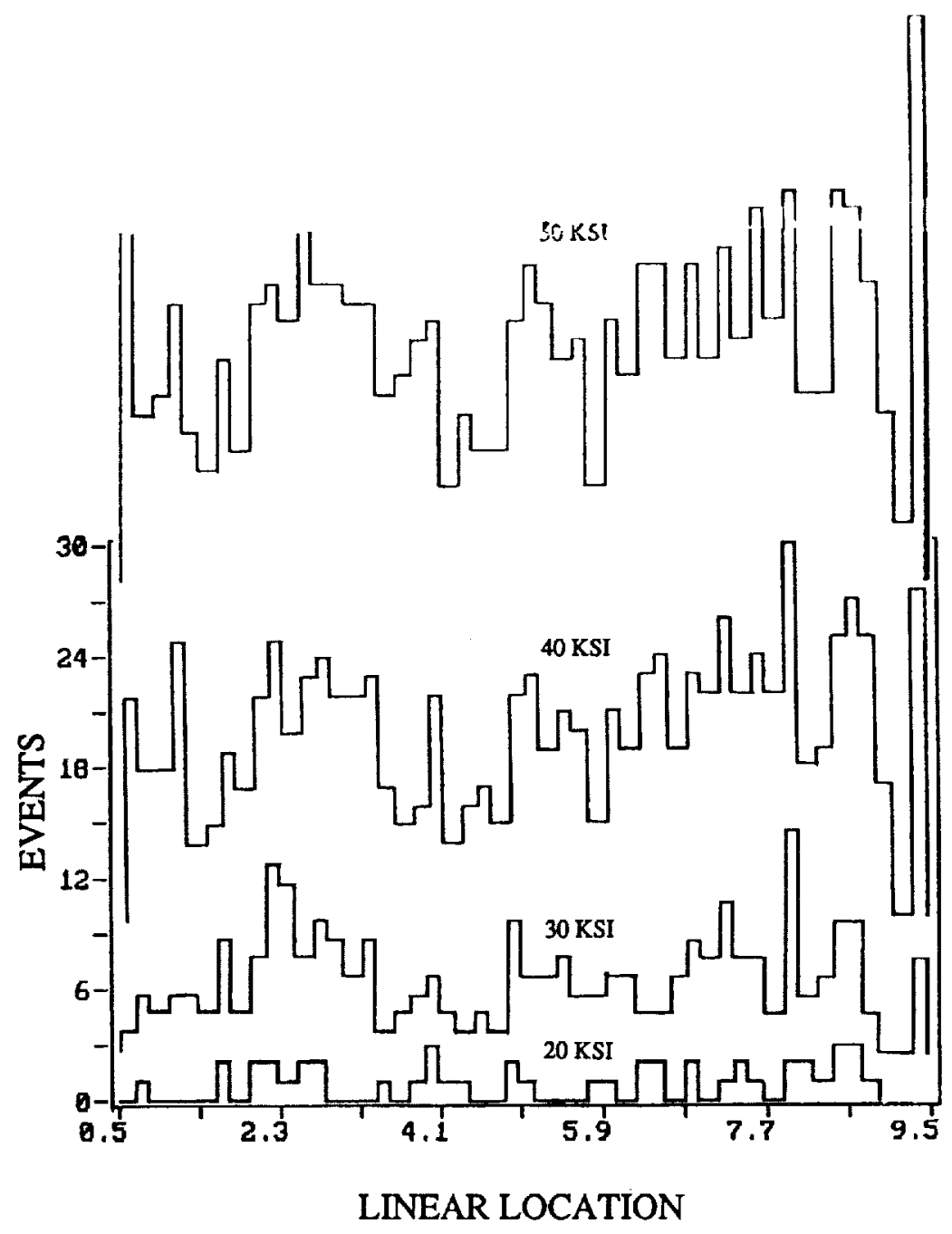

Figure 64. Series of location histograms for specimen impacted at $0.6 \mathrm{ft}-\mathrm{lbs}$ and loaded using MTS Model 647.10 hydraulic wedge grips. Impact site located at approximately 2 inches. 
During tension loading, AE reliably detected and located low velocity impact damage which included fiber breakage. Fiber breakage was produced in the outer ply of quasi-isotropic laminates when the support configuration prevented flexure during impact. All specimens with fiber breakage exhibited a loss of in-plane tensile strength and ultimately failed at the impact sites.

AE did not reliably locate impact damage which consisted of only delaminations and matrix cracking. This type of damage was produced when specimens were supported by a membrane configuration which allowed bending flexure during impact. Specimens with only delamination and matrix cracking damage did not fail at the impact sites during tensile loading.

The AE system detected and located damage initiation and progression in epoxy specimen to tab bonds. The bond failures produced large levels of $\mathrm{AE}$ activity with event amplitudes ranging from 40 to $100 \mathrm{~dB}$. This finding suggests that $\mathrm{AE}$ has the potential to monitor the proof testing of bonded joints, which are used extensively in composite structures. Examples are tube to end-fitting and honeycomb face-skin to core bonds. These types of bonds are often the weakest link in composite structures, and hence may require proof testing as well as NDE inspections.

During tensile loading, the AE system detected and located damage initiation throughout the specimen gauge lengths. The damage, which was probably in the form of matrix cracking, initiated at stress levels below 25 percent of the ultimate tensile strength of the laminate. Stress concentrations created by excessive porosity may have contributed to the damage initiation. Matrix cracking damage can change the CTE and stiffness of composite laminates. This consequence must be considered when using proof testing to satisfy fracture control requirements.

The attenuation of $\mathrm{AE}$ events in the specimens was nonlinear and the rate of attenuation was as high as five $\mathrm{dB}$ per inch within the first several inches of specimen travel. The rate of attenuation was a function of specimen lay-up and source event amplitude. The complexity of the attenuation made it difficult to interpret the $\mathrm{AE}$ results. In particular, it was difficult to reliably associate event amplitudes with failure mechanisms during linear location data acquisition.

Reflector-plate through-transmission immersion ultrasonics did not detect areas of fiber failure. The technique did reliably detect delamination damage. This finding suggests that ultrasonic inspection of composites should include backscatter or angle beam techniques to screen for matrix cracking and fiber failure damage.

$\mathrm{AE}$ has the potential to improve the reliability of structural composite proof tests, but its success relies on the interpretation of results. Confident interpretation requires extensive baseline testing and experience. The cost of gaining confidence can be high and hence, $\mathrm{AE}$ appears to be most suited for production environments where large numbers of components are tested. 


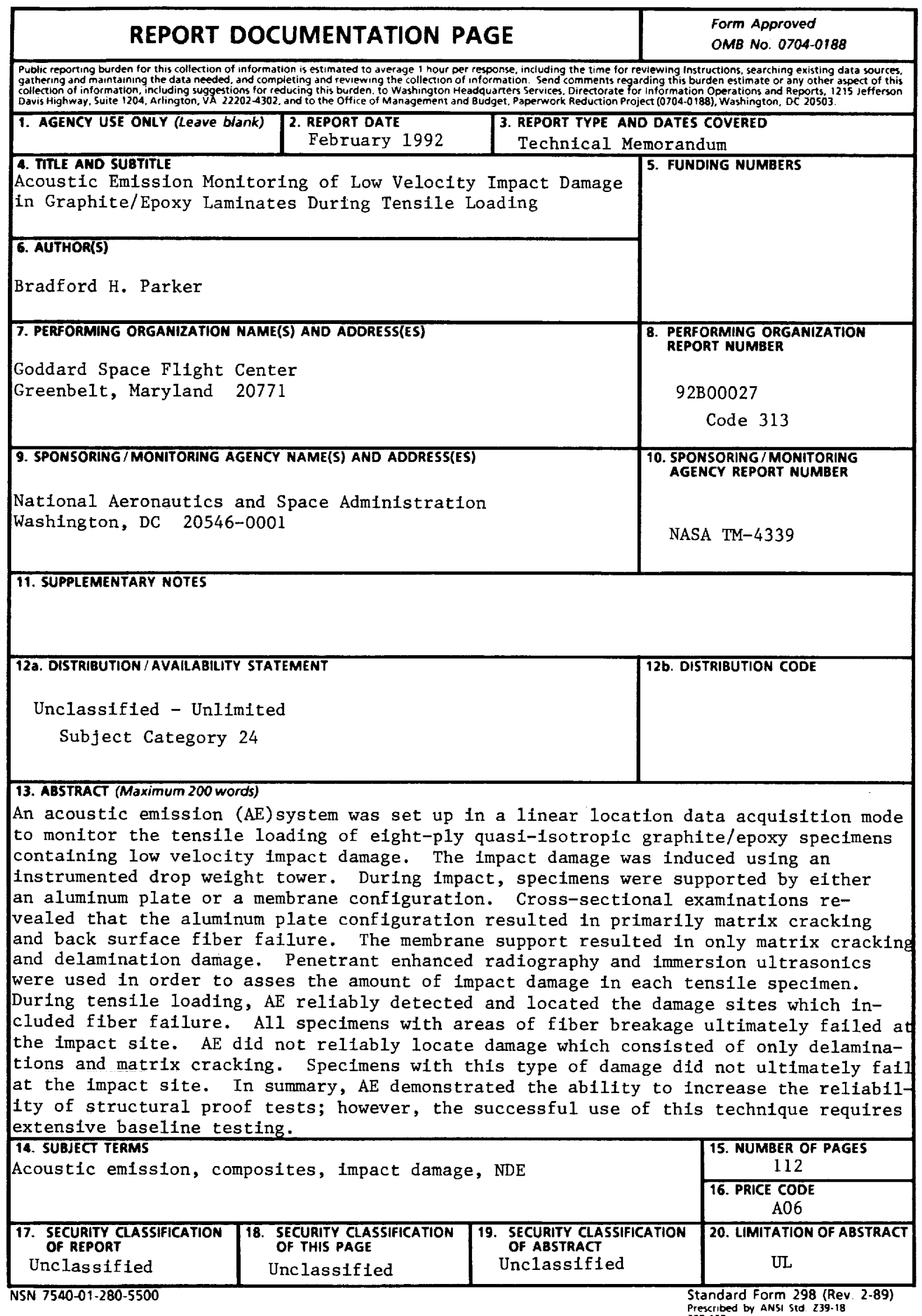




\subsection{CONCLUSIONS}

During tension loading, AE reliably detected and located low velocity impact damage which included fiber breakage. Fiber breakage was produced in the outer ply of quasi-isotropic laminates when the support configuration prevented flexure during impact. All specimens with fiber breakage exhibited a loss of in-plane tensile strength and ultimately failed at the impact sites.

AE did not reliably locate impact damage which consisted of only delaminations and matrix cracking. This type of damage was produced when specimens were supported by a membrane configuration which allowed bending flexure during impact. Specimens with only delamination and matrix cracking damage did not fail at the impact sites during tensile loading.

The AE system detected and located damage initiation and progression in epoxy specimen to tab bonds. The bond failures produced large levels of $\mathrm{AE}$ activity with event amplitudes ranging from 40 to $100 \mathrm{~dB}$. This finding suggests that AE has the potential to monitor the proof testing of bonded joints, which are used extensively in composite structures. Examples are tube to end-fitting and honeycomb face-skin to core bonds. These types of bonds are often the weakest link in composite structures, and hence may require proof testing as well as NDE inspections.

During tensile loading, the AE system detected and located damage initiation throughout the specimen gauge lengths. The damage, which was probably in the form of matrix cracking, initiated at stress levels below 25 percent of the ultimate tensile strength of the laminate. Stress concentrations created by excessive porosity may have contributed to the damage initiation. Matrix cracking damage can change the CTE and stiffness of composite laminates. This consequence must be considered when using proof testing to satisfy fracture control requirements.

The attenuation of $\mathrm{AE}$ events in the specimens was nonlinear and the rate of attenuation was as high as five $\mathrm{dB}$ per inch within the first several inches of specimen travel. The rate of attenuation was a function of specimen lay-up and source event amplitude. The complexity of the attenuation made it difficult to interpret the AE results. In particular, it was difficult to reliably associate event amplitudes with failure mechanisms during linear location data acquisition.

Reflector-plate through-transmission immersion ultrasonics did not detect areas of fiber failure. The technique did reliably detect delamination damage. This finding suggests that ultrasonic inspection of composites should include backscatter or angle beam techniques to screen for matrix cracking and fiber failure damage.

$\mathrm{AE}$ has the potential to improve the reliability of structural composite proof tests, but its success relies on the interpretation of results. Confident interpretation requires extensive baseline testing and experience. The cost of gaining confidence can be high and hence, $\mathrm{AE}$ appears to be most suited for production environments where large numbers of components are tested. 


\section{REFERENCES}

1. Engineered Materials Handbook: Composites, ASM International, Metals Park, OH, 1987, pp. 816-822.

2. Hull, $\mathrm{D}$., An Introduction to Composite Materials, Cambridge University Press, 1981, pp. 3-8.

3. Tenney, D.R., Sykes, G.F., and Bowles, D.E., "Composite Materials For Space Structures," Proceedings of Third European Symposium on Spacecraft Materials in Space Environments, Noordwijk, Netherlands, 1985.

4. "General Fracture Control Plan for Payloads Using the Space Transportation System (STS)," GSFC 731-0005, Revision B, NASA, Goddard Space Flight Center, Greenbelt, MD, 1988.

5. Engineered Materials Handbook: Composites, ASM International, Metals Park, OH, 1987, pp. 236-251.

6. Tompkins, S.S., Sykes, G.F., and Bowles D.E., "The Thermal and Mechanical Stability of Composite Materilas for Space Structures," NASA Langley Research Center, Hampton, VA, 1985.

7. Nondestructive Testing Handbook: Acoustic Emission Testing, American Society for Nondestructive Testing, 1987, p. 245.

8. Bailey, C.D., Hamilton, J.M. and Pless, W.M., "Acoustic Emission of ImpactDamaged Graphite/Epoxy Composites," Materials Evaluation, 37, 1979, pp. 43-48.

9. Hawkins G.F., "Determining the Reliability Increase of Rocket Motors Due to Acoustic Emission Monitoring, "Proceedings of International Symposium on Acoustic Emission from Composite Materials, Paris, France, 1989, pp.180-183.

10. Nondestructive Testing Handbook: Acoustic Emission Testing, American Society for Nondestructive Testing, 1987, p. 203.

11. Crane, R.M. and Juska, T.D., "Intrumented Impact Testing of Composite Materials," DTRC-SME 88/73, David Taylor Research Center, Bethesda, MD 1989.

12. Engineered Materials Handbook: Composites, ASM International, Metals Park, OH, 1987, pp. 259-267.

13. Husman, G.E., Whitney, J.M., and Halpin, J.C., "Residual Strength Characterization of Laminated Composites Subjected to Impact Loading," Foreign Object Impact Damage to Composites, ASTM STP 568, American Society for Testing and Materials, 1975, pp. 92-113.

14. Nettles, A.T., "Instrumented Impact and Residual Tensile Strength Testing of Eight-Ply Carbon/Epoxy Specimens," NASA Technical Paper 2981, 1990. 
15. Cunningham, M.E., Schoultz, S.V., and Toth, J.M., "Effect of End-Tab Design on Tension Specimen Stress Concentrations," Recent Advances in Composites in the United States and Japan, ASTM STP 864, American Society for Testing and Materials, Philadelphia, PA, 1985, pp. 253-262.

16. "Standard Test Method for Strength Properties of Adhesives in Shear by Tension Loading," ASTM Standard D1002, American Society for Testing and Materials, Philadelphia, PA, 1988.

17. Garg, A. and Ishai, O., "Characterization of Damage Initiation and Progression in Graphite/Epoxy Laminates by Acoustic Emission," Engineering Fracture Mechanics, 22, 1985, pp. 595-608.

18. Engineered Materials Handbook: Composites, ASM International, Metals Park, OH, 1987, p. 259.

19. Akay, M., "Relaxation Transitions, Fracture Toughness and Post-Impact Residual Capacity of Carbon-Fibre Reinforced Composites," Composites Science and Technology, 33, 1988, pp. 1-18.

20. Lloyd, B.A. and Knight, G.K., "Impact Damage Sensitivity of Filament-Wound Composite Pressure Vessels," Morton Thiokol, Inc./Wasatch Operations, Brigham City, UT.

21. Moore, D.R. and Prediger, R.S., "A Study of Low-Energy Impact of Continuous Carbon-Fiber-Reinforced Composites," Polymer Composites, 9, 1988, pp. 330-336.

22. Gardiner, D.S. and Pearson, L.H., "Acoustic-Emission Monitoring of Composite Damage Occuring Under Static and Impact Loading," Experimental Techniques, 5, 1985, pp. 22-28.

23. Jang, B.Z., Chen, L.C., Zee, R.H., Shih, W.K., and Jang, B.P., "Instrumented Impact Testing of Composite Laminates: Data Analysis and Interpretation," Proceeding of International Symposium for Testing and Failure Analysis, Los Angles, CA, 1988, pp.265-276.

24. Smith, B.T., Heyman, J.S., Buoncristiani, A.M., Blodgett, E.D., Miller, J.G., and Freeman, S.M., "Correlation of the Deply Technique with Ultrasonic Imaging of Impact Damage in Graphite-Epoxy Composites," Materials Evaluation, 47, 1989, pp. 1408-1415.

25. Jones, T.S. and Berger, H., "Application of Nondestructive Inspection Methods to Composites," Materials Evaluation, 47, 1989, pp. 390-398.

26. Engineered Materials Handbook: Composites, ASM International, Metals Park, OH, 1987, pp. 774-778.

27. Walkden, P., "Automated Ultrasonic Defect Discrimination," Metals Evaluation, 47, 1989, pp.1000-1004. 
28. Subramanian, K. and Rose, J.L., "C-Scan Testing for Complex Parts," Advanced Materials and Processes, 2, 1987, pp. 40-43.

29. Metals Handbook: Nondestructive Evaluation and Quality Control, ASM International, Metals Park, OH, 1989, p. 239.

30. Metals Handbook: Nondestructive Evaluation and Quality Control, ASM International, Metals Park, OH, 1989, pp. 241-246.

31. Rodgers, J., "Acoustic Emission Monitoring of Flaw Growth in a Graphite-Epoxy Experimental Wing Segment," Journal of Acoustic Emission, 4 1985, pp. 1-8.

32. Awerbach, J. and Ghaffari, S., "Monitoring Acoustic Emission in Impact-Damaged Composites," Proceedings of International Symposium on Composite Materials and Structures, Beijing, China, 1986, pp. 879-888.

33. Awerbach, J., "Monitoring Damage Progression in CFRP by Acoustic Emission," Translation into English from Schadensmech von Faserverstaerkten Verbundstruckt, 1981, pp. 47-88.

34. Cohen, J. and Awerbuch, J., "Monitoring Delamination Progression in Composites through Acoustic Emission During Fatigue Loading," Proceedings of Japan-U.S. Conference on Composite Materials, Washington, D.C., 1988, pp. 1035-1046.

35. Shippen, N.C. and Adams, D.F., "Acoustic Emission Monitoring of Damage Progression in Graphite/Epoxy Laminates," Journal of Reinforced Plastics and Composites, 4, 1985, pp. 242-261.

36. Henneke, E.G., "Signature Analysis of Acoustic Emission from Composites," NASA Grant NSG 1238, 1978.

37. Favre, J.P. and Laizet, J.C., "Acoustic Analysis of the Accumulation of Cracks in CFRP Cross-Ply Laminates Under Tensile Loading," Proceedings of International Symposium on Acoustic Emission from Composite Materials, Paris, France, 1989, pp. 278-285.

38. Bascom, W.D., "Fractography of Composite Delamination," NASA Contractor Report 181965, 1990.

39. Yamaguchi, K., Oyaizu, H., Johkaji, J., and Kobayashi, Y., "Recognition of Fracture Modes and Behavior in FRP by AE Waveform-Microdata," Proceedings of International Symposium on Acoustic Emission from Composite Materials, Paris, France, 1989, pp. 268-277.

40. Kawamoto, K. and Ono, K., "Pattern Recognition Analysis of Acoustic Emission Signals from Carbon Fiber/Epoxy Composites," Proceedings of International Symposium on Acoustic Emission from Composite Materials, Paris, France, 1989, pp. 230-239.

41. Nondestructive Testing Handbook: Acoustic Emission Testing, American Society for Nondestructive Testing, 1987, pp. 103-107. 
42. Awerbuch, J. and Eckles, W.F., "Detection of Failure Progression in Cross-Ply Graphite/Epoxy Through Acoustic Emission," Proceedings of International Symposium of Composite Materials and Structures, Beijing, China, 1986, pp. 889-898.

43. Bailey, C.D., Hamilton, J.M. and Pless, W.M., "Acoustic Emission of Impact-Damaged Graphite/Epoxy Composites," Materials Evaluation, 37, 1979, pp. 43-48.

44. Awerbuch, J., Madhukar, M., and Gorman, M.R., "Monitoring Damage Accumulation in Filament-Wound Graphite/Epoxy Laminate Coupons During Fatigue Loading Through Acoustic Emission," Journal of Reinforced Plastics and Composites, 3, 1984, pp. 2-39.

45. Ghaffari, S. and Awerbuch, J., "Monitoring Initiation and Growth of Matrix Splitting in a Unidirectional Graphite/Epoxy Composite," Journal of Acoustic Emission, 8, 1989, pp. 301-305.

46. Bouheraoua, A., "An Accurate Acoustic Emission Location Method Adapted for Composite Materials," Proceedings of International Symposium on Acoustic Emission from Composite Materials, Paris, France, 1989, pp. 375-379.

47. Engineered Materials Handbook: Composites, ASM International, Metals Park, OH, 1987, pp. 230-235. 


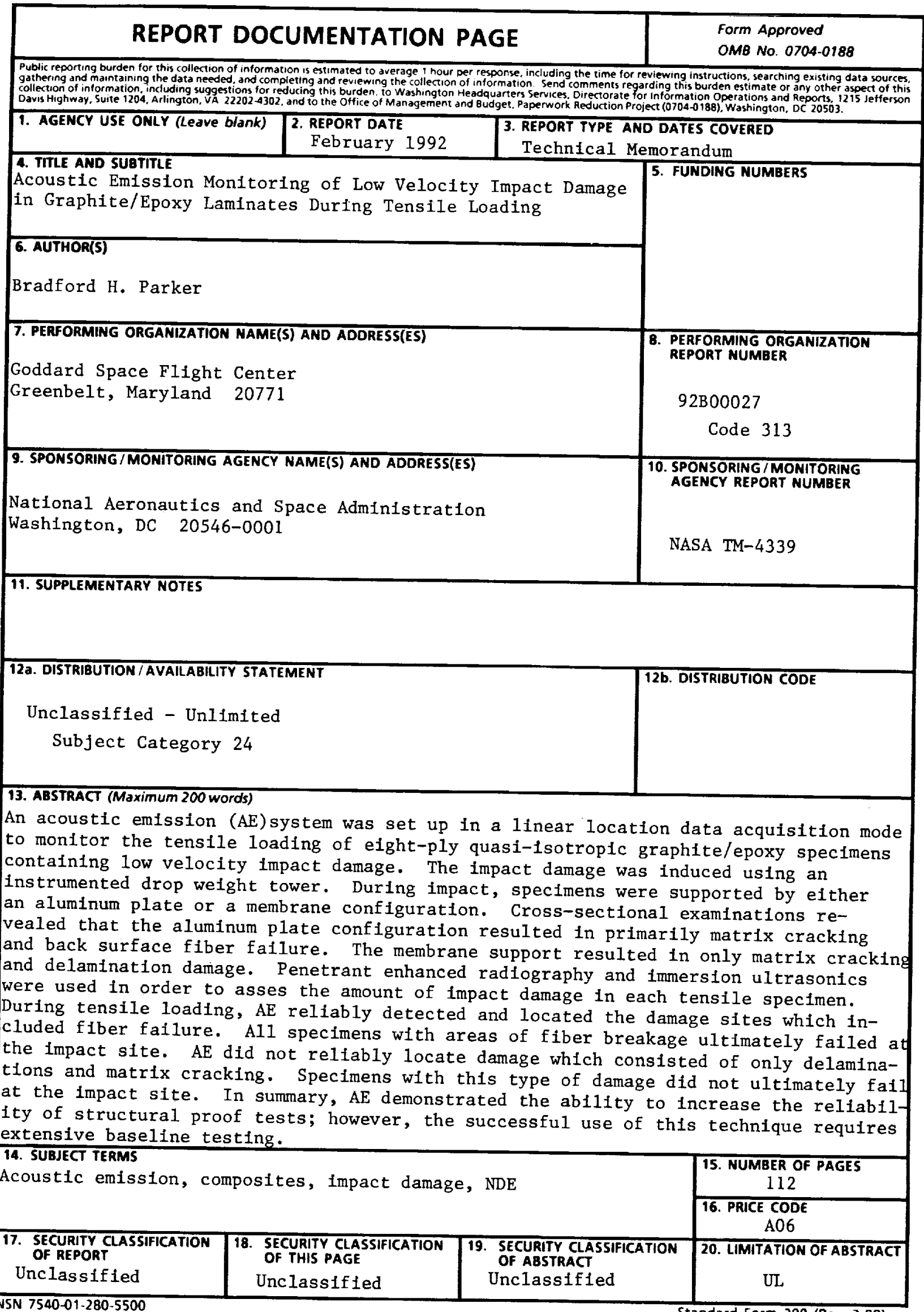

NSN 7540-01-280-5500 